

\section{STUDIA UNIVERSITATIS HEREDITATI}

Znanstvena revija za raziskave in teorijo kulturne dediščine

Letnik 6, številka 2, 2018

Studia universitatis hereditati je humanistična znanstvena revija za raziskave in teorijo kulturne dediščine z mednarodnim uredniškim odborom. Objavlja znanstvene in strokovne članke s širšega področja kulturne dediščine (arheologija, arhitektura, etnologija, jezikoslovje, literarna, kulturna, glasbena, intelektualna, religijska, vojaška zgodovina, zgodovina idej itn.) in pregledne članke ter recenzije tako domačih kot tujih monografij z omenjenih področij. Revija izhaja dvakrat letno. Izdajata jo Fakulteta za humanisticne studije (Oddelek za arheologijo in dedisčino) in Založba Univerze na Primorskem.

Poglavitni namen revije je prispevati k razvoju raziskav kulturne dediščine v najširšem in k topoglednemu interdisciplinarnemu pristopu k teoretičnim in praktičnim raziskovalnim vprašanjem. Tako revija posebno pozornost namenja razvoju slovenske znanstvene in strokovne terminologije, konceptov in paradigem na področju raziskovanja kulturne dediščine v okviru humanističnih ved.

\section{Glauni in odgovorni urednik}

dr. Gregor Pobežin (Fakulteta za humanistične študije Univerze na Primorskem, Koper) Urednici stevilke

dr. Zrinka Mileusnić in dr. Alenka Tomaž (Fakulteta za humanistične študije Univerze na Primorskem, Koper) Tehnična ureditev revije, oblikovanje in prelom

dr. Jonatan Vinkler (Fakulteta za humanistične študije Univerze na Primorskem, Koper)

Lektor (slovenska besedila)

Davorin Dukič (Univerza na Primorskem, Koper)

\section{Uredniski odbor}

dr. Zdravka Hincak (Filozofski fakultet, Sveučilište u Zagrebu), dr. Matej Hriberšek (Filozofska fakulteta, Univerza v Ljubljani), dr. Katja Hrobat Virloget (Fakulteta za humanistične študije Univerze na Primorskem, Koper), dr. Irena Lazar (Fakulteta za humanistične študije Univerze na Primorskem, Koper), dr. Maša Sakara Sučevič (Pokrajinski muzej, Koper), dr. Alenka Tomaž (Fakulteta za humanistične študije Univerze na Primorskem, Koper), dr. Tomislav Vignjevič (Fakulteta za humanistične študije Univerze na Primorskem, Koper), dr. Jonatan Vinkler (Fakulteta za humanistične študije Univerze na Primorskem, Koper), dr. Paola Visentini (Museo Friulano di Storia Naturale, Udine)

Izdajatelj: Univerza na Primorskem - Založba Univerze na Primorskem (za Fakulteto za humanistične študije Univerze na Primorskem)

(C) 2017 Založba Univerze na Primorskem

Zanjo: prof. dr. Dragan Marušič, rektor

Titov $\operatorname{trg} 4$

SI-6000 Koper

ISSN 2350-5443

DOI: https://doi.org/10.26493/2350-5443.6(2)

\section{(c) (i) $\circledast$


studia universitatis hereditati 



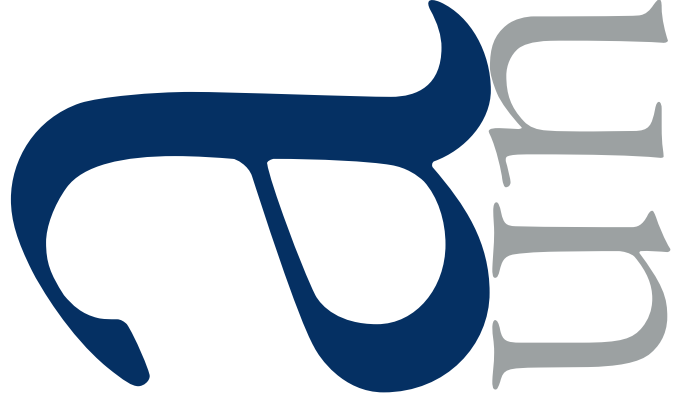

○
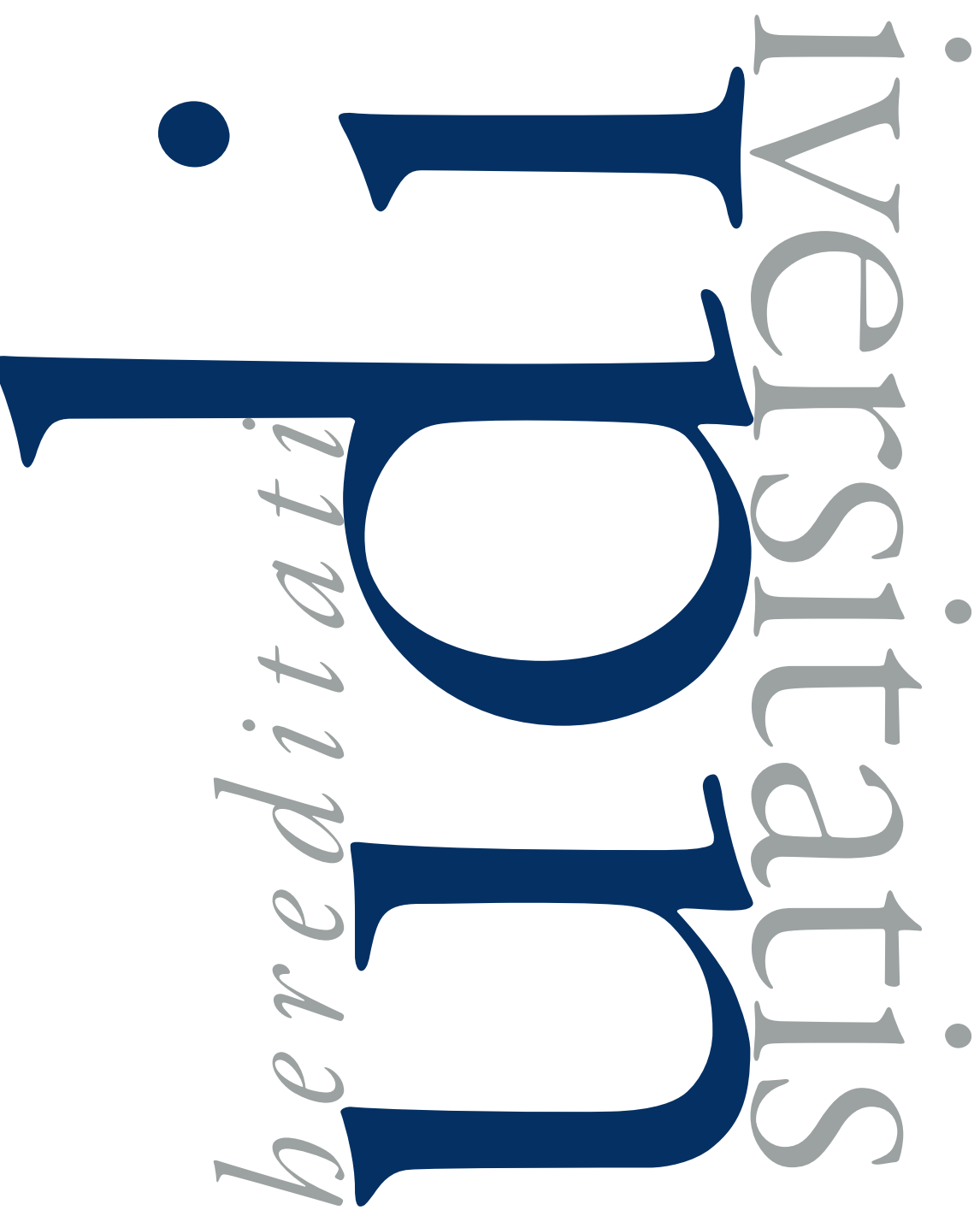

LETNIK 6

ŠTEVILKA 2

LETO 2018
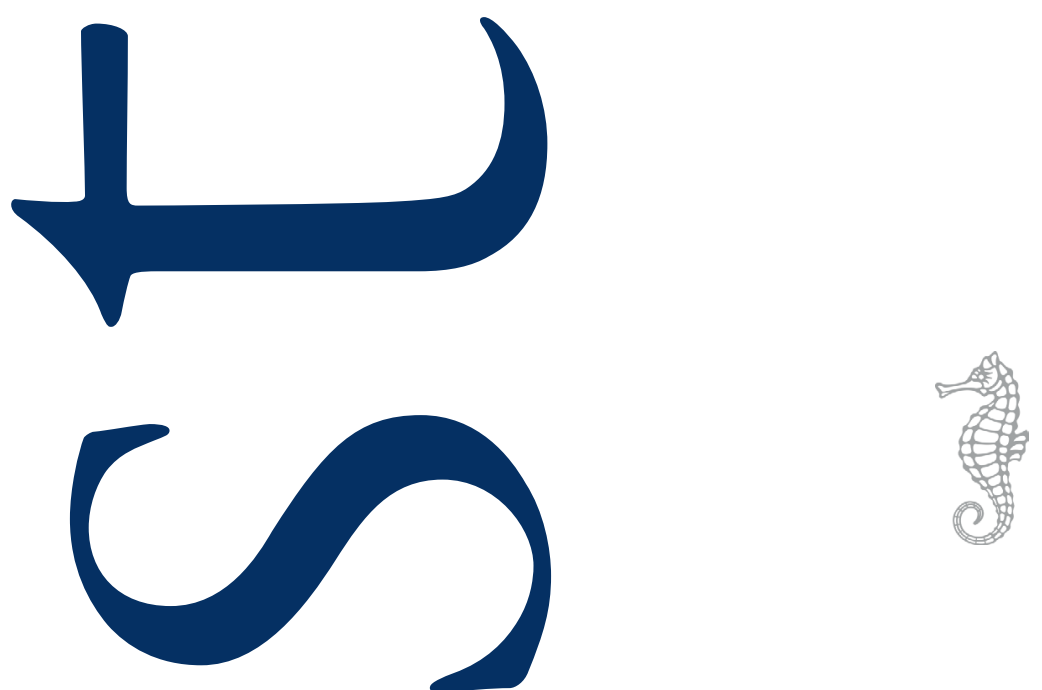
-

r

$\downarrow$

G

1

-

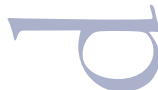

( )

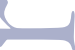

(U)

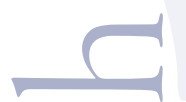




\section{Vsebina/Contents}

Jadranka Cergol

9 Parallelismi tra la provocazione di Numano Remulo ai Troiani e l'incoraggiamento di Tarconte agli Etruschi

Massimo Medeot, Mario Crevato, Alja Margon

I5 Punjert, castello "perduto" dell'alta val Rosandra

Manca Vinazza, MatejDraksler

29 Na sledi zgodnje bronastodobne poselitve v dolini Rižane: arheološke raziskave na najdišču Ključ

Lenka Mrázová

47 Are worksheets death? Words in museum education

Tereza Preśeren, Alenka Janko Spreizer, Nataša Kolega, Petra Kavrecič, Srečko Gombač

63 Pot tovarn kot pripoved o dediščini ribištva in predelovalne industrije s poudarkom na Izoli Helena Vicic

77 Why style matters? Some noises and barriers for textual information processing

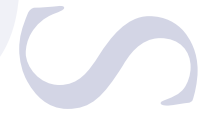


-

r

$\downarrow$

G

1

-

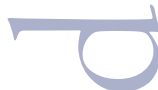

( )

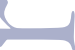

(U)

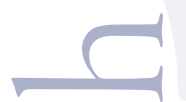




\title{
Parallelismi tra la provocazione di Numano Remulo ai Troiani el'incoraggiamento di Tarconte agli Etruschi
}

\author{
Jadranka Cergol, Università del Litorale, Facoltà di studi umanistici
}

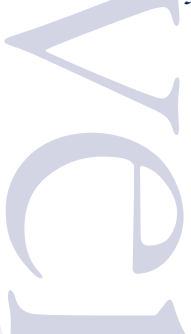

Namen članke je izpostaviti vzporednice med dvema odlomkoma iz Vergilijeve Eneide, in sicer med besednim napadom Numana Remula na Trojance (9.598-620) in Tarhonovim spodbujevalnim govorom Etruščanom (II.732-740). Avtorica namreč želi s filološko analizo dokazati, da je Vergilij namenoma postavil na vzporedne tirnice stereotipno predstavo Trojancev in Etruščanov s ciljem, da je obema ljudstvoma pripisal podobne značilnosti, ki se popolnoma ujemajo: predajanje ljubezenskim dogodivščinam in plesu, strah pred poženščeno naravo človeka, hrabri nastop dveh voditeljev, in sicer Askanija in Tarhona.

Ključne besede: Vergilij, Eneida, stereotipi, Etruščani, Trojanci

The article aims to highlight the parallels between two passages of Virgil's Aeneid: the verbal attack of Numanus Remulus to the Trojans (9,598-620) and the encouraging speech of Tarcone to the Etruscans (II.732-740). The author's aim is to demonstrate through the philological analysis that Virgil has put in parallel the stereotypical representation of the Trojans and the Etruscans, in order to attribute to both peoples similar tendencies: abandonment to amorous adventures and dances, the fear of looking like women, and the courageous reaction of the two leaders, respectively of Ascanio and Tarcone.

Key words: Virgil, Aeneid, stereotypes, Etruscans, Troians

$\mathrm{N}$

elle discussioni scientifiche sull'Eneide non si è ancora individuata un'analisi parallela e approfondita fra due passaggi nella seconda metà dell'Eneide, che per struttura e contenuto presentano molte similitudini, anche se non sono di fondamentale importanza per la drammaturgia dell'opera nel suo insieme. Si tratta dell'attacco verbale di Numano Remulo ai Troiani (9.598-620) e del discorso di incoraggiamento di Tarconte agli Etruschi (II.732-740). Entrambi i frammenti, infatti, contengono elementi tipici della descrizione etnografica dei popoli e offrono due rappresentazioni parallele dei Troiani e degli Etruschi: i tratti che vengono attribuiti ai Troiani da Numano Remulo sono gli stessi che Tarconte attribuisce agli Etruschi. Una parte importante del discorso di Remulo è dedicata anche alla marcatura dei lati positivi dei Rutuli - questo passaggio però non verrà trattato in questa sede perché non risulta rilevante ai fini della nostra analisi.

Numano Remulo è una figura inventata da Virgilio che però porta un nome eloquente: nei Romani richiamava sicuramente l'immagine del re di Roma Numa Pompilio, mentre Remulo era un richiamo ai gemelli Romolo e Remo. Entrambi i nomi sono quindi strettamente connessi con gli inizi della storia romana e Virgilio li scelse per sottolineare il significato del suo attacco ai Troiani. Nel contesto dell'Eneide la figura di $\mathrm{Nu}$ mano Remulo è del tutto insignificante, ma il suo nome ha un grande effetto sonoro (Horsfall, 
1971, 778). Nella storia si pone più attenzione al suo status che alle sue azioni - Numano Remulo è, infatti, il cognato di Turno, ovvero il marito della sorella di Turno. La storia, però, non ne descrive le gesta eroiche, e quindi rimane una figura marginale.

Il discorso di Numano è più lungo di quello di Tarconte, ma contiene anche la descrizione dei componenti dei Rutuli e il confronto della loro educazione contrapposta allo stile di vita troiano. Lo scopo del discorso di Numano Remulo si esplica nel vantarsi del coraggio e della perseveranza di Rutulo (duritia) e nel marchiare il carattere molle (mollitia) e la lussuria (luxuria) dei Troiani. L'obiettivo di Tarconte è diverso: con le sue parole, infatti, vuole spronare i propri soldati a una lotta ancora più dura contro i nemici e li invita a dimostrare di non essere deboli e viziati, ma coraggiosi e abili in battaglia. Nell'introduzione del discorso di Numano il poeta sottolinea il fatto che il cognato di Turno parlasse di "cose degne e non degne di essere ridette", e quindi è rimasto solo ciò che risultava accettabile. Numano Remulo attacca i Troiani in questo modo:

\section{Vobis picta croco et fulgenti murice vestis, Desidiae cordi, iuvat indulgere choreis, Et tunicae manicas et habent redimicula mitrae. $O$ vere Phrygiae (neque enim Phyrges), ite per alta Dindyma, ubi adsuetis biforem dat tibia cantum! Tympana vos buxusque vocat Berecyntia Matris Idaeae: sinite arma viris et cedite ferro.« (9.6I $4-620)$}

Tarconte utilizza le seguenti parole per spronare i propri compagni alla battaglia:

Femina palantis agit atque haec agmina vertit! Quo ferrum quidve haec gerimus tela inrita dextris? At non in Venerem segnes nocturnaque bella Aut ubi curva choros indixit tibia Bacchi Exspectate dapes et plenae pocula mensae (hic amor, hoc studium), dum sacra secundus haruspex nuntiet ac lucos vocet hostia pinguis in altos! (iI.734-740)

Numerosi ricercatori hanno già ribadito che soprattutto il primo discorso assume tratti caratteristici di una vituperatio, per la quale Virgilio aveva molte fonti (Cato, Orig. 76; Var., gent. 34; Hom., Ody. 8.248, Serv., ad Aen. 9.600), da cui trarre ispirazione (Horsfall 1971, I108; Thomas 1982, 99; Dickie 1985, 168). Proprio l'esempio dell'Odissea è quello più evidente e a portata di mano: Alcinoo attacca i vizi dei Feaci e ne critica soprattutto le vesti ricche, i tipi di danze sconvenienti e la pigrizia. Nell'Eneide simili critiche vengono ascritte sia ai Troiani che agli Etruschi. Alcuni ricercatori sono concordi nell'affermare che Virgilio non prese ispirazione da altre fonti, bensì riportò la rappresentazione stereotipata e idealizzata tradizionale del contadino romano e l'immagine negativa degli abitanti effeminati del vicino oriente (Horsfall 1971; Dickie 1985; Thomas 1982). Anche Matthew Dickie, che nella sua analisi si dedica alle similitudini fra gli Etruschi e i Feaci del racconto di Odisseo, si chiedeva se queste rappresentazioni stereotipate fossero semplici topoi letterari e culturali, oppure se dietro si nascondessero effettivamente veri stereotipi, e di conseguenza anche le idee che i contemporanei di Virgilio avevano riguardo a un determinato popolo (Dickie 1982). La conclusione a cui giunse Dickie è effettivamente ancora più problematica dell'ipotesi stessa, infatti non offre una risposta concreta, ma si orienta verso l'ipotesi che Virgilio avesse incluso di proposito alcuni elementi stereotipati dell'immagine dei Troiani. Anche personalmente ci orientiamo verso questa ipotesi: nonostante il fatto che le cattive abitudini che sia Tarconte, sia Numano Remulo imputano ai Troiani e/o agli Etruschi, siano tipiche per la rappresentazione stereotipata di un determinato popolo, Virgilio rincara la dose e le sottolinea ulteriormente per mettere in parallelo la sorte degli Etruschi e dei Troiani. Inoltre, nel caso degli Etruschi, ha voluto ribadire ulteriormente quell'aspetto che però non si trova nei Troiani, ovvero la presenza di un vecchio aruspice che avverte gli Etruschi riguardo alla dimensione religiosa della loro missione (Cairns 1990, I27 ss.; Cergol 20II).

Già all'inizio del primo discorso si osserva un confronto immediato con il mondo femminile: mentre Numano Remulo nella parte fina- 
le del suo discorso con un esclamazione dichiara che i suoi nemici sono donne e non uomini (Frigie, e non Frigi), Tarconte, invece, inizia il suo intervento menzionando una donna che spaventa $\mathrm{i}$ compagni - in questo caso si tratta di Camilla. Entrambi, quindi - e in dettaglio uno nella parte finale e uno nella parte iniziale - costruiscono un confronto con la donna, affermando che la figura femminile non appartiene al campo di battaglia e nell'immaginario stereotipato è meno coraggiosa e meno indicata per la guerra se paragonata all'uomo. Inoltre, Numano Remulo afferma che i suoi avversari, che prima venivano paragonati alle donne, dovrebbero cedere le proprie armi agli uomini veri. È quindi presente una critica alla natura effeminata sia dei Troiani, sia degli Etruschi; agli occhi di una parte importante della società romana, infatti, l'effeminatezza arrivava da Oriente e rappresentava la disgregazione della virilità romana, che si fondava sull'idea di duritia. Il secondo elemento della natura effeminata dei Troiani e degli Etruschi è il loro amore per la danza: entrambi si riferiscono al flauto che invita al divertimento e alle danze. Nell'antica Grecia e a Roma il rapporto con il ballo era controverso: alcuni lo accettavano come qualcosa di normale, ma esistevano anche gravi pregiudizi contro la sua espressione (Herter 1959, 638). L'amore per la danza, però, non era qualcosa di negativo; anche se ai tempi della repubblica l'arte della danza veniva ancora ignorata, nel periodo di Augusto era invece accettata con interesse ed entusiasmo (Horsfall I97 I, III 4). È anche vero che molto dipendeva dal tipo di ballo, in quanto ai tempi di Augusto erano diffuse anche le danze orgiastiche della dea Cibele, che però erano moralmente inaccettabili (Herter 1959, 621-2). La danza era collegata soprattutto con il pregiudizio della effeminatezza e della mollezza, ad ogni modo non era indicata per gli uomini; la danza era una cosa da donne.

Il terzo punto in comune di entrambi i discorsi è indirizzato alle avventure amorose che entrambi descrivono con locuzioni metaforiche. A onor del vero Tarconte è più esplicito $\mathrm{e}$ racconta che ai suoi compagni piacciono le lot- te notturne sotto l'ala di Venere, mentre Numano Remulo menziona soltanto le desidiae cordis che potrebbero essere interpretati come normale pigrizia, ma visto che sono legati al cuore, possiamo dedurre che si tratti effettivamente di avventure di amore che in questa locuzione acquisiscono una connotazione ancora più marcata di ozio, assopimento, inattività, il che naturalmente è in contrasto con il carattere attivo dei soldati latini. Nel discorso di Remulo ci si imbatte in un'altra mossa stereotipata, che però non può trovare un parallelismo con il discorso di Tarconte - si tratta della critica ai Troiani che portano tuniche con le maniche lunghe, altro segno di effeminatezza. I Romani, infatti, avevano l'abitudine di indossare vesti senza maniche, in modo da lavorare più agevolmente nei campi anche in questo caso si tratta ovviamente di un segno della loro laboriosità e solerzia. I Troiani, invece, portavano maniche lunghe, un abbigliamento non adeguato per un simile lavoro e adatto soltanto per godersi l'ozio all'ombra dei sontuosi palazzi - più lunghe erano le maniche, più era evidente il segno della natura effeminata (Dickie 1985, I7I).

È quindi dimostrato chiaramente che entrambi i discorsi si basano sul contrasto duritia - luxuria. Remulo sottolinea il duro lavoro e il sacrificio delle genti italiche e marchia la natura pigra e viziata dei nemici troiani. Le stesse connotazioni sono presenti anche nell'intervento di Tarconte che attribuisce ai suoi compagni le stesse mancanze elencate dai Numano Remulo.

La similitudine dei due interventi si intravede anche nella reazione di cui furono oggetto. L'intervento di Remulo ferisce l'orgoglio di Ascanio, che prima di tutto chiede al dio Giove di sostenere la sua causa, poi lancia le sue armi con tutte le sue forze e ferisce a morte il nemico e in questo caso lo aiuta lo stesso Apollo ("Macte nova virtute, puer, sic itur ad astra" 9.64I). Ascanio quindi rigetta con forza e coraggio tutti i difetti che erano stati criticati da Numano Remulo e dimostra che le accuse di natura effeminata e pigra erano del tutto infondate, in quanto i Troiani erano molto coraggiosi e abili in battaglia, e 
inoltre sono stati anche onorati dalla benevolenza degli dei. Inoltre va aggiunto che Remulo pronunciò il suo discorso subito dopo che gli Italici si erano dimostrati essere soldati irresponsabili, abbandonandosi al bere e al gioco, senza curarsi di alimentare il fuoco e di sorvegliare il proprio accampamento. Tutto questo ci fa pensare che le parole di Remulo fossero del tutto fasulle, se non addirittura ironiche, da buon principio - il lettore, infatti, aveva già notato che quei Rutili, descritti da Remulo come coraggiosi e abili, in verità non erano così; dall'altra parte Ascanio dimostra il coraggio e l'abilità dei Troiani. Nello stesso libro siamo stati testimoni di un Niso altrettanto valoroso, che si lancia senza timore in battaglia per il suo popolo, non curandosi dei pericoli e delle trappole. I giovani soldati troiani quindi dimostrano che l'immaginario stereotipato che li vuole effeminati e oziosi è del tutto infondato. Una situazione analoga si nota anche nella reazione al discorso di Tarconte. Lo stesso Tarconte, infatti, dimostra il valore del suo popolo: è pronto a sacrificare la vita e attacca un nemico altrettanto valoroso. Il poeta confronta Tarconte con un'aquila che si lancia su un serpente, per afferrarlo alla fine con i suoi artigli. In entrambi i casi quindi si pone in primo piano un eroe, il primo è Ascanio, il secondo Tarconte, un Troiano e un Etrusco. Entrambi dimostrano che le parole pronunciate non corrispondono alla realtà, in quanto entrambi sconfiggono il nemico con gesta coraggiose, degne di un eroe epico. Le analogie fra i due frammenti sono quindi sostanziose. Nei discorsi di Numano Remulo e Tarconte, che si riferiscono a due momenti diversi nelle vicende dell'Eneide, e sono rivolti a due comunità diverse, ci imbattiamo in elementi simili, ovvero in quattro elementi che accomunano la rappresentazione stereotipata dei due popoli: il rapporto tra il valore bellico e le donne; l'abbandonarsi alle danze e ai divertimenti, che non sono appannaggio degli uomini, e alle avventure amorose, e il rifiuto delle gesta dei due eroi, il Troiano Ascanio e l'Etrusco Tarconte, in risposta alle critiche mosse. Inoltre, ci si imbatte anche in alcuni fenomeni che nei due discorsi non coincidono: Numano Remulo, infatti, critica i Troiani per le loro vesti decorate di croco e porpora, per le loro tuniche con le maniche lunge e le mitre decorate da nastrini, mentre nel discorso di Tarconte non c'è menzione riguardo all'abbigliamento. Al contrario, Tarconte inserisce un elemento tipico degli Etruschi, ovvero il momento religioso, in quanto richiama alla memoria l'antico aruspice che li invita alle celebrazioni rituali nei luoghi consacrati.

Si ritiene che Virgilio abbia messo in parallelo la rappresentazione stereotipata dei Troiani e degli Etruschi di proposito, in modo da attribuire a entrambi i popoli tendenze simili. Gli antichi ascoltatori hanno indubbiamente collegato i due discorsi e hanno richiamato alla mente le parole di Tarconte pronunciate in precedenza, nel discorso di Numano rivolto ai Troiani. Virgilio non nasconde i pregiudizi negativi che valevano per gli Etruschi e per i Troiani. Anche lo stesso Tarconte ammette che il suo popolo etrusco si abbandona volentieri alle avventure amorose, all'ozio e alle danze. Allo stesso tempo si sottolinea il lato positivo dei due popoli: nell'Eneide gli Etruschi vengono caratterizzati dall'epiteto fortis (10.238) e pius (8.494), proprio come succede con i Troiani, fra cui spicca la forza e la devozione del loro condottiero Enea: "pietate insignis et armis" (6.403, 6.769). Virgilio ha valorizzato entrambi i popoli, inoltre ha ulteriormente ribadito la devozione del popolo etrusco alla volontà divina, un popolo che conosce l'arte della profezia e che capisce la volontà degli dei, a cui si sottomette completamente.

\section{Povzetek}

Avtorica je v članku primerjala z vsebinskega zornega kota dva odlomka iz Vergilijeve Eneide, na katere še noben raziskovalec Vergilijevega opusa še ni bil pozoren. Gre namreč za odlomka iz devete knjige Eneide, v katerem Numanus Remulus ostro napade Trojance in jih pripiše nekaj stereotipnih značilnosti (9.598-620), ter za odlomek iz enajste knjige, v katerem pa tvoja etruščanskih čet Tarhon spodbuja svoje sobojevnike (II.732740). Namen prispevka je osvetlili paralelizme teh dveh odlomkov ter odkazati, da je Vergilij namenoma pos- 
tavil na vzporedne tirnice stereotipno predstavo Trojancev in Etruščanov s ciljem, da je obema ljudstvoma pripisal podobne značilnosti, ki se popolnoma ujemajo. Stereotipne značilnosti, ki jih Vergilij pripisuje obema ljudstvoma so lahkotno predajanje ljubezenskim dogodivščinam, otiumu in plesu. Nasprotno pa sta obe ljudstvi tudi nositeljici pozitivnih lastnosti, in sicer verske pobožnosti (pietas) ter vojaške hrabrosti (fotitudo).

\section{Summary}

In the article, the author compares from the substantive point of view two excerpts from Vergil's Aeneid, to which no researcher of Vergil's opus has yet been paid attention. It is a passage from the ninth book of the Aeneid, in which Numanus Remulus strongly attacks the Trojans and attributes to them some stereotypical features (9,598-620), and a passage from the eleventh book, in which the Etruscan fellow Tarhon encourages his mates (II,732-740). The purpose of the paper was to illuminate the parallelism of these two excerpts and to indicate that Vergil deliberately set up a stereotypical representation of Trojans and Etruscans on parallel rails, with the aim of attributing similar characteristics to the two peoples. Stereotypical representations attributed by Vergil to both peoples are an easy passage to love adventures, to otium and to dancing. On the contrary, both peoples are also the bearers of positive qualities, namely religious devotion (pietas) and military courage (fortitudo).

\section{Bibliografia}

Cairns, F. 1990. Vergil's Augustan epic. Cambridge: Cambridge University Press.

Cergol, J., 20r.. 'Gli eroi della stirpe etrusca nella seconda metà dell'Eneide.' Maia, rivista di letterature classiche 3: 497-507.

Dickie, M. 1985. 'The Speech of Numanus

Remulus (Aeneid 9.598-620).' Papers of the Liverpool Latin Seminar 5: 165-221.

Herter, H. 1959. 'Effeminatus.' Reallexikon für Antike und Christentum 4: 638.

Horsfall, N. 197ı. 'Numanus Remulus: Ethnography and Propaganda in Aeneid 9.598ff.' Latomus 30: 1108-16
Horsfall, N. 1987. 'Numanus Remulus'. In Enciclopedia Virgiliana, 778. Roma: Istituto dell'Enciclopedia italiana.

Thomas, R. F., 1982. 'Lands and Peoples in Roman Poetry: The Ethnographical Tradition.' Proceedings of the Cambridge Philological Society. Supplementary Volume 7:99. 
-

r

$\downarrow$

G

1

-

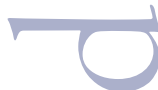

( )

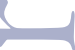

(U)

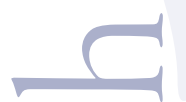




\section{Punjert, castello "perduto" dell'alta val Rosandra}

Massimo Medeot, Mario Crevato, Alja Margon, Društvo Limes arheologija prostora

Associazione Limes archeologia per il territorio, Hrpelje - Kozina, Slovenija

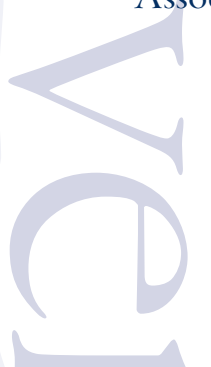

V članku predstavljamo najnovejše raziskave na območju arheološkega najdišča Punjert. Najdišče se nahaja v zgornjem delu doline Glinščice (Občina Hrpelje - Kozina), na njem pa se nahajajo skromni ostanki manjše utrdbe iz obdobja srednjega veka. S pomočjo kartografskih, bibliografskih in neinvazivnih terenskih raziskav smo izdelali hipotetično grafično rekonstrukcijo utrdbe in postavili nekaj možnih hipotez o starosti utrdbe in njene vloge v prostoru. Pri interpretaciji rezultatov smo prvenstveno upoštevalibližnji že do dobra preučen grad Vichimberch.

Ključne besede: Punjert, grad, Srednji vek, Dolina Glinščice, Vichimberg

This research paper presents the archaeological park known as Punjert, located in the upper Rosandra Valley (territory of Slovenia, municipality of Hrpelje - Kozina), which consists of the remains of a small fortification or castle dating to the Medieval period. Through cartographic, bibliographic, on site (non-invasive) research and the analysis and processing of data collected from the Lidar system and GPR it has been possible to create a graphic rendering of the site and develop hypotheses on the construction date and purposes, with specific reference to the not too far away and previously researched Vichimberch castle.

Keywords: Punjert, castle, Middle Ages, Rosandra valley, Vichimberg

L

'alta val Rosandra (in sloveno Dolina Glinščice) è stata abitata fin dalla Preistoria, ma solo al periodo Protostorico risale la costruzione delle prime opere fortificate ${ }^{\mathrm{I}}$. Si tratta essenzialmente di castellieri (con vallo semplice o multiplo), notati già nel XIX secolo, per l'imponenza dei ruderi, da autori come Marchesetti (1903). Degni di nota sono quello del Monte Carso/Sela ${ }^{2}$, di Lorencon ${ }^{3}$ e, sul versante opposto della valle, di Gradec ${ }^{4}$. Il periodo

I Per un quadro d'insieme dei ritrovamenti e dei siti archeologici nella zona in esame, valido strumento è il database reso disponibile dal Ministero della Cultura della Repubblica di Slovenia e utilizzabile per mezzo del sito: http://rkd.situla.org/

2 Dal database citato in nota I, n. 9164

$3 \quad$ Ibidem n. 9163

$4 \quad$ Ibidem n. 483 romano è pure stato caratterizzato dalla costruzione, nella parte superiore della valle o nelle sue immediate adiacenze, di altre fortificazioni: in particolare le postazioni difensive sul cosiddetto Crinale (Flego e Žerjal 1992) sopra la chiesa di S.Maria di Siaris, la grotta delle Porte di Ferro $^{5}$, la fortificazione a Nasirec ${ }^{6}$ ed infine il castrum recentemente scoperto presso Grozzana/ Gročana (Bernardini 2016). Poco si conosce della situazione nell'Altomedioevo, ad eccezione di un possibile sito fortificato sul Mali Kras, oggetto di studio da parte dell'associazione/društvo Limes a.p., e dell'ipotetica presenza di una tor-

\footnotetext{
5 La grotta è inserita nel Catasto ragionato informatico delle grotte archeologiche del FVG con il numero 504; maggiori info sul sito http://siticar.units.it/ca/criga/

6 Dal database citato in nota I, n. 7299
} 
re nei pressi dell'odierna chiesa S. Maria di Siaris, finora non documentata da alcuna evidenza archeologica (Flego e Zupančič 199I). Migliore la situazione per il periodo a partire dal XIII secolo, abbastanza noto, grazie alla documentazione reperibile sul castello di Vichumberg/Lorencon (Colombo 2000, Sapač 20II) sulle fortificazioni di Klanec (Pečar 1996, Sapač 20II) ed infine sul cosiddetto tabor di Draga ${ }^{7}$ (Colombo 2002, Sapač 20I4). L'Età moderna è ben testimoniata da fonti veneziane ed austriache, quella contemporanea da austriache, italiane, jugoslave e slovene.

La posizione del sito di Punjert si colloca all'interno del parco regionale di Beka (comune di Hrpelje - Kozina), sui versanti meridionali dell'alta Val Rosandra. L'abitato più vicino è il villaggio di Beka, da cui Punjert dista circa I km. Dalle cartine allegate ${ }^{8}$ si può vedere la posizione del sito rispetto a Beka e la zona esaminata nel presente saggio, situata all'interno dell'area posta sotto tutela dal Zavod za varstvo kulturne dediščine Republike Slovenije (Istituto per la tutela dei beni culturali della Republica di Slovenia). Punjert è collocato su un poggio leggermente degradante (plateau) in direzione SO-NE a quota $376 \mathrm{~m}$, con coordinate Lat: $45^{\circ} 36^{\prime} 29$, $05^{\prime \prime}$ e Lon: $13^{\circ} 533^{\prime} 42,91^{\prime \prime}$.

L'area del sito si presenta geologicamente formata da arenarie, sottoposte a notevoli processi erosivi che hanno formato gole e forre; è presente un articolato sistema idrografico di superficie, composto da ruscelli affluenti nel corso del Rosandra. A valle del sito, si possono notare, sia dalla cartografia che sul terreno, estesi movimenti franosi, alcuni antichi ed altri tuttora attivi. La vegetazione della zona è formata da un bosco relativamente giovane, composto di aghifoglie (pino nero) e latifoglie (principalmente querce, cerri, carpini, robinie). Non sono presenti tracce di recente antropizzazione, né di colture o pascoli, ad eccezione del pianoro adiacente al villaggio di Beka. La rete di sentieri creata dalla frequentazione umana è in stato di abbandono,

Ibidem, n. 9166

8 La cartografia utilizzata per questo saggio è stata ricavata elaborando la cartografia ufficiale della Repubblica di Slovenia, reperibile al sito: https://gisportal.gov.si/portal/apps/

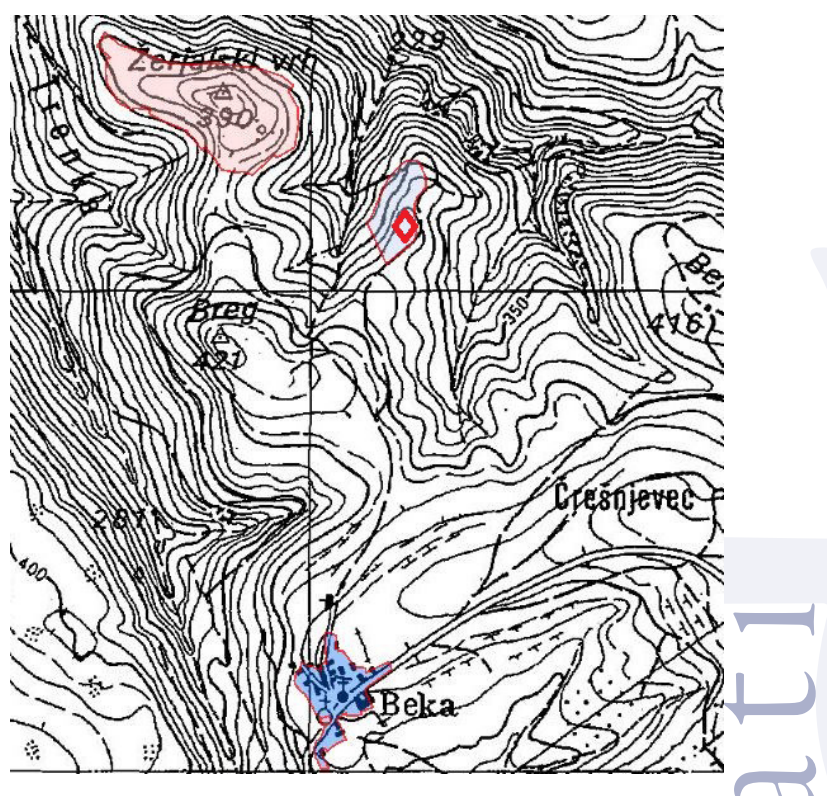

Immagine r: Il rombo rosso indica il sito di Punjert, presso quota 376

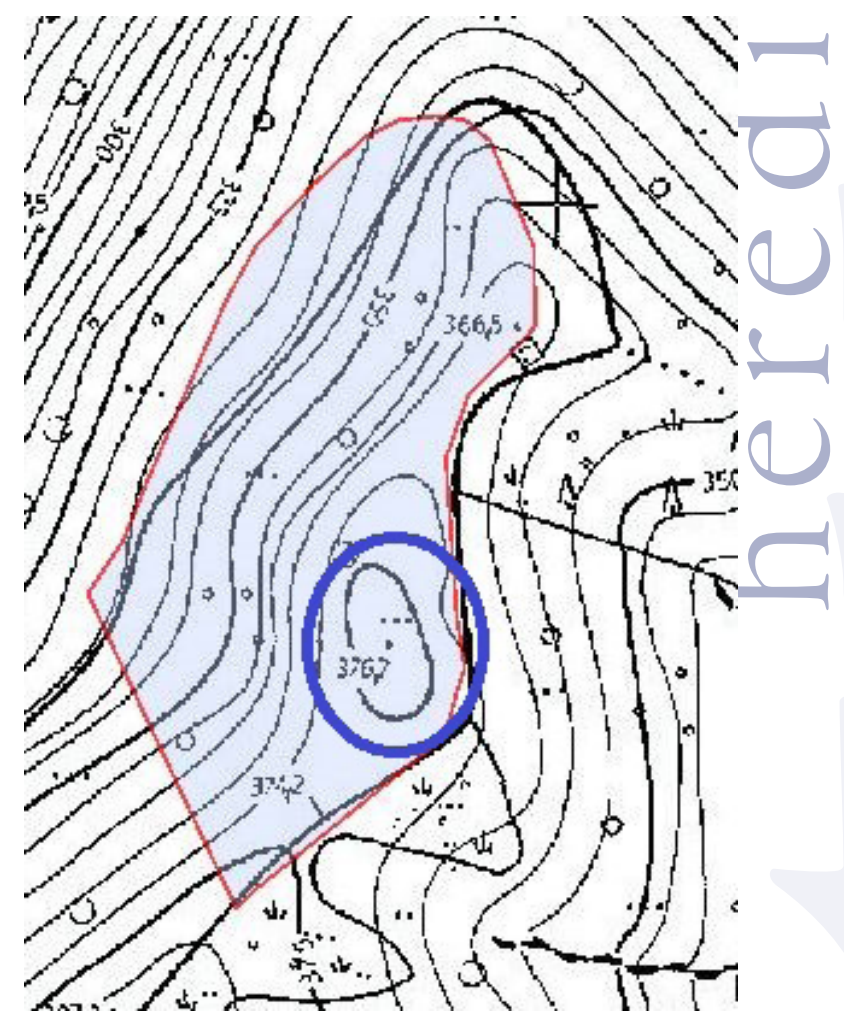

Immagine 2: L'ovale azzurro indica l'area oggetto di indagine 
e $25 \mathrm{~m}$ di larghezza (direzione O-E). Il fossato difensivo, profondo mediamente $2 \mathrm{~m}$ rispetto al terreno circostante, è ancora ben visibile attorno al plateau. Sul lato nord del sito, in cima della cresta, circa a $60 \mathrm{~m}$ nel punto in cui essa inizia a scendere verso Nord e la valle della Rosandra, si trova un ripido fossato naturale di forma quasi lineare in direzione $\mathrm{S}-\mathrm{N}$, che è quasi parallelo con il sentiero che corre verso il corso d'acqua e in parte circonda la cima della collina. Il fossato è di I $\mathrm{m}$ di profondità, in media, lungo circa $65 \mathrm{~m}$ metri e termina in corrispondenza con una curva del sentiero. Circa a $80 \mathrm{~m}$ in direzione del torrente, sul lato ovest del sito, ci sono dei resti di costruzioni a secco in pietra, di probabile origine moderna, la cui funzione è probabilmente legata al percorso che esisteva lungo il torrente.

Circa $450 \mathrm{~m}$ a NO del sito, sorgono i resti del castello di Vichimberch (Colombo 2000), un maniero gestito dai Conti di Gorizia e costruito alla metà del XIII secolo, su autorizzazione del vescovo di Trieste Ulrico, da Almerico di Carsperch (Foscan e Vecchiet, 200I). Tale famiglia nobile già controllava il castello di Karstberg, presso Golac/Golazzo, che presenta notevoli somiglianze costruttive. Un profondo vallone, creato da un'affluente del Rosandra, separa i due siti.

Il castello di Vichimberch, collocato sulla sommità della Žerjalski vrh, (secondo la toponomastica usata nella cartografia slovena) a quota 390, prima della sua distruzione, avvenuta nel mese di maggio del 136I ad opera delle milizie triestine, era stato costruito, secondo il Colombo (2000) "in un luogo appartato, in una posizione non proprio dominante, piuttosto distante dalle vie di comunicazione tra l'entroterra e la costa" ed presentava un "rilievo sommitale non artificiale ma reso più evidente e pronunciato dalla realizzazione del fossato, il materiale del quale fu utilizzato forse... per realizzare le murature di minor pregio /.../ L'aspetto che più caratterizza quel che rimane della struttura è il fossato /... / di dimensione e caratteristiche non facilmente riscontrabili nel panorama castellano locale. Lo scavo /.../ interessa i lati del pendio di
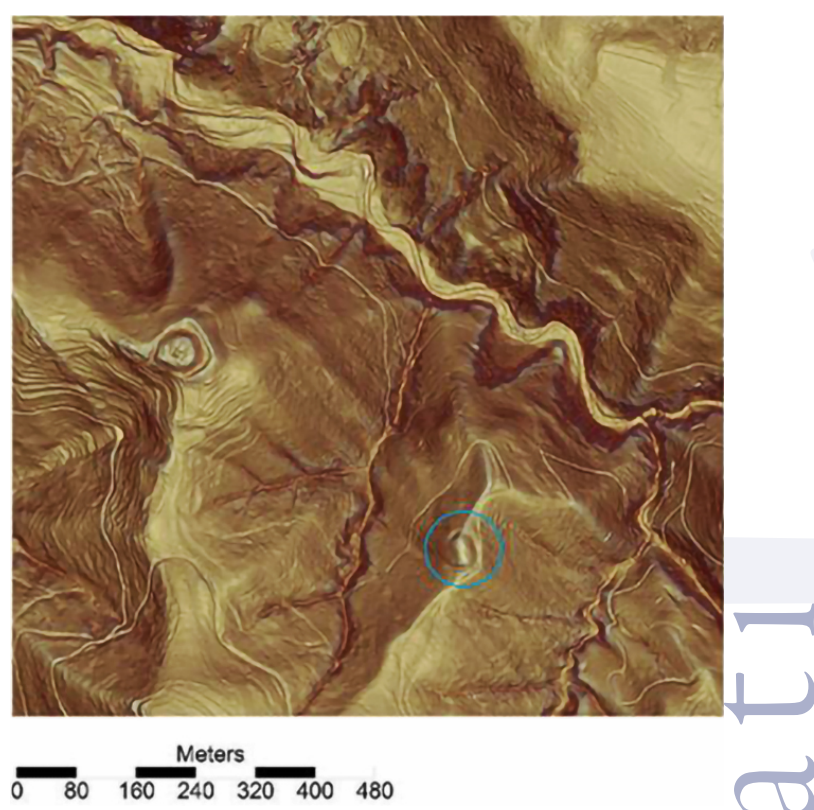

Immagine 4: Posizione di Vichimberch (a sinistra, si noti il fossato difensivo circolare) e Punjert (a destra, nel cerchio azzurro) attraverso l'elaborazione dati Lidar

minor pendenza, più esposti in caso di assedio" ed è "probabile che per il resto dell'edificio e delle costruzioni realizzate al suo interno si sia fatto largo uso del legno che non doveva certo mancare nei dintorni".

Poiché a Punjert, da decenni, o meglio dal tempo della scoperta, non veniva svolta alcun tipo di indagine, si è deciso di operare sul sito con metodi non invasivi. In particolare, si è investigato con un analisi sul terreno, con quella della cartografia antica e moderna, con l'elaborazione dei dati Lidar, con un rilievo georadar, senza trascurare lo studio ed il confronto delle fonti scritte che trattassero la zona. La finalità era di capire se, sul poggio denominato Punjert, circondato da un fossato di chiara origine artificiale, ci fosse stata un'opera fortificata, di quale probabile epoca, con quale funzione e, possibilmente, creare un rendering grafico della costruzione. Lavoro complesso perché, ad una prima ricognizione, come già si poteva presumere dai colloqui avuti con l'archeologo che aveva segnalato per primo il sito, nessun resto, o reperto, appariva in superficie. 


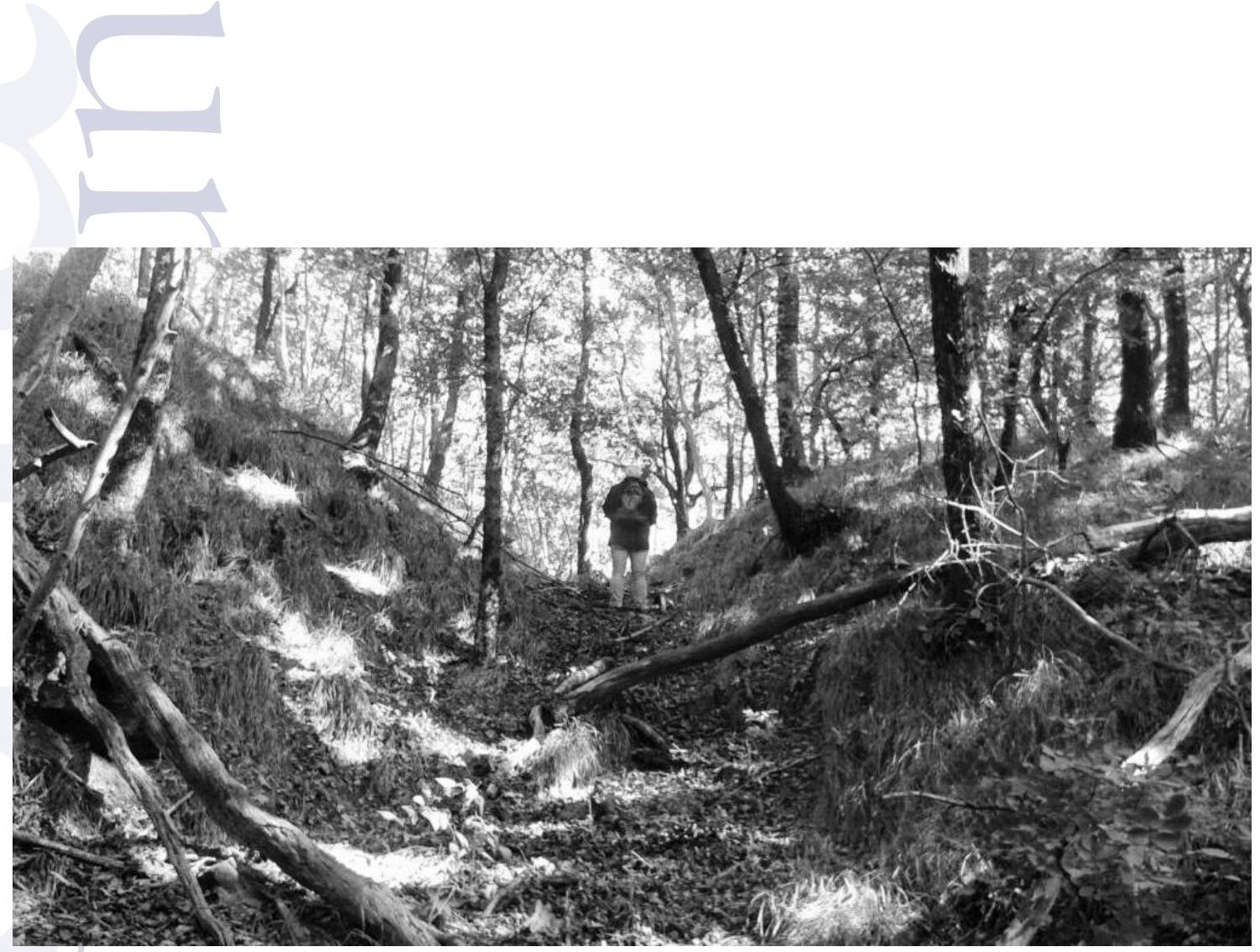

Immagine 5: Il fossato di Punjert, lato meridionale

L'analisi del terreno, oltre ad accertare la presenza del fossato e la presenza di alcune discontinuità sulla superficie pianeggiante del plateau, non ha dato ulteriori risultati. A favorire le successive indagini è stata la presenza di una rada vegetazione arborea, quasi priva di sottobosco (cespugli/rovi); nessun reperto o resto interpretabile come appartenente alla fortificazione è stato reperito in superficie, nonostante sia stato esaminato il plateau stesso, il fossato e lo scosceso declivio che proteggeva il sito dal versante meridionale. Si è deciso quindi di procedere ad un'analisi della cartografia disponibile oltre, naturalmente, ad un'attenta ricerca bibliografica. Ma, oltre ai rilievi topografici, nulla è stato reperito, nemmeno sulla cartografia di epoca austriaca (a partire dal XVIII) o tardoveneziana (il confine con la Serenissima correva a pochi chilometri). Nulla di notevole pure dallo studio delle mappe catastali giuseppine e franceschine.

Ulteriore passo è stato l'uso dei dati ricavabili per mezzo del Laser Surface Scanning, normalmente indicato come Lidar (Light Detection and Ranging), che è un metodo di rilevamento capace di misurare con grande accuratezza la superficie terrestre. Installando un laser su un mezzo aereo, si può illuminare la superficie terrestre con i raggi emessi dal laser stesso che, riflessi dal suolo, ritornano entro un certo tempo al ricevitore installato a bordo. La durata del tempo di riflessione permette di calcolare con esattezza la distanza dal suolo; utilizzando poi il sistema GPS, è possibile calcolare le coordinate tridimensionali del punto misurato. Il Lidar quindi rileva l'altezza della superficie terrestre e di tutte le strutture posizionate su di essa; grazie alla capacità di penetrare attraverso la copertura vegetale, ci permette di analizzare pure zone coperte da boschi e foreste. Con una successiva elaborazione dei dati ricavati, è quindi possibile ricavare l'altezza, punto per punto.

L'utilità del Lidar nel caso del sito di Punjert è emblematica: l'osservazione tradizionale dal cielo, per mezzo di foto aeree, satellitari o ricavate da droni non dava alcuna informazione di qualche importanza, mentre grazie al sistema Lidar, funzionante nonostante la copertura boschiva, si potevano raccogliere tutta una serie di 
dati ed immagini utili alla ricerca archeologica. Infatti, il sistema permette di vedere chiaramente tracce antropogeniche positive (in altezza), quali mura, tumuli, argini e negative quali trincee, affossamenti, fossati. Naturalmente tali tracce vanno selezionate e categorizzate con attenzione, soprattutto per evitare di interpretare fenomeni o formazioni naturali come strutture opera dell'uomo. Limitazioni all'elaborazione sono state riscontrate per la presenza di rilievi (e rilievi coperti da foreste), geologicamente recenti (Mlekuž 20I2); Punjert presentava proprio un terreno di questa tipologia ed è stata necessaria un notevole mole lavoro di elaborazione dati.

Grazie al National Lidar Shooting Project sloveno, accessibile sul sito dell'Agenzia per l'ambiente della Repubblica di Slovenia, si sono potute ricavare i dati e le immagini che sono presentate in questo saggio, usando il blocco 4I3_52. Dal Lidar si può vedere che il fossato (di lunghezza di circa $130 \mathrm{~m}$ ) è di forma triangolare irregolare. Dall' indagine sul terreno, il fossato è appena visibile nella parte settentrionale, mentre a sud non è visibile, ma risulta chiaro grazie all'immagine LIDAR. A prima vista, non è visibile alcun resto di edifici. Tuttavia, l'immagine LIDAR è in grado di rilevare una parte "nascosta" del fossato sul lato ovest, che è stato riempito da detriti, mentre sul bordo meridionale del plateau è parzialmente visibile una struttura della dimensione di circa 20 x I5 m (grossomodo rettangolare) parallela al fossato.

In considerazione di questi importanti indizi, nella ragionevole speranza che il terreno (coltre di terra) del plateau potesse celare ancora i tratti inferiori delle murature, si è deciso di procedere ad un rilievo georadar (GPR) multifrequenza. Lo scopo era quello di analizzare il terreno fino ad una profondità di circa 1,5 metri per l'eventuale localizzazioni di strutture sepolte di possibile interesse archeologico. Sono stati realizzati 29 profili longitudinali con l'impiego di due frequenze diverse, per un totale di circa 350 $\mathrm{m}$ di registrazioni. Il georadar (GPR - Ground

Io Il Lidar nella Repubblica di Slovenia è reperibile al link: http://gis. arso.gov.si/evode/profile.aspx?id=atlas_voda_Lidar@Arso

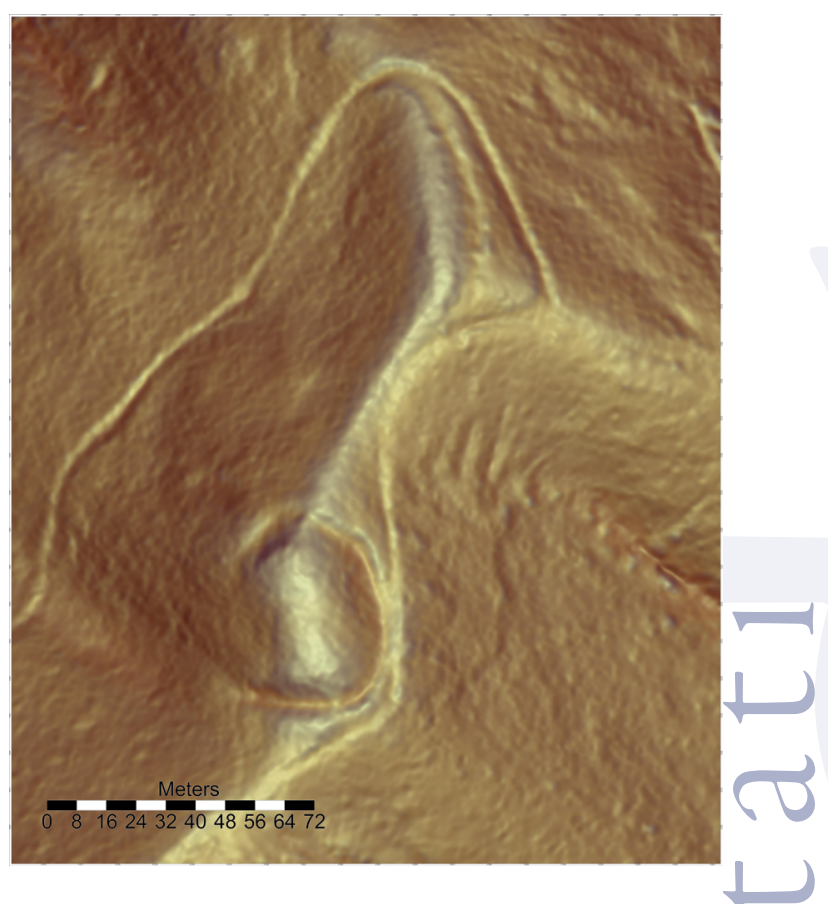

Immagine 6: Immagine ricavata dall'elaborazione dati Lidar del sito di Punjert

Penetrating Radar) utilizza onde elettromagnetiche immesse nel terreno da antenne trasmittenti, che vengono registrate in superficie da antenne riceventi. Questa registrazione costituisce la traccia radar che porta informazioni dal sottosuolo. La sezione o profilo GPR rappresenta l'insieme delle tracce che si ottengono muovendo la coppia di antenne (trasmittente/ricevente) sulla superficie del terreno ed effettuando campionamenti a intervalli di spazio regolari, nel presente caso pari a o,Io m. Per l'acquisizione dei dati Georadar è stata utilizzata un'apparecchiatura MALA GPR ProEx System ed in funzione degli obiettivi dell'indagine, si è deciso di utilizzare due antenne bistatiche, aventi frequenza pari a 500 e $300 \mathrm{MHz}$. La prima è in generale in grado di raggiungere profondità fino un metro e mezzo con un grado di dettaglio (risoluzione) dell'ordine di qualche centimetro, mentre l'antenna a più alta frequenza permette di indagare in media fino a circa $80 \mathrm{~cm}$ di sotto della superficie topografica, con precisione subcentimetrica. Il sistema GPR è stato equipaggiato con un ricevitore; 
Punjert-Beka UTM Mreža v r.s. D96TM (EPSG:3794) D=5m

413815

413820

413825

413830
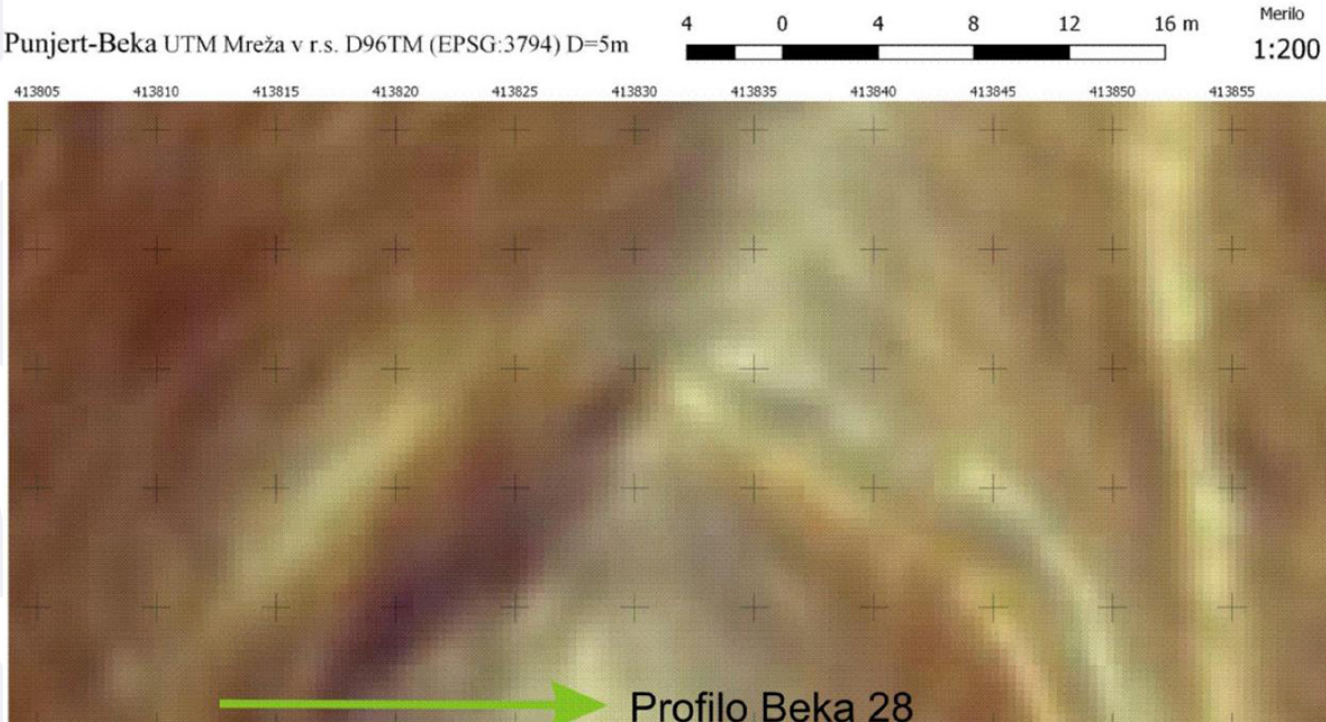

\section{Profilo Beka 27}

Profilo Beka 28

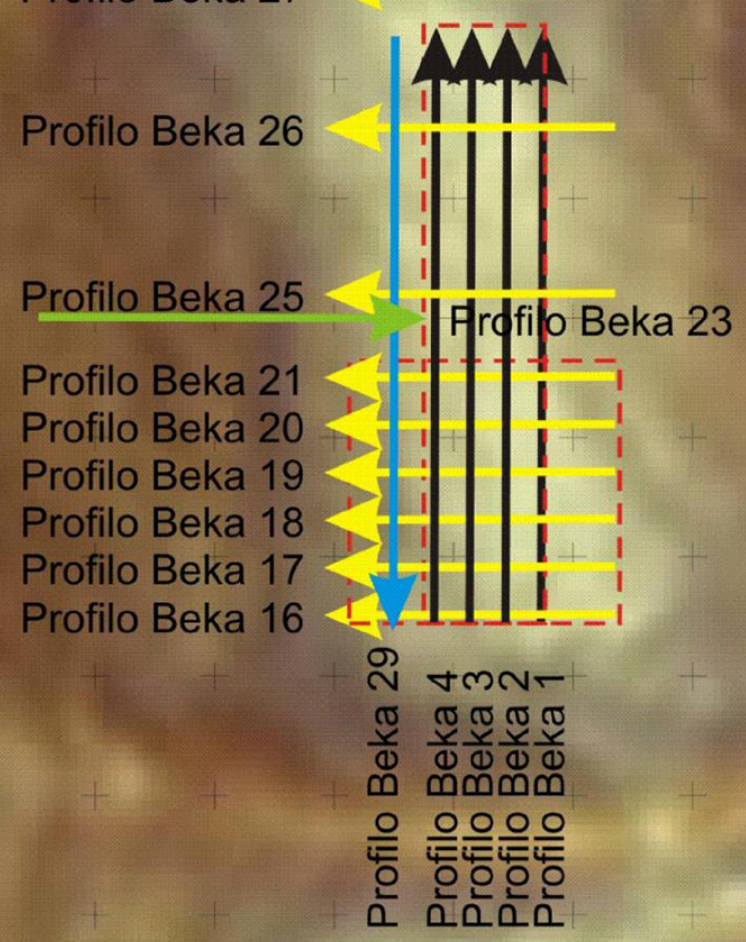



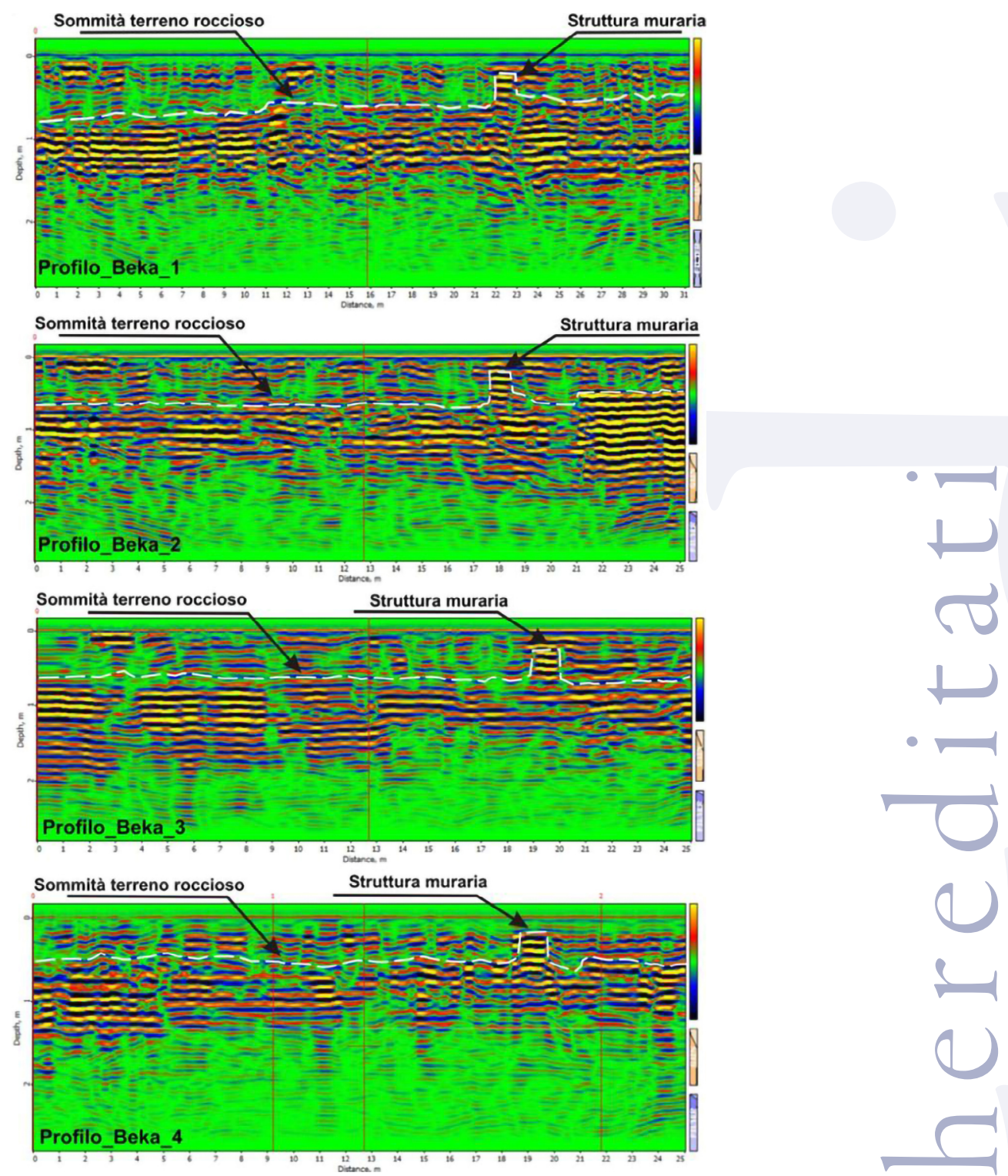

Immagine 8: Profili GPR elaborati con indicate le anomalie create da una struttura muraria sepolta e dalla sommità del terreno roccioso

l'emissione dell'impulso elettromagnetico è stata configurata "a distanza" regolata da un odometro collegato alla ruota del sistema GPR per poter controllare la distanza percorsa. Sono stati eseguiti 29 profili complessivi utilizzando le due antenne (500 e $300 \mathrm{MHz}$ ): di seguito è presentata una veduta d'insieme dell'area con le posizioni di alcuni profili eseguiti.
Nelle aree indagate sono stati localizzati diversi elementi che indicano la presenza di strutture sepolte che presentano le caratteristiche di porzioni di murature di medie o piccole dimensioni mentre più in profondità è stata individuata la sommità del terreno roccioso che varia da un profondità minima di $50 \mathrm{~cm}$ ad una massima di $90 \mathrm{~cm}$. I risultati riportati nelle figure seguen- 


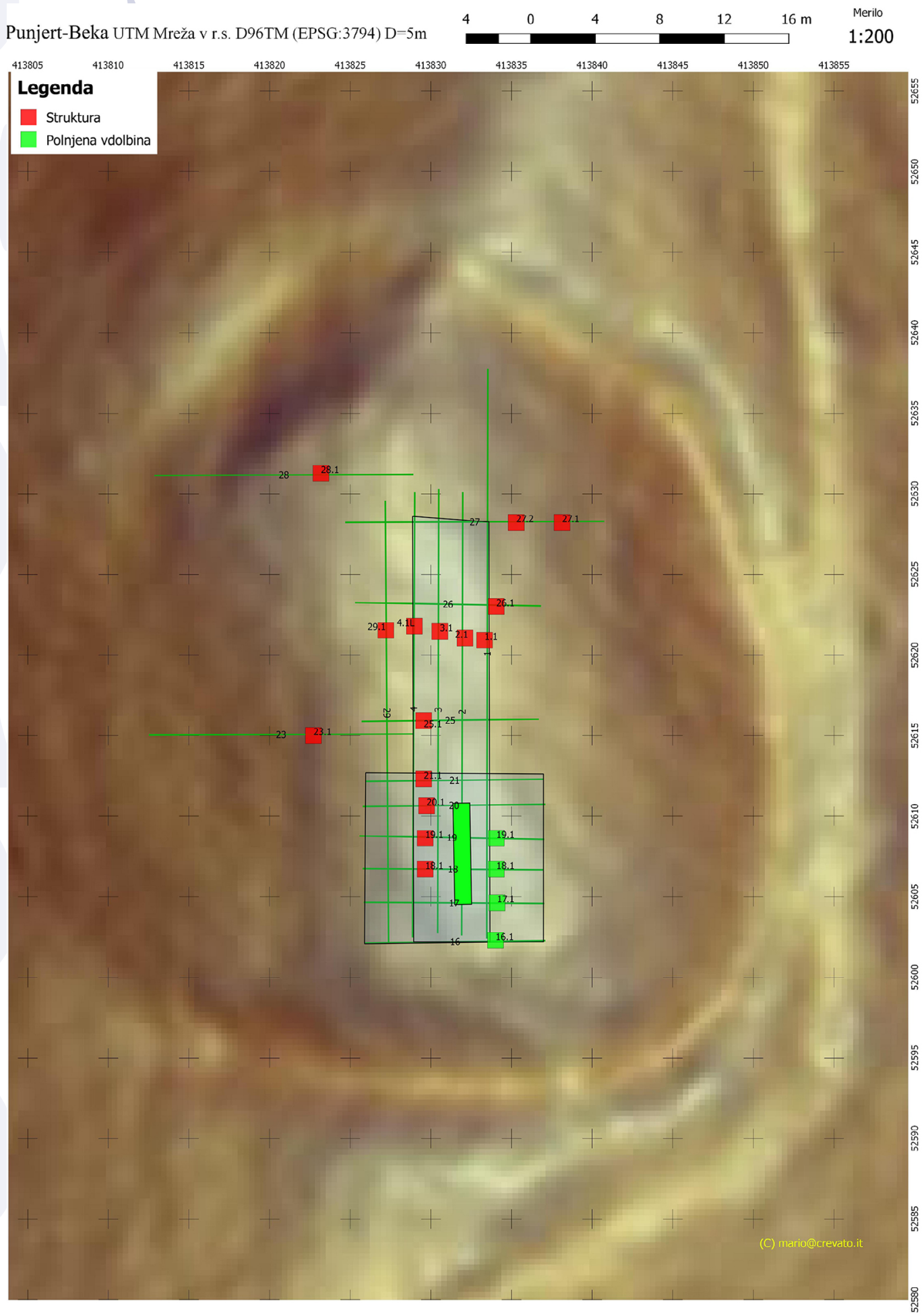

Immagine 9: Elaborazione georadar con segnali di strutture murarie (rosso) e cavità (verde) 
ti sono suddivisi seguendo le direzioni di profili complementari in modo da dare una continuità alle strutture identificate. Le anomalie riscontrate sui profili radar sono essenzialmente di 2 tipologie diverse. La prima tipologia è costituita dalla sommità del terreno roccioso che è sempre ben identificabile in ogni profilo, mentre la seconda è costituita strutture murarie che sono state riscontrate in tutti i profili elaborati.

L'indagine georadar nel sito evidenzia e conferma la presenza di strutture sepolte interpretate come porzioni di opere murarie. Queste strutture presentano una continuità (linearità) e sono di forme e dimensioni diverse. Al centro dell'area indagata, la sommità del terreno roccioso presenta alcuni affossamenti di natura antropica, mentre negli altri settori la sommità rocciosa naturale è pressoché costante. Dai rilievi si può notare che i resti delle strutture murarie hanno uno spessore poco inferiore al metro, ad eccezione del muro trasversale, posizionato a circa $2 / 3$ della lunghezza del plateau che, con ogni probabilità, è congruente con il modesto "gradino" percettibile sul terreno. Considerato il maggior spessore di queste ultime strutture murarie, che arrivano a circa $1,5 \mathrm{~m}$, e il loro posizionamento, si presume, con sufficiente certezza, che siano i resti di una torre di difesa in posizione semicentrale. Per quanto riguarda gli affossamenti di origine antropica, ora interrati, potrebbe trattarsi di vani quali cantine e/o riserve d'acqua; pur essendoci tutta una serie di ruscelli nei dintorni, il plateau era (si nota l'assenza di fenomeni erosivi) ed è privo di acque superficiali.

Alla conclusione di tutte le ricerche non invasive, risultano a disposizione le seguenti informazioni, per la creazione di una ipotetica ricostruzione grafica di Punjert e la stesura di alcune ipotesi sulla sua datazione: analisi del terreno, immagini Lidar, dati ottenuti con il georadar, studio comparato delle fortificazioni finora studiate in zona, risalenti al Medioevo. Si è proceduto, usando come base il profilo del rilievo ottenuto per mezzo del Lidar, a tracciare uno primo schizzo della struttura fortificata. Al fine di implementare l'attendibilità del rendering grafico, si è interpellato il prof. I. Sapač ${ }^{11}$, massimo esperto per quanto riguarda il processo di incastellamento e la sua evoluzione in Slovenia, autore di oltre una decina di testi monografici dedicati ai castelli, inviandogli i dati disponibili (in particolare Lidar e georadar), le considerazioni ed il disegno preliminare. Grazie alle sue considerazioni e consigli, si è giunti alla stesura definitiva dell'ipotetica ricostruzione grafica. Trattasi quindi tratta una fortificazione, che ha probabilmente difeso l'ex percorso che da Trieste, attraverso la val Rosandra, proseguiva lungo la linea di minima pendenza verso Mihele e Beka. Presso quest'ultimo villaggio, nel punto più strategico, si trovava Punjert. Prima dell'imboschimento dell'area (a pino nero), da questo punto era possibile un'ampia visuale sulla val Rosandra (nella sua zona flyschoide ed oltre).

Dai risultati delle ricerche l'ipotesi è che Punjert nasconda, nel sottosuolo, i resti di un piccolo castello medioevale. Probabilmente era una modesta fortificazione con una semplice cortina muraria (forse parzialmente lignea) e torre (semi)centrale difensiva, costruito forse su un sito già utilizzato per una fortificazione tardoantica. Punjert nel passato aveva una buona posizione strategica, potendo appunto controllare le vie di traffico dell'alta Val Rosandra. Tali percorsi sono ancora visibili sia (parzialmente) sul terreno che attraverso il sistema Lidar, ma sono per lo più interrotti ed abbandonati a causa di evidenti movimenti franosi e fenomeni erosivi; l'abbandono di tale rete viaria potrebbe esser stata causa dell'inutilità e progressiva distruzione di tale fortificazione.

In conclusione, si possono formulare tre ipotesi sull'origine e la datazione di Punjert. La prima vede una datazione del sito intorno all'anno Iooo, quando sul Carso i Weimar fecero costruire una prima serie di castelletti e punti fortificati, da cui ne consegue che Punjert fosse già stato distrutto o abbandonato già prima del XIII secolo, quando fu costruito il castello di Vichimberch. Data l'assenza di resti e tracce murarie in

Il prof. Sapač, considerata il probabile range nella datazione della struttura (1000-1300) ha suggerito la probabile presenza sulla torre di un tetto a spioventi, inizialmente pensata con tetto a terrazza. 


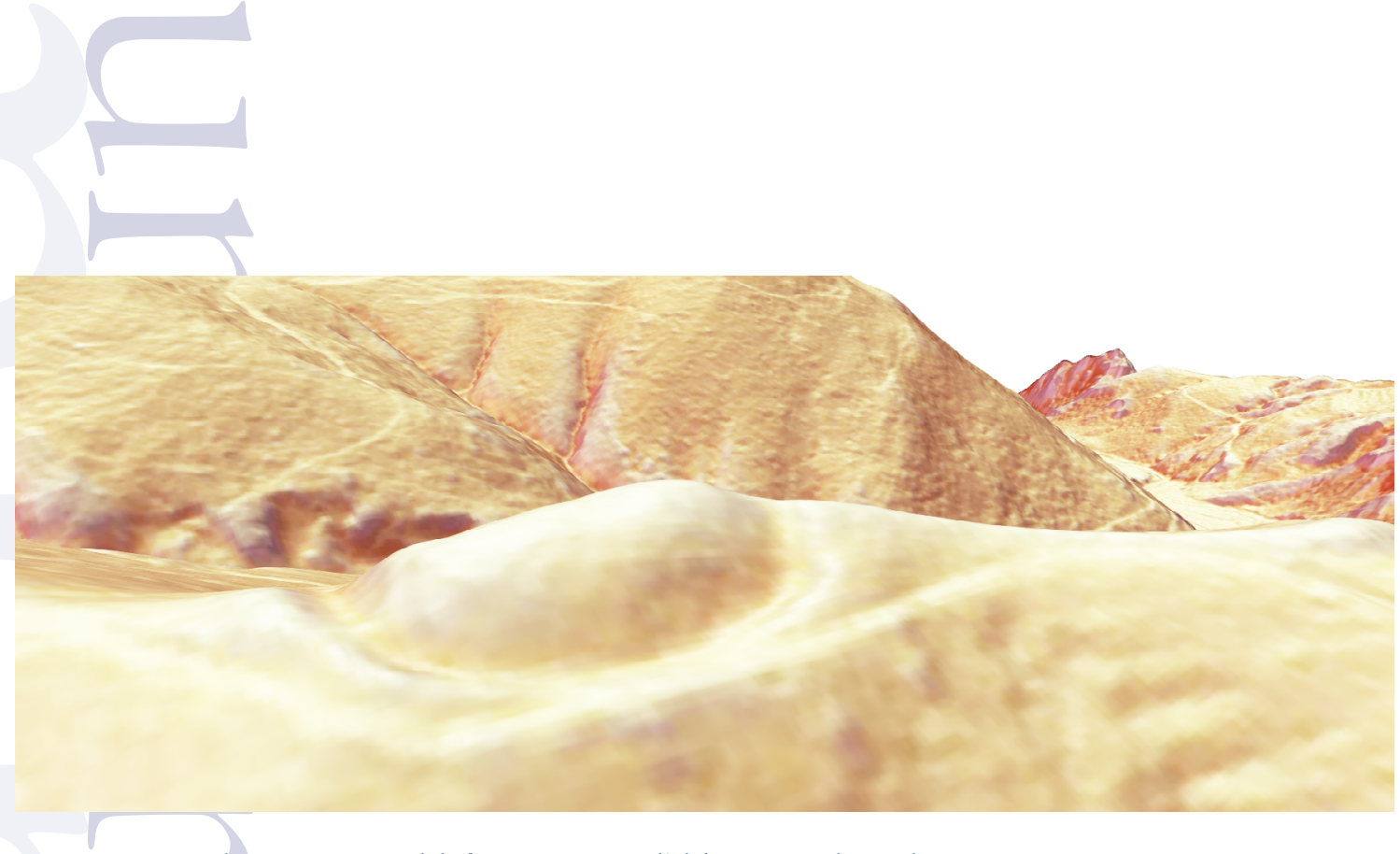

Immagine ı: Veduta prospettica del plateau attraverso l'elaborazione dati Lidar

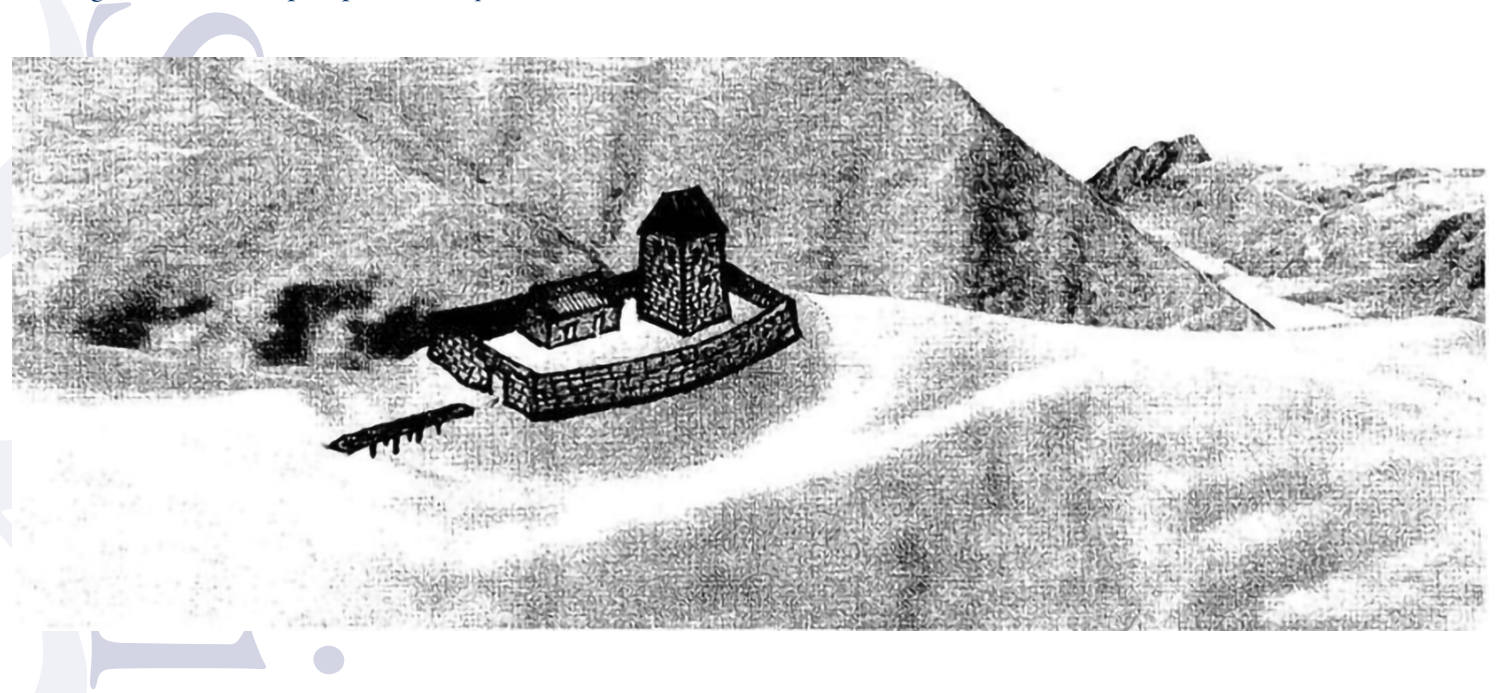

Immagine II: Ricostruzione grafica (ipotetica) di Punjert

superficie, è molto probabile, seguendo tale ipotesi, che Vichimberch fosse stato costruito, almeno in parte, utilizzando i materiali di Punjert; pure possibile che siano stati utilizzati per la costruzione (successiva) del villaggio di Beka ${ }^{12}$, poiché queste tre località sono relativamente vicine e ben collegate tra loro: dal pianoro di Beka è semplice raggiungere i siti delle due fortificazioni, senza affrontare particolari dislivelli. La seconda ipotesi, cioè quella che Punjert sia stato il "campo" temporaneo delle milizie triestine, destinate all'assalto del castello di Vichimberch del 1361, appare poco sostenibile, in considerazione della scarsa superficie del sito, della distanza dal castello target, dalla presenza di un profondo fossato (che ha richiesto chiaramente un grande lavoro di scavo) e dalla sua posizione, opposta alla probabile provenienza delle milizie triestine. Con le armi a getto dell'epoca, poi, sarebbe stato del tutto impossibile colpire Vichimberch essendo posizionati a Punjert. La terza ipotesi è che Punjert sia stato un propugnacolo o, meglio, una fortificazione avanzata destinata ad implementarne la resa bellica del castello di Vichimberch, 
quindi ad esso coevo, forse sorto sui resti di qualche avamposto tardoantico.

$\mathrm{Si}$ auspica che in un prossimo futuro, forse a causa del grandi lavori necessari per il "Drugi Tir" o per il potenziamento del parco regionale di Beka, si possa procedere ad una serie di indagini invasive che possano, sperabilmente, render più chiara l'origine di tale castello "perduto" nell'alta val Rosandra.

\section{Povzetek}

V članku predstavljamo najnovejše raziskave na območju arheološkega najdišča Punjert. Najdišče se nahaja v zgornjem delu doline Glinščice, na njem pa se nahajajo skromni ostanki manjše utrdbe iz obdobja srednjega veka. $S$ pomočjo kartografskih, bibliografskih in neinvazivnih terenskih raziskav smo izdelali hipotetično grafično rekonstrukcijo utrdbe in postavili nekaj možnih hipotez o starosti utrdbe in njene vloge v prostoru. Pri interpretaciji rezultatov smo prvenstveno upoštevali bližnji že do dobra preučen grad Vichimberch.

$\mathrm{V}$ zaključku lahko formuliramo tri hipoteze o izvoru in datumu Punjerta. Prva datira lokacijo okoli leta Iooo in iz nje izhaja, da je bil Punjert že uničen ali opuščen pred I3. stoletjem, ko je bil zgrajen grad Vichimberch. Verjetno je Vichimberch, vsaj delno, zgrajen s pomočjo materialov iz Punjerta; možno je, da je bil material uporabljen tudi za gradnjo vasi Beka. Druga hipoteza, da je bil Punjert začasni "tabor" tržaških enot, namenjen napadu na grad Vichimberch leta 1361, se zdi nevzdržna, glede na površino, oddaljenost od ciljnega gradu, prisotnost. globokega jarka in njegovega položaja. Takratno jet orožje bi bilo potem popolnoma nemogoče, da bi udaril Vichimbercha, ki bi bil postavljen na Punjert. Tretja hipoteza je, da je bil Punjert propugnaculum ali, še bolje, prednja utrdba, sočasna gradu Vichimberch.

\section{Summary}

This research paper presents the archaeological park known as Punjert, located in the upper Rosandra Valley, which consists of the remains of a small fortification or castle dating to the Medieval period. Through cartographic, bibliographic, on site (non-invasive) research and the analysis and processing of data collected from the Lidar system and GPR it has been possible to create a graphic rendering of the site and develop hypotheses on the construction date and purposes, with specific reference to the not too far away and previously researched Vichimberch castle. Three hypotheses on the origin and dating of Punjert are possible. The first dates the site around the year 1000, and it follows that Punjert had already been destroyed or abandoned before the izth century, when Vichimberch castle was built. It is very likely, that Vichimberch was built, at least in part, using the materials of Punjert and it is possible that they were used for the construction of the village of Beka. The second hypothesis, that Punjert was the temporary "camp" of the Trieste militias, destined for the assault of the castle of Vichimberch in 1361, appears to be unsustainable, considering the scarce surface of the site, the distance from the target castle, from the presence of a deep ditch and of its position. The third hypothesis is that Punjert was a propugnaculum or front fortification, contemporary with Vichimberch castle.

\section{Bibliografia di riferimento}

Bernardini, F. 2016. "Nuova luce sugli antichi accampamenti militari romani" in Il Sapere, 1: 28-33. DOI: 10.12919/ sapere.2016.01.4

Colombo, F. 2000. "Vichimberch I249-136I. La breve vita di un castello vescovile, gestito dai conti di Gorizia, in territorio triestino" in Archeografo Triestino IV (LX): 183-237.

Colombo, F. 2002. "Il “Taber" di Draga e la genesi delle strutture erette a difesa delle incursioni turche nei dintorni di Trieste alla fine del Quattrocento" in Archeografo Triestino IV (LXII): 285-322.

De Marchesetti, C. I903. I castellieri preistorici di Trieste e della Regione Giulia. Trieste: Italo Svevo (ristampa 198I).

Flego, S., e I. Žerjal, 1992. "Rimske vojaške opazovalnice v dolini Glinščice” Jadranski koledar. II7-I24.

Flego, S., e M. Zupančič. 1991. Arheološka topografija občine Dolina. Trst: Narodna in študijska knjižnica, Odsek za zgodovino.

Foscan, L., e E. Vecchiet. 200I. I castelli della Carsia orientale. Trieste: Luglio edizioni.

Mlekuž, D. 20r2. "Messy landscapes: lidar and the practices of landscaping." in 
Interpreting archaeological topography: lasers, ${ }_{3} D$ data, observation, visualisation and applications. Edited by R. S. Opitz, and D. Cowley, 90-ror. Oxford: Oxbow.

Pečar, D. 1996. Predzgodovinska gradišča, rimske utrdbe, srednjeveški gradovi in tabori na malem Krasu. Klanec: samozaložba.

Sapač, I. 2014. Gradovi, utrdbe, dvorci, vilev Slovenskem primorju in v bližnji soseščini. Ljubljana: Viharnik.

Sapač, I. 20II. Grajske stavbe v zahodni Sloveniji: Kras in Primorje. Ljubljana: Viharnik. 



\title{
Na sledi zgodnjebronastodobne poselitve v dolini Rižane Arheološke raziskave na najdišču Ključ
}

\author{
Manca Vinazza, Oddelek za arheologijo, Filozofska fakulteta, Univerza v Ljubljani \\ Matej Draksler, Skupina STIK
} $<$

V članku predstavljamo najdišče Ključv dolini Rižane. Na podlagi tehnološke in tipološke analize keramike opredeljujemo najdišče v zgodnjo bronasto dobo. Ključno vlogo pri izbiri lokacije najdišča je domnevno odigrala bližina vode in prometna povezava pod Kraškim robom oz. Podgorskim Krasom, ki povezuje Tržaški zaliv in Istro po kopnem. V neposredni bližini Ključa poznamo le eno sočasno najdišče, Jama nad Brežcem, kar je po našem mnenju posledica stanja raziskav.

Ključne besede: zgodnja bronasta doba, nižinska naselbina, dolina Rižane, Ključ, kaštelir

In this article we present lowland type of settlement Ključ in Rižana valley. Due to technological and typological pottery analysis, we are able to date this site to Early Bronze Age. Nearby fresh water and communication route under Karts Edge, which connects Gulf of Trieste and Istria, were presumably the main reasons for selecting Ključ as a location. There is only one other known contemporaneous site nearby Ključ - cave Jama nad Brežcem. We believe this is only a consequence of the state of research.

Keywords: Early Bronze Age, lowland settlement, Rižana river valley, Ključ, hillfort

V prispevku predstavljamo arheološko najdišče Ključ v dolini reke Rižane, kjer so leta 2014 potekale arheološke raziskave, ki so kljub skromnemu obsegu pomembno prispevale $\mathrm{k}$ poznavanju tega prostora $\mathrm{v}$ bronasti dobi.

Arheološko najdišče Ključ se nahaja na nižji vzpetini, ki leži na stičišču treh pokrajin, Podgorskega Krasa (Kraški rob), Brega (Bržanija) in doline Rižane. Podgorski Kras ima apnenčasto osnovo, a so se kraške oblike tu slabo razvile. Prehod v flišno pokrajino Slovenske Istre namreč ni nenaden. Pod stenami (stopnjami), ki so nastale kot posledica součinkovanja tektonskih in erozijskih procesov, se vleče razmeroma položno pobočje, ki je le v osrednjem delu prekrito z debelejšimi sloji flišnih kamnin, medtem ko je v zgornjem delu, bliže stenam, takoj pri vrhu še apnenec ali debela plast grušča, pomešane- ga $\mathrm{z}$ rdečerjavo kraško prstjo. Ta predel predstavlja izrazito prehodno pokrajino, ki se začne $\mathrm{v}$ občini Dolina na italijanski strani in se razteza od Socerba, Ospa, Gabrovice, Črnega Kala, Loke, Bezovice do Podpeči. Medtem pa nižje, od Dola nad Hrastovljami do Sermina poteka dolina reke Rižane s ploskim dnom, ki je pri Dolu in Hrastovljah prekrito $\mathrm{z}$ debelimi sloji flišnih naplavin. V njenem zgornjem delu, od Dola do izvira Rižane, gre za suho dolino Rižane. Danes teče od Hrastovelj le potok hudourniškega značaja, ki poleti praviloma presahne.

Reka Rižana danes izvira v Zvročku, manj kot kilometer stran zračne linije severozahodno od Ključa. Dolina je med Dolom in Hrastovljami ozka in globoka, pri izviru Rižane pa se na široko odpre v rahlo valovito ravnico. Prav na tem mestu leži obravnavano najdišče Ključ. Del doline pri izviru je iz eocenskih apnencev, ves preos- 


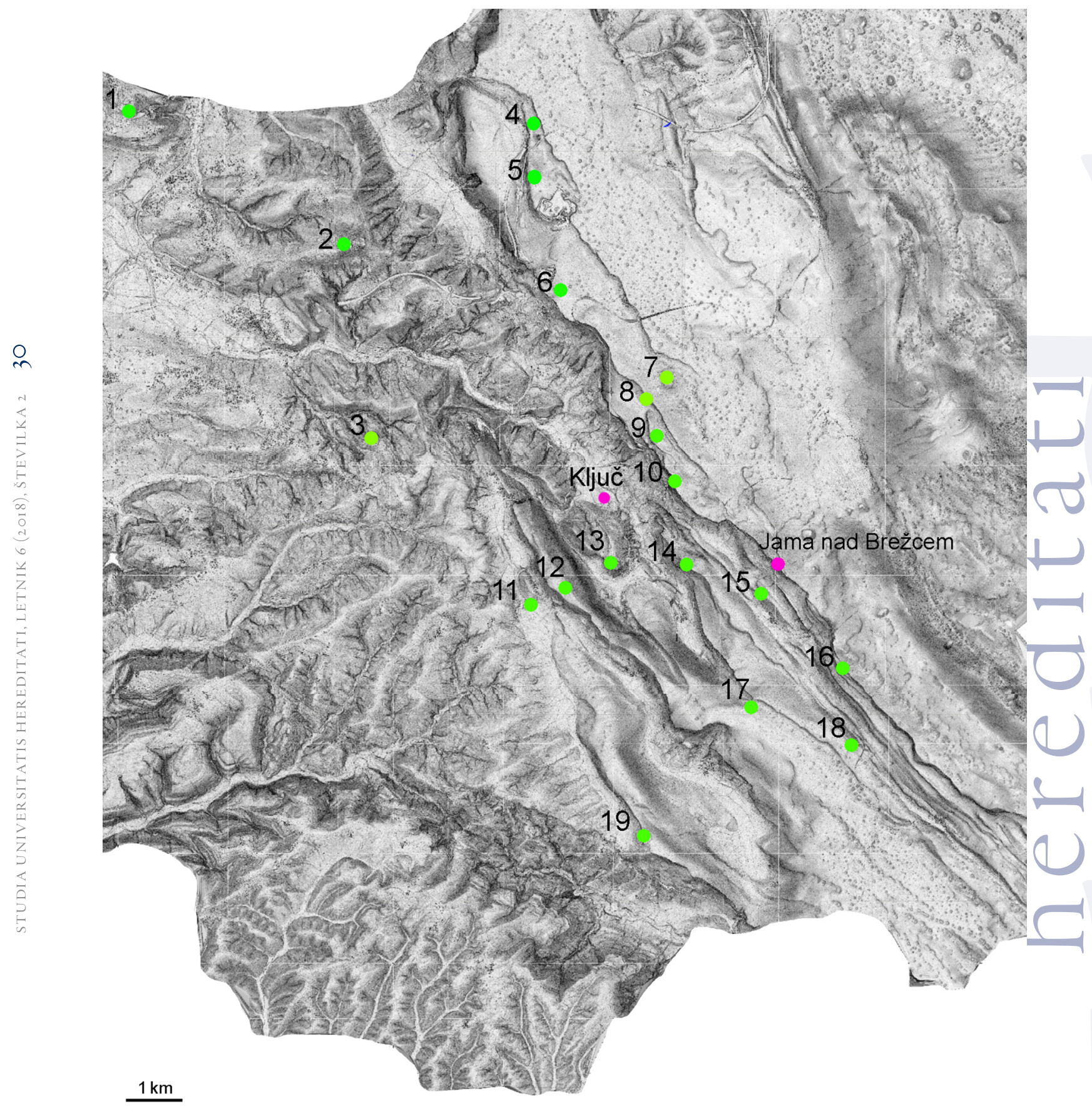

Slika I. Lega zgodnje bronastodobnih najdišč Ključ in Jama nad Brežcem (magenta) ter kaštelirji (zelena) (prirejeno po RKD pregledovalniku). I. Jelarji, 2 Tinjan, 3.Sv. Anton, 4. Kastelec (Varda), 5. Kastelec (Hrib), 6. Črnotiče (Mozar), 7. Črnotiče (Marija Snežna), 8. Bezovica (Stena), 9. Bezovica (Brgode), Io. Podpeč pri Črnem Kalu, II. Gračišče (Griža), 12. Gračišče (Lačna), 13. Hrastovlje (Vrh), 14. Zaningrad (Kovk), 15. Zazid (Zjat), 16. Zazid (Mojbrma), 17. Dol pri Hrastovljah (Gradež), 18. Zazid (Na Krasu), 19. Sočerga (Sv. Kvirik). 
tali del pa iz flišnih kamnin, med katerimi je najbolj pogost lapor (Šiškovič I990, 9-I2).

\section{Zgodovina raziskav}

Kraški rob je skupaj z Bržanijo imel od nekdaj strateški pomen. Tu se namreč ločuje flišna Istra in apnenčast Kras, v širšem smislu Sredozemlje in celina. Na tem stiku so že v prazgodovini stala gradišča oz. kaštelirji (slika I; npr. Mali Kras severno od Socerba, Grad na Socerbu, gradišče nad Prebenegom, Hrib nad Kastelcem, Mozar nad Črnim Kalom, Gradišče (Marija Snežna) pri Prapročah, Stena nad Loko, Brgode, gradišče nad Podpečjo, Kovk nad Zanigradom in Gradež nad Movražom), ki so nadzorovali poti iz notranjosti celine oz. Tržaškega zaliva na istrski polotok (Zupančič 1990, 19; Gorenc 2006, 98).

Arheološko najdišče Ključ (slika I) prvič omenja že Alberto Puschi (Benussi 1927-1928, 261; Truhlar 1975, 129), prve arheološke raziskave pa so tu potekale šele leta $2014^{1}$, in sicer na parc. $42 \mathrm{I} / \mathrm{I}, 42 \mathrm{I}$ in $\mathrm{I} 407 / \mathrm{I}$, vse k. o. Loka.

$\mathrm{V}$ neposredni okolici Ključa poznamo več najdišč iz različnih obdobij, saj gre za izrazito prehoden in zato strateško pomemben prostor. Omeniti velja predvsem večje število kaštelirjev, ki pa so večinoma opredeljeni v pozno bronasto in začetek starejše železne dobe (Register kulturne dediščine RS). Glede na analizo keramike, ki je bila odkrita pri arheoloških raziskavah na Ključu, ugotavljamo, da so najdbe starejše, natančneje iz zgodnje in/ali srednje bronaste dobe. Najdišča iz tega časa so na tem prostoru maloštevilna. Sočasne najdbam na Ključu so nekatere najdbe iz Jame nad Brežcem (Sakara Sučević 2004; slika I), medtem ko sodi bodalo iz Jernejeve jame pri Črnem kalu, ki ga je skupaj s keramiko našel B. Lonza in domnevno predstavlja naselbinsko najdbo, v srednjo oz. mlajšo bronasto dobo (Šinkovec 1995, 95, kat. št. I83). Tudi nekatera jamska najdišča in vrtače so okvirno

Predhodne arheološke raziskave v obliki arheološkega terenskega izkopa in arheološke raziskave ob gradnji je izvedla Skupina STIK, pod vodstvom Sama Hvalca in Mateja Drakslerja (oba Skupina STIK) in pod konservatorskim nadzorom Jake Bizjaka (ZVKDS, OE Piran). opredeljena v bronasto dobo (Register nepremične kulturne dediščine RS).

\section{Arheološke raziskave}

\section{Metodologija in potek raziskave}

Metodologija terenskih raziskav je bila pogojena s standardi arheoloških raziskav, predvidenih za arheološki testni izkop ${ }^{2}$. Arheološke plasti so bile izkopane ročno stratigrafsko. Dokumentacija je obsegala geodetsko, fotografsko in opisno dokumentiranje evidentiranih plasti in arheoloških ostalin.

\section{Rezultati arheološkega testnega sondiranja}

$\mathrm{Na}$ obravnavanem območju (slika 2) je bilo najprej ročno izkopanih Io testnih sond velikosti I $\times$ I m, katerih globina je segala do geološke osnove (slika 4). Slednja se je pojavila na globini med 5 in $40 \mathrm{~cm}$. V tej fazi raziskave so bili odkriti predvsem številni odlomki prazgodovinske lončenine, nekaj odlomkov rimskodobne lončenine in gradbenega materiala ter nekaj časovno neopredeljivih kosov. Na podlagi arheoloških rezultatov je bilo izkopno polje na prostoru predvidene postavitve treh pomožnih gospodarskih stavb, kasneje razširjeno. Izkopane so bile tri sonde $(\mathrm{I}-3)$, velikosti $6,3 \times 6,3 \mathrm{~m}$, skupne površine ca. $120 \mathrm{~m}^{2}$.

Arheološke raziskave so razkrile sledove prazgodovinske poselitve prostora, ki je bila izrazitejša v severozahodnem delu registrirane enote kulturne dediščine Hrastovlje - Kaštelir Ključ, kjer so raziskave potekale. Rimskodobne najdbe so bile odkrite izključno na pobočju ob vznožju vzpetine (slika 2), in kaže na rabo tega prostora tudi v tem obdobju.

Najdišče leži v celoti na močno prepereli in razpokani apnenčevi skalni osnovi (SE roo5, SE 2004, SE 3003; slika 4). Na razgibani podlagi je $z$ naravnimi in antropogenimi procesi nastala različno debela plast temno rumenkasto rjavega glinenega melja (SE 1002, SE 2002, SE 3002; slika 3). V tej plasti smo našli prazgodovinske najdbe, ki so bile najštevilnejše v razpokah in kotanjah apnenca. Površje se je v zad-

\footnotetext{
Pravilnik o arheoloških raziskavah (Ur. l. RS št. 3/2013).
} 


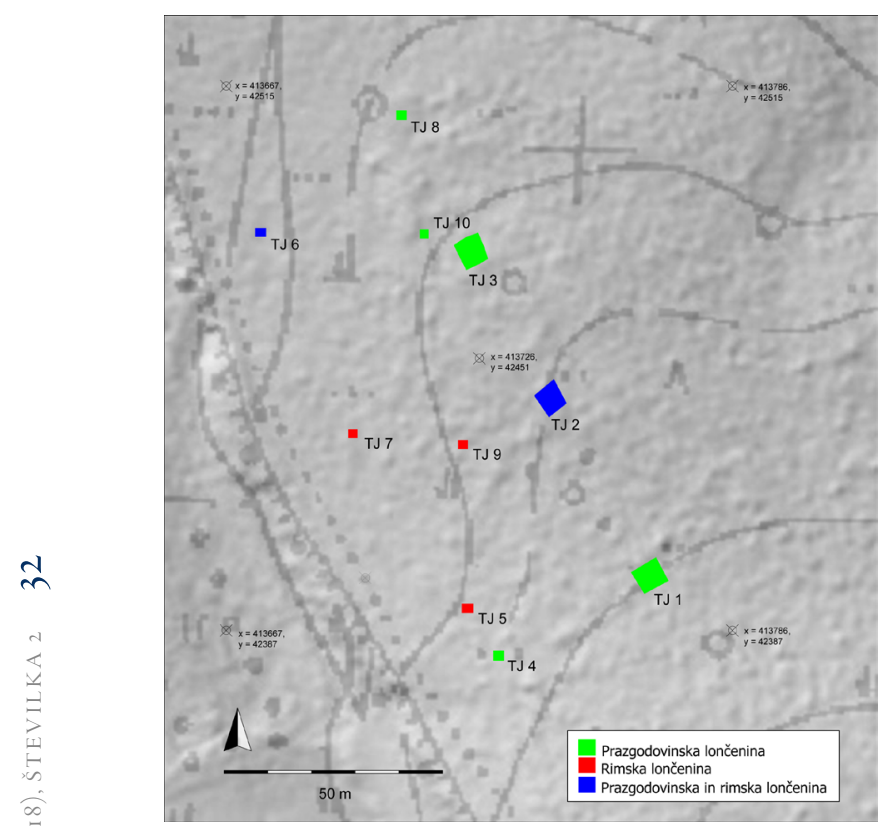

Slika 2. Ključ, lega testnih sond (prirejeno po RKD pregledovalniku ).

njih tisočletjih precej spremenilo, na eni strani $s$ kemičnimi procesi v skalni podlagi, na drugi pa zaradi človekovega vpliva, ki je z uporabo prostora (travnišvo, pašništvo idr.) vzpetino na Ključu razgalil in s tem povzročil denudacijo površja. Morebitne uporabne površine, ki bi jih lahko $\mathrm{v}$ povezavi s prazgodovinskimi najdbami pričakovali, so bile zato uničene oz. odstranjene. Pri izkopavanju sonde 3 je bila najdena večja koncentracija prazgodovinske lončenine, ožgane gline ter glinenega ometa, kar nas napeljuje $\mathrm{k}$ predpostavki, da lahko na tem delu najdišča domnevamo enega ali več prazgodovinskih objektov. V vseh treh sondah smo namreč ugotovili domnevno antropogene izravnave (npr. SE 2004; slika 5) skalne osnove (Draksler in Klasinc 201 4, 45-47).

\section{Keramično gradivo}

$\mathrm{V}$ treh sondah je bilo odkritih 743 odlomkov lončenine ( $5554 \mathrm{~g}), 6$ kosov hišnega ometa $\mathrm{z}$ vidnimi odtisi prepleta ( $132 \mathrm{~g})$, I kos železa ( $16 \mathrm{~g})$ in I živalska kost (17 g). Vse najdbe so prazgodovinske. Od tega smo za izris izbrali iz sond 24 kosov in le $\mathrm{v}$ manjšem obsegu uspeli rekonstruirali premer ustja ali dna posod, saj gre po večini za zelo majhne odlomke.

Lončenino smo obravnavali tehnološko in tipološko, saj je pri tako slabo ohranjenem keramičnem gradivu način izdelave lončenine bistveno bolj izpoveden. Način izdelave lončenine smo opazovali na makroskopskem nivoju po Horvatovi (Horvat 1999). Osnovne sestavine lončarskih mas smo ugotavljali z lupo. Za potrebe lažje predstavitve beleženja posameznih kosov smo vsak obravnavani odlomek fotografirali pod stereo lupo (Leica ES 2 - Stereo microscope; slika 6), pri čemer je potrebno izpostaviti, da gre pri fotografiji zbruska za namen osnovnega prikaza, in da smo pri ugotavljanju sestavin opazovali tudi druge dele odlomka.

Lončenina je $\mathrm{z}$ vidika načina izdelave zelo enotna. Izdelana je prostoročno. Prevladujejo finozrnate mase (velikost zrnc 0,25 do $0,50 \mathrm{~mm}$ ) (19 odlomkov oz. $79 \%$ ), ostalo pa so zelo finozrnate mase (velikost zrnc do o,25 mm) (4 odlomki oz. 2I \%). Ugotovili smo 8 različnih lončarskim mas (od tu dalje LM) (sliki 6-7), pri katerih gre $\mathrm{z}$ izjemo LM I, kjer smo prepoznali kamnino (A), ki ne reagira z Io \% vodno raztopino vodikovega klorida $(\mathrm{HCl})$, za mase $s$ kombinacijo sljude (C), organskih materialov (D), železovih oksidov (E), groga (G) in/ali glinenih jeder (F). Ugotavljamo odsotnost primesi kalcijevega karbonata (B). Prevladujeta dve lončarski masi (LM 5; 8 odlomkov in LM 8; 7 odlomkov; sliki 6-7), pri katerih osnovne primesi predstavljajo sljuda (C), železovi oksidi (E) in grog (G). Med seboj se ločita le po prisotnosti organskih sestavin (D).

Pri dodelavi površine prevladuje brisanje, in sicer kar v 96 \% (23 odlomkov). Na Monkodonji npr. glajenje predstavlja prevladujoč način dodelave površine, ki je zastopan v 5i \% (Hellmuth Kramberger 2017a, 42).

Od načinov žganja keramike smo ugotovili le tri. Gre za prevladujočo redukcijsko (I7 odlomkov oz. 71 \%) in nepopolno oksidacijsko žganje ( 5 odlomkov oz. 21 \%) ter redukcijsko z oksidacijsko atmosfero v končni fazi ( 2 odlomka oz. 8 


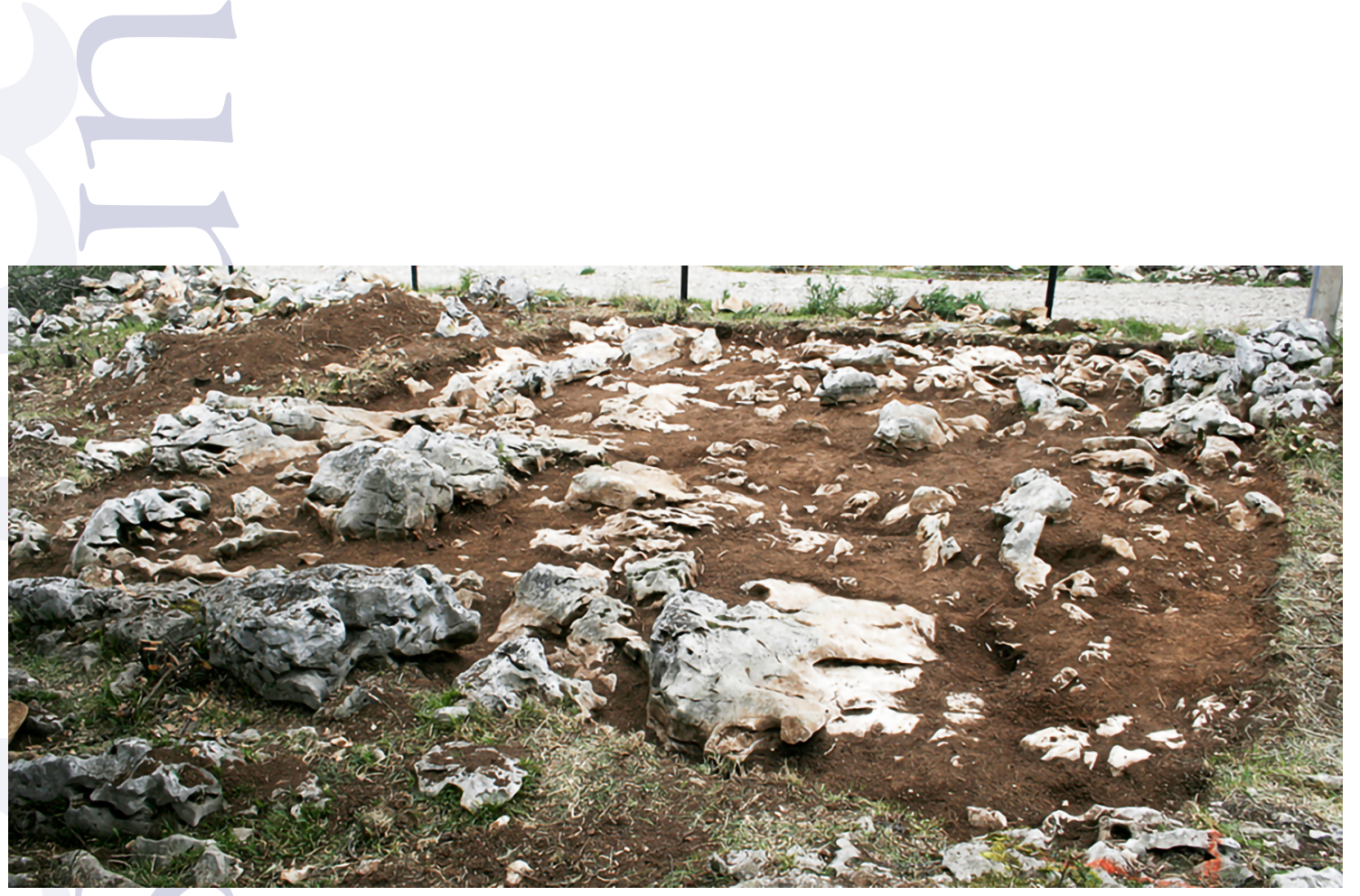

Slika 3. Ključ, pogled na glineno meljasto plast v sondi I (SE IO02), ki je prekrivala apnenčevo skalno osnovo (SE ı००5). Pogled proti severu. Foto: G. Babič.

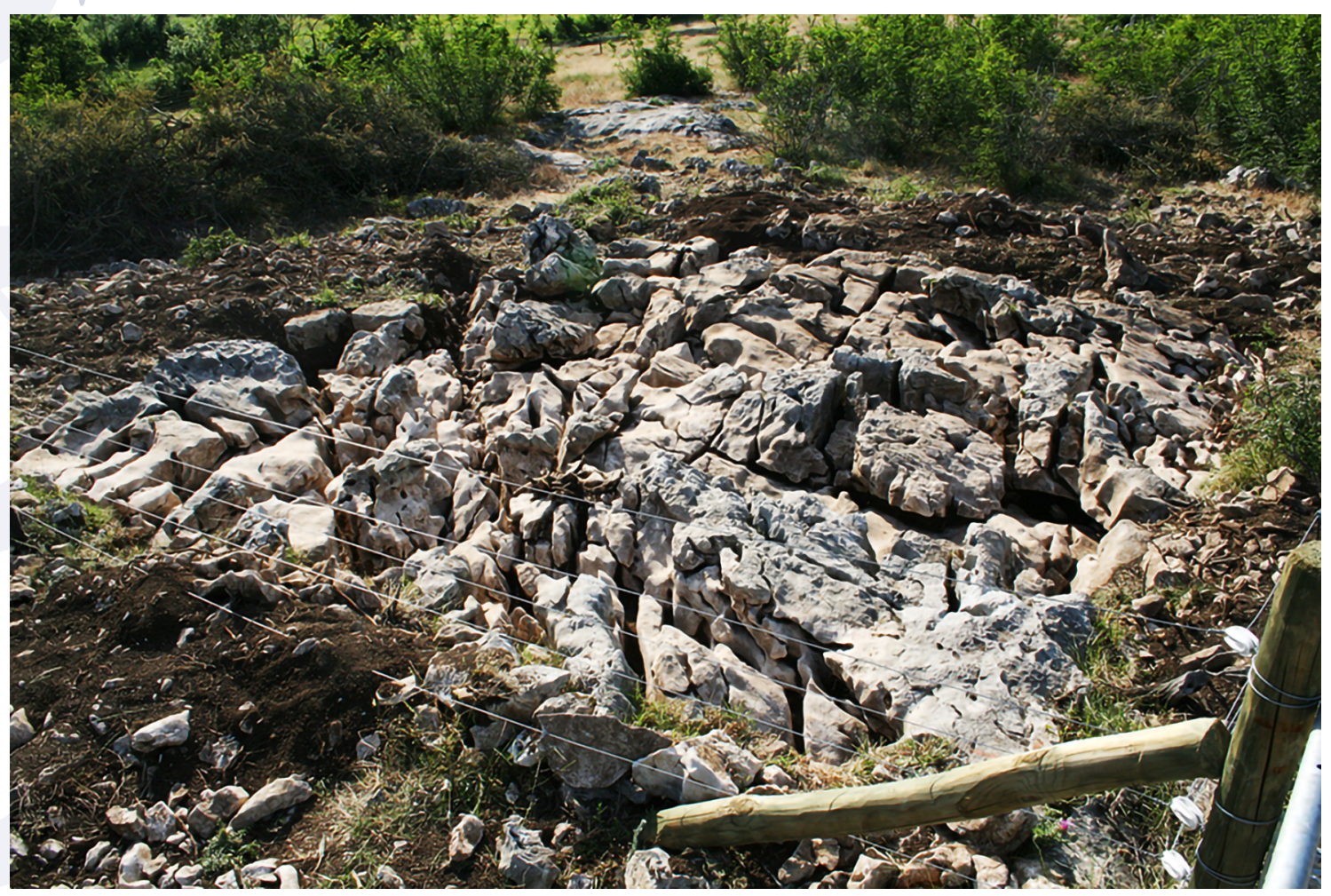

Slika 4. Ključ, apnenčeva skalna osnova v sondi 3 (SE 3003 ). Pogled proti severozahodu. Foto: G. Babič. 


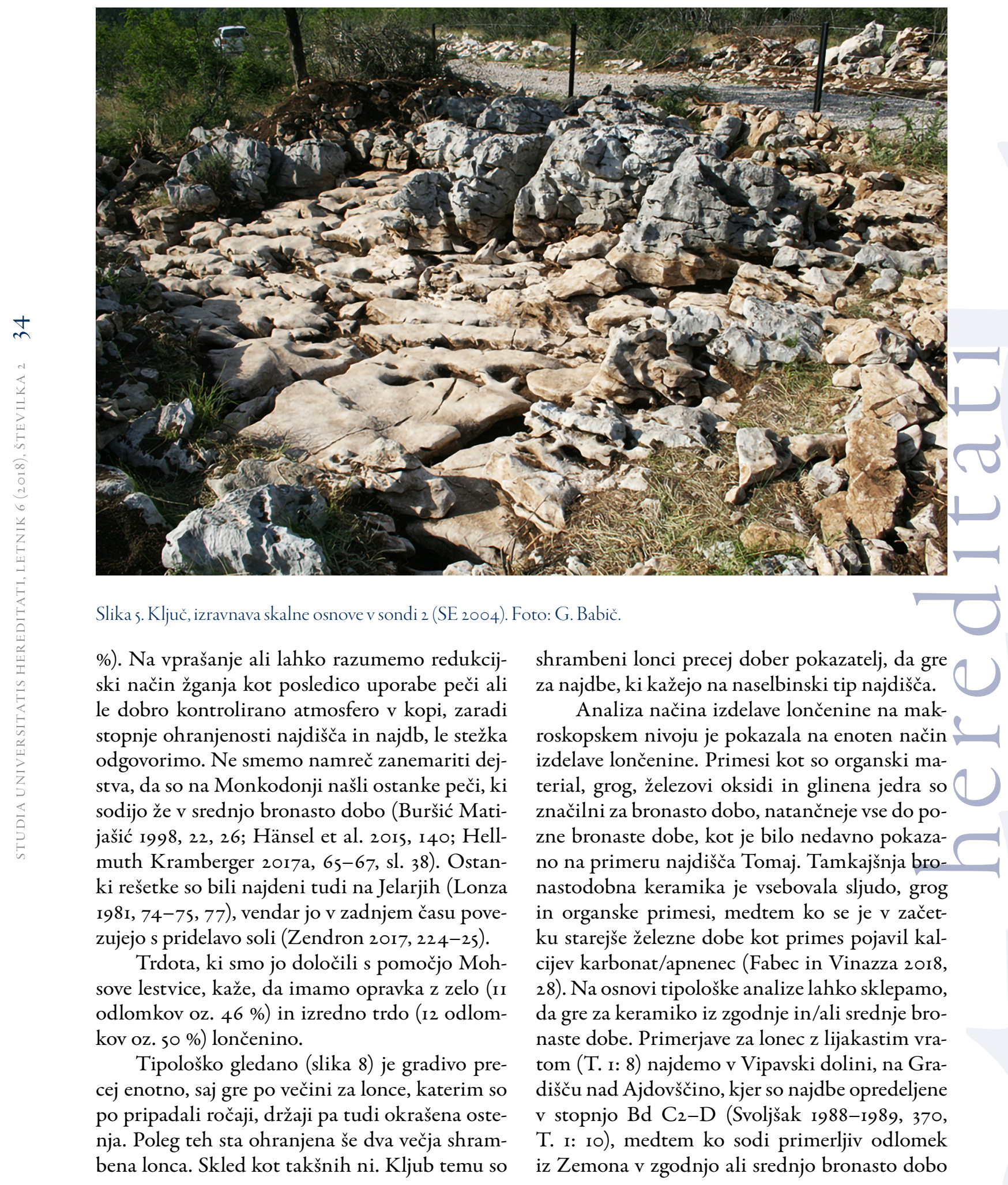




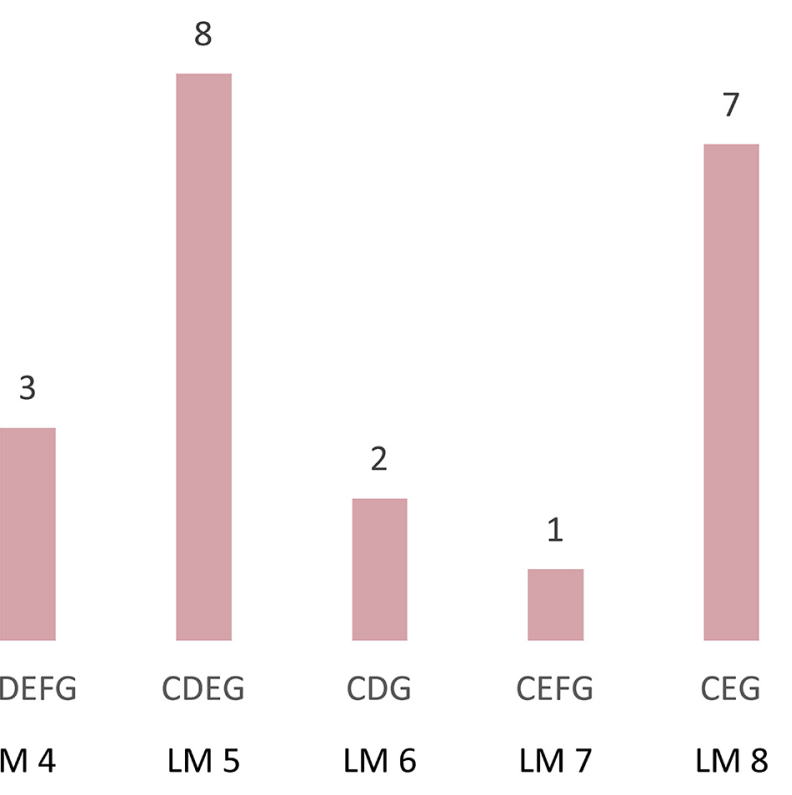

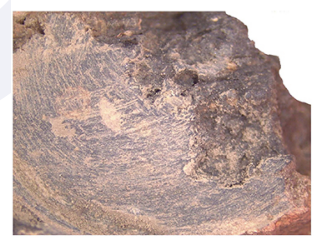

LM 1

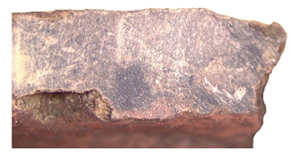

LM 5

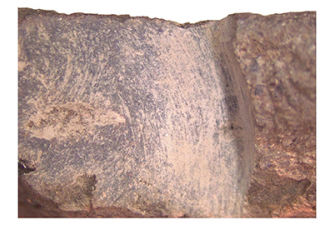

LM 2

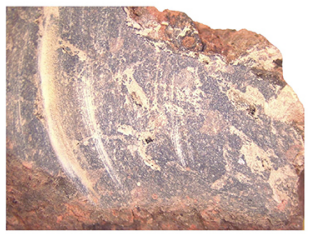

LM 6

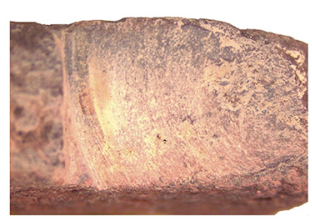

LM 3

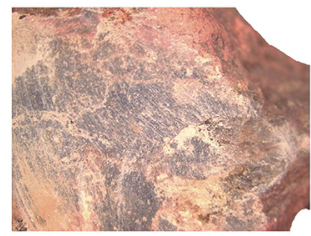

LM 7

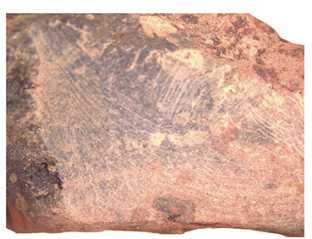

LM 4

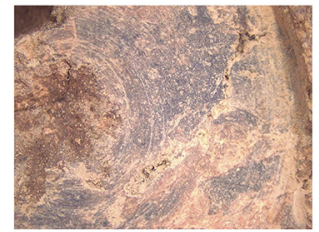

LM 8

Slika 6. Lončarske mase iz Ključa (LMI-8).

(Bratina 2014a, 566, sl. 35.4:3). Večjemu shrambenemu loncu (T. ı: 6) najdemo primerjavo na najdišču Gropi - Stari Guran v Istri, ki sodi v zgodnjo bronasto dobo (Mihovilić 2007-2008, 46, tab. 7: 73). Tudi sicer najdemo na tem najdišču več primerjav za obravnavano najdišče, kot je npr. ustje lonca (T. ı: IO) (Mihovilić 2007-2008, 46, tab. 5: 5I) ter okrašeno ostenje s rebrom (T. 2 : 2I), ki poteka vodoravno in navpično (Mihovilić 2007-2008, 46, Tab. 3: 19). Slednji motiv sreča- mo prav tako tudi v Vipavski dolini, na najdišču Log pri Vipavi, tako v gladki kot s prsti razčlenjeni obliki, opredeljen je v zgodnjo ali srednjo bronasto dobo (Bratina 201 4b, 576, sl. 36.6: 23, 25). Takšen primer iz Sermina sodi v srednjo bronasto dobo (Josipovič et al. 1997, 26, T. 30: I8; Svetličič 1997, 53). V zgodnjo ali srednjo bronasto dobo sodijo tudi lonci z rahlo izvihanim ustjem (T. I: II), s primerjavami ravno tako $\mathrm{v}$ Vipavski dolini (Bratina 2014b, 576, sl. 36.6: Io), na Monkodonji 


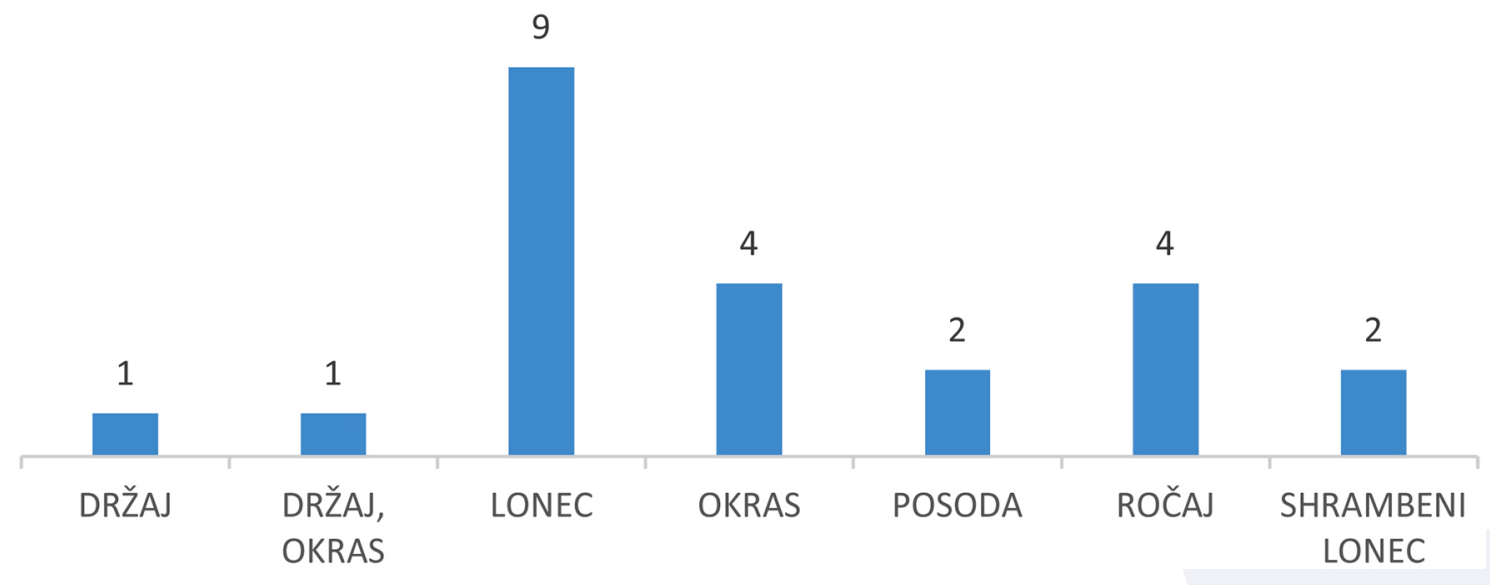

Slika 7. Število prepoznanih tipov in delov posod iz najdišča Ključ.

(Hellmuth 2017b, T. 136: 7) ter na zgodnjebronastodobnem kolišču Mali Otavnik na Ljubljanskem barju (Gaspari 2008, 65, T. 3: 6). Odlomek ustja lonca (T. I: 13) spominja na kroglaste lonce iz Jelarjev, ki so opredeljeni širše, v bronasto dobo (Lonza 198I, Tav. I4: I), medtem ko so iz Malega Otavnika zgodnje bronastodobni (Gaspari 2008, 65, T. I0: 7). Držaj z odtisom prsta (T. I: I), kakršne najdemo v jami Srđani v Istri, sodi v zgodnjo bronasto dobo (Čuka 2009, 24, T. 5: 24). Takšne držaje poznamo tudi iz jame Orehova pejca/Grotta dei Ciclami v 3. režnju, v katerem je bila najdena tako kaštelirska keramika kot zgodnja, eneolitsko/bronastodobna lončenina (Gilli in Montagnari Kokelj 1993, I59, fig. 64: 668), kar kaže torej na čas pred gradišči oz. pred srednjo bronasto dobo. Polkrožne kanelure so načeloma večinoma obdajale aplicirane bradavice (T. 2: 22), kar srečamo na Monkodonji v sondi 9, torej v času zgodnje oz. začetka srednje bronaste dobe (Hellmuth Kramberger 2017a, 322-325, 4I0; Hellmuth Kramberger 2017b, T. 19: 9). V srednjo bronasto dobo sodi okrašeno ostenje iz Ključu bližnje Jame nad Brežcem (Sakara Sučević 2004, 230, sl. 6: 7).

Tako tehnološka kot tipološka analiza keramike je pokazala na precej enoten keramični zbir. Primerjava $z$ drugimi najdišči kaže na čas zgodnje in/ali srednje bronaste dobe, vendar se predvsem na podlagi primerjav $\mathrm{z}$ najdišči kot so Gropi - Stari Guran, Monkodonja in Mali
Otavnik nagibamo, da gre za čas zgodnje bronaste dobe.

\section{Sklep}

Arheološke raziskave, izvedene na najdišču Ključ leta 20I4, so pokazale, da gre za tip poselitve, ki v dolini Rižane in pod Kraškim robom še ni bil znan. Na celotnem območju registrirane enote kulturne dediščine in njene bližnje okolice nismo uspeli odkriti sledov obrambnega sistema. Podobno lego ima tudi območje nekdanje prazgodovinske poselitve na mestu današnje cerkve sv. Trojice v Hrastovljah, ki po našem mnenju verjetno predstavlja enak tip naselbine. Čeprav skromna slika, pa v določenih potezah spominja na Vipavsko dolino z najdišči, kot sta Log in Zemono iz zgodnje oz. srednje bronaste dobe, medtem ko okoliška gradišča z izrazitimi obrambnimi zidovi ležijo na višjih legah (npr. Gradišče nad Ajdovščino in Sv. Pavel nad Vrtovinom).

Keramične najdbe iz Ključa so zelo slabo ohranjene, opravka imamo z zelo fragmentiranimi kosi. Takšno situacijo srečamo tudi na najdišču Gropi - Stari Guran v južni Istri (Mihovilić 2007-2008, 46), ki velja velja za zgodnje bronastodobno naselbino odprtega tipa, brez obzidja. Tovrstne naselbine je za območje zahodne Hercegovine kot takšne opredelil Borivoj Čović, za katere pravi, da so postavljene na terasah na manj strmih pobočjih ali na rahlo zaobljenih 
gričih, običajno nedaleč od ravnin in dolin. Zanje je značilna ohranjenost tanke kulturne plasti, sledovi stavbnih ostalin pa so vidni na površini ali v temnem humusnem sloju (Čović 1983, I 43-144; Čović 1989, 83-94; Mihovilić 20072008, 47-48; Buršić Matijašić 2oII, 65). Tudi v severni Dalmaciji se v tem času pojavljajo takšne oblike naselbin, vendar so v primerjavi s sočasnimi gradišči, maloštevilne (Batović 1990, 137; Mihovilić 2007-2008, 48). V Istri poznamo večje število takšnih, bronastodobnih najdišč v okolici Kanfanara in Limske Drage, zanesljivo v zgodnjo bronasto dobo pa sodi najdišče Japlenica $\mathrm{v}$ bližini Ližnjana (Buršić Matijašič 20II, 65-68).

Kljub temu, da je najdišče Ključ v Registru kulturne dediščine evidentirano kot kaštelir, lahko sklenemo, da najdišče nima osnovnih značilnosti gradišča. Pri tem ponovno izpostavljamo odsotnost obrambnih struktur ter nadmorsko višino najdišča, ki znaša na njenem najvišjem delu $124 \mathrm{~m}$, predel, kjer so bile izkopane sonde I-3 pa med ${ }_{10} 4$ in $109 \mathrm{~m}$. To pomeni da je vrh Ključa (I24 n. m. v.) od ravninske okolice dvignjen med 30 in $50 \mathrm{~m}$. Če primerjamo okoliške kaštelirje so njihove nadmorske višine bistveno višje, in sicer od $300-400 \mathrm{~m} \mathrm{n}$. v. (slika I). Ključ po našem mnenju predstavlja neutrjeno naselbino na neizpostavljeni lokaciji, torej gre za tip poselitve, kakršnega poznamo v Istri, Dalmaciji in Hercegovini pod izrazom zunajgradiščne naselbine. O sami funkciji tovrstnih naselbin lahko le domnevano, čeprav se nam trenutno zdi edina smiselna razlaga sezonska oblika poselitve.

Ta tip naselbin je zaradi svoje lege in odsotnosti obrambnega sistema bistveno težje prepoznati kot kaštelirje oz. gradišča. Morda prav zato v neposredni bližini Ključa in celotni dolini Rižane ter pod Kraškim robom beležimo le eno sočasno najdišče, to je jama pod Brežcem (Sakara Sučević 2004). Zagotovo so takratni prebivalci Ključa izkoristili tudi bližino vode, izvir Rižane in lego ob poti, ki je povezovala Tržaški zaliv in Istrski polotok. $V$ tem smislu razumemo tudi Kraški rob kot markantno geografsko značilnost, ki je služila za orientacijo v prostoru.
Arheološke raziskave na najdišču Ključ so pokazale, da gre za naselbino brez zidane obrambne gradnje na blago dvignjeni legi v dolini, brez obrambnih struktur nad dolino. Poselitev so najverjetneje pogojevali različni doslej ugotovljeni dejavniki, kot je bližina vode (izvir Rižane), rodovitna zemlja (flišne naplavine v dolini) in prehodnost prostora (povezava med $\mathrm{Tr}$ žaškim zalivom in Istro). Trenutno gre za edino tovrstno najdišče iz zgodnje bronaste dobe na tem prostoru. Podobno najdišče pričakujemo tudi na območju cerkve sv. Trojice v Hrastovljah, saj je današnja slika najdišč iz tega časa najverjetneje le posledica stanja raziskav.

\section{Katalog najdb}

\section{Sonda I, SE 1002}

I. Odlomek ostenja z okrašenim držajem. Sestava: zelo finozrnata (LM 2); dodelava površine: glajenje; okras: odtisi prstov; žganje: redukcijsko; izredno trda; barva: zunanja in notranja površina temno siva (IOYR 4/I). Vel. 5,I $\times 3,6 \mathrm{~cm}$.

2. Odlomek ostenja z okrašenim držajem. Sestava: finozrnata (LM 2); dodelava površine: brisanje; okras: odtisi prstov; žganje: redukcijsko; izredno trda; barva: zunanja površina rdečkasto rjava ( $5 \mathrm{YR}$ 4/4), notranja zelo temno siva ( $\left.\mathrm{IOYR}_{3} / \mathrm{I}\right)$. Vel. $5,4 \times 2,9 \mathrm{~cm}$.

3. Odlomek ostenja z ročajem. Sestava: finozrnata (LM 5); dodelava površine: brisanje; žganje: redukcijsko; izredno trda; barva: zunanja površina močno rjava $\left(7.5 Y R_{5} / 6\right)$, notranja zelo temno siva (IoYR $3 / \mathrm{I}$ ). Vel. $6.6 \times 4,5 \mathrm{~cm}$.

4. Odlomek ročaja. Sestava: finozrnata (LM 4); dodelava površine: brisanje; žganje: redukcijsko; zelo trda; barva: zunanja površina rdeča $(2.5 \mathrm{YR} 4 / 6)$, notranja zelo temno siva $\left(7.5 \mathrm{YR}_{3} / \mathrm{I}\right)$. Vel. 2,6 × 2,3 cm. Sonda 2, SE 2002

5. Odlomek ostenja z ročajem. Sestava: finozrnata (LM 2); dodelava površine: brisanje; žganje: redukcijsko; zelo trda; barva: zunanja površina temno sivkasto 


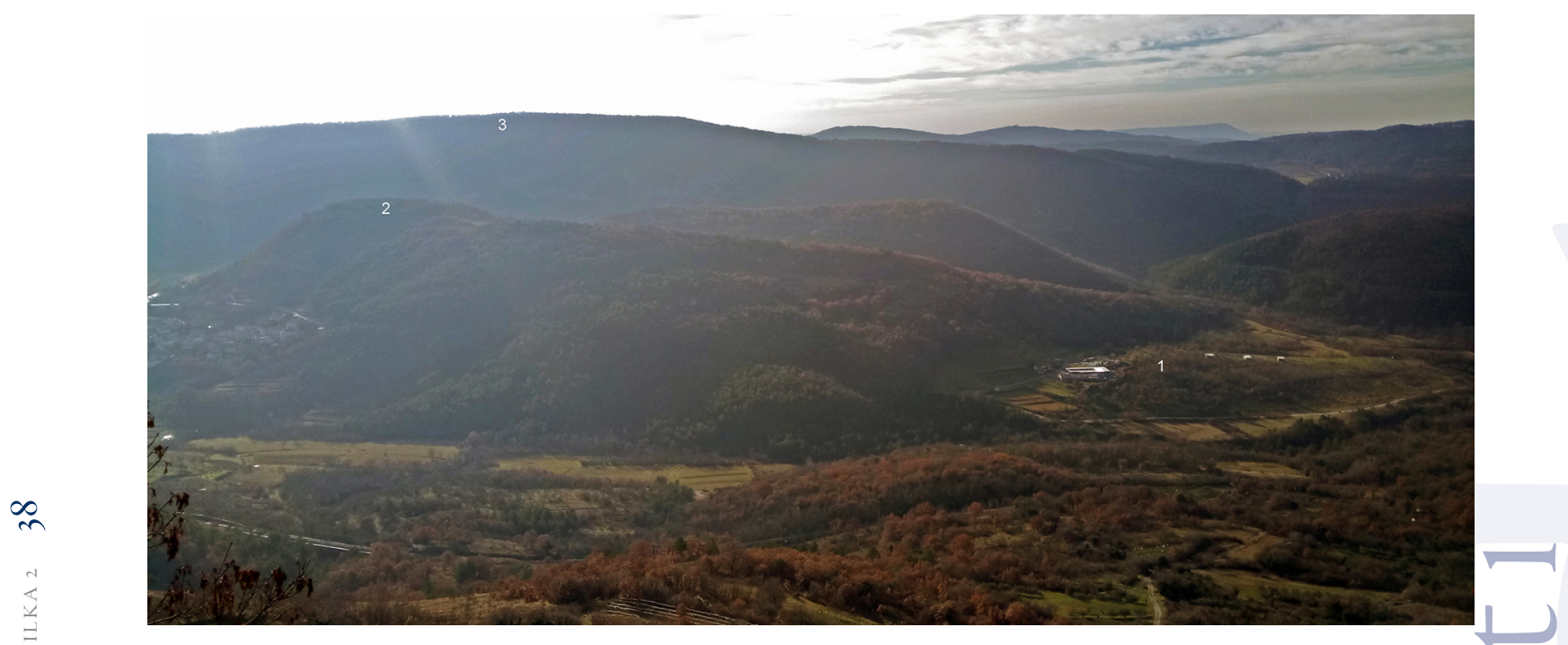

Slika 8. Arheološko najdišče Ključ (I) z Vrhom (2) in Lačno (3) v ozadju.

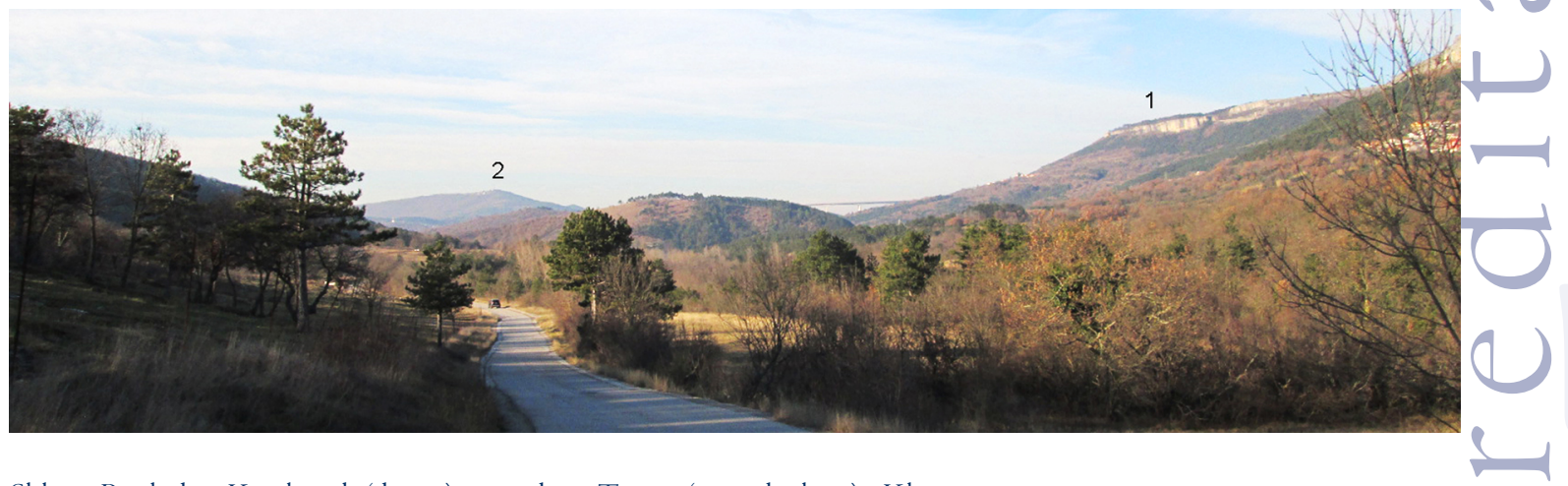

Slika 9. Pogled na Kraški rob (desno) in gradišče Tinjan (v ozadju levo) s Ključa.

rjava (IoYR 4/2), notranja rumenkasto rdeča $\left(5 Y R{ }_{4} / 6\right)$. Vel. 5, I $\times 3,1 \mathrm{~cm}$.

Sonda 3 , SE 3002

6. Odlomek ustja shrambenega lonca.

Sestava: finozrnata (LM 7); dodelava površine: brisanje; žganje: redukcijsko, v končni fazi oksidacijsko; izredno trda; barva: zunanja in notranja površina močno rjava (7.5YR 5/6). Vel. II,O × 5,6 cm.

7. Odlomek ustja shrambenega lonca. Sestava: zelo finozrnata (LM 5); dodelava površine: brisanje; žganje: redukcijsko; zelo trda; barva: zunanja površina rumenkasto rjava (IoYR 5/4), notranja rumenkasto rdeča $(5 Y R 4 / 6)$. Vel. 5,9 $\times 4,7 \mathrm{~cm}$.
8. Ustje lonca. Sestava: zelo finozrnata (LM 7); dodelava površine: brisanje; žganje: nepopolno oksidacijsko; zelo trda; barva: zunanja površina rjava (7.5YR 4/4), notranja temno sivkasto rjava ( IOYR $_{4} / 2$ ). Rek. premer ustja 24,6 cm, ohr. viš. $6,5 \mathrm{~cm}$.

9. Odlomek ustja lonca. Sestava: finozrnata (LM 2); dodelava površine: brisanje; žganje: redukcijsko; zelo trda; barva: zunanja površina rumenkasto rjava (IoYR 5/4), notranja rjava (7.5YR 4/4). Rek. premer ustja $\mathrm{I} 2,4 \mathrm{~cm}$, ohr. viš. $4,0 \mathrm{~cm}$.

Io. Odlomek ustja lonca. Sestava: finozrnata (LM I); dodelava površine: brisanje; žganje: redukcijsko; zelo trda; barva: zunanja in 
notranja površina temno rumenkasto rjava (IOYR 4/4). Vel. 2,8 × 2,7 cm.

II. Odlomek ustja posode. Sestava: zelo finozrnata $\left(\mathrm{LM}_{3}\right)$; dodelava površine: brisanje; žganje: nepopolno oksidacijsko; izredno trda; barva: zunanja površina rjava (7.5YR 4/4), notranja rumenkasto rdeča (5YR 5/6). Vel. $3,3 \times 3,4 \mathrm{~cm}$.

I2. Odlomek ustja lonca. Sestava: finozrnata (LM 7); dodelava površine: brisanje; žganje: redukcijsko; izredno trda; barva: zunanja površina rumenkasto rjava (IoYR $5 / 4)$, notranja temno siva (IoYR 4/I). Vel. $5, \mathrm{I} \times 3,4 \mathrm{~cm}$.

I3. Odlomek ustja lonca. Sestava: finozrnata (LM 2); dodelava površine: brisanje; žganje: nepopolno oksidacijsko; zelo trda; barva: zunanja površina rdečkasto rumena (7.5YR 6/6), notranja temno sivkasto rjava ( IOYR $_{4} / 2$ ). Vel. 2,9 $\times 2,5 \mathrm{~cm}$.

I4. Odlomek ustja lonca. Sestava: finozrnata (LM 5); dodelava površine: brisanje; žganje: redukcijsko; izredno trda; barva: zunanja in notranja površina močno rjava (7.5YR 5/6). Vel. 3,6 × 2,2 cm.

15. Odlomek ustja posode. Sestava: finozrnata (LM 2); dodelava površine: brisanje; žganje: redukcijsko; zelo trda; barva: zunanja površina rumenkasto rdeča ( $5 \mathrm{YR}$ $5 / 6)$, notranja sivkasto rjava (IOYR $4 / 2$ ). Vel. $1,5 \times 2,1 \mathrm{~cm}$.

16. Odlomek ustja lonca. Sestava: finozrnata ( $\mathrm{LM}_{7}$ ); dodelava površine: brisanje; žganje: redukcijsko; zelo trda; barva: zunanja površina rumenkasto rjava (IOYR $5 / 4)$, notranja rumenkasto rdeča $(5 \mathrm{YR}, 5 / 6)$. Vel. $3,3 \times 2,9 \mathrm{~cm}$.

17. Odlomek dna lonca. Sestava: finozrnata (LM 2); dodelava površine: brisanje; žganje: redukcijsko, v končni fazi oksidacijsko; izredno trda; barva: zunanja in notranja površina močno rjava $(7.5 \mathrm{YR}$ 5/6). Rek. premer dna Io,8 cm, ohr. viš. 2,8 $\mathrm{cm}$.
18. Odlomek dna lonca. Sestava: finozrnata (LM 2); dodelava površine: brisanje; žganje: nepopolno oksidacijsko; trda; barva: zunanja površina rumenkasto rdeča ( 5 YR 5/6), notranja sivkasto rjava (IoYR $4 / 2)$. Vel. $6,3 \times 4,5 \mathrm{~cm}$.

19. Odlomek okrašenega ostenja posode. Sestava: finozrnata (LM 2); dodelava površine: brisanje; okras: vodoravno aplicirano rebro, razčlenjeno z odtisi prstov; žganje: nepopolno oksidacijsko; izredno trda; barva: zunanja in notranja površina rumenkasto rdeča $(5 \mathrm{YR} 4 / 6)$. Vel. $5,5 \times 6,3 \mathrm{~cm}$.

20. Odlomek okrašenega ostenja posode. Sestava: finozrnata (LM 7); dodelava površine: brisanje; okras: vodoravno aplicirano rebro, trikotnega preseka; žganje: redukcijsko; izredno trda; barva: zunanja in notranja površina močno rjava (7.5YR 5/6). Vel. 7,0 × 5,6 cm.

21. Odlomek okrašenega ostenja posode. Sestava: zelo finozrnata (LM 8); dodelava površine: brisanje; okras: vodoravno in navpično aplicirano rebro, trikotnega preseka; žganje: redukcijsko; izredno trda; barva: zunanja in notranja površina močno rjava $(7.5 \mathrm{YR} 5 / 6)$. Vel. $5,8 \times 7,5 \mathrm{~cm}$.

22. Odlomek okrašenega ostenja. Sestava: finozrnata (LM 6); dodelava površine: brisanje; okras: polkrožna kanelura; žganje: redukcijsko; izredno trda; barva: zunanja površina močno rjave (7.5 $\mathrm{YR} 5 / 6)$, notranja zelo temno siva ( IoYR $\left._{3} / \mathrm{r}\right)$. Vel. $9,2 \times 5,2 \mathrm{~cm}$.

23. Odlomek držaja. Sestava: finozrnata (LM 2); dodelava površine: brisanje; žganje: redukcijsko; zelo trda; barva: zunanja in notranja površina rumenkasto rdeča ( $5 \mathrm{YR}$ 4/6). Vel. 6,0 × 3,0 cm.

24. Odlomek ročaja. Sestava: finozrnata (LM 2); dodelava površine: brisanje; žganje: redukcijsko; zelo trda; barva: zunanja površina zelo temno siva ( $\left.\mathrm{IOYR}_{3} / \mathrm{I}\right)$, notranja rumenkasto rjava $(5 \mathrm{YR} 4 / 6)$. Vel. $4,6 \times 4,7 \mathrm{~cm}$. 

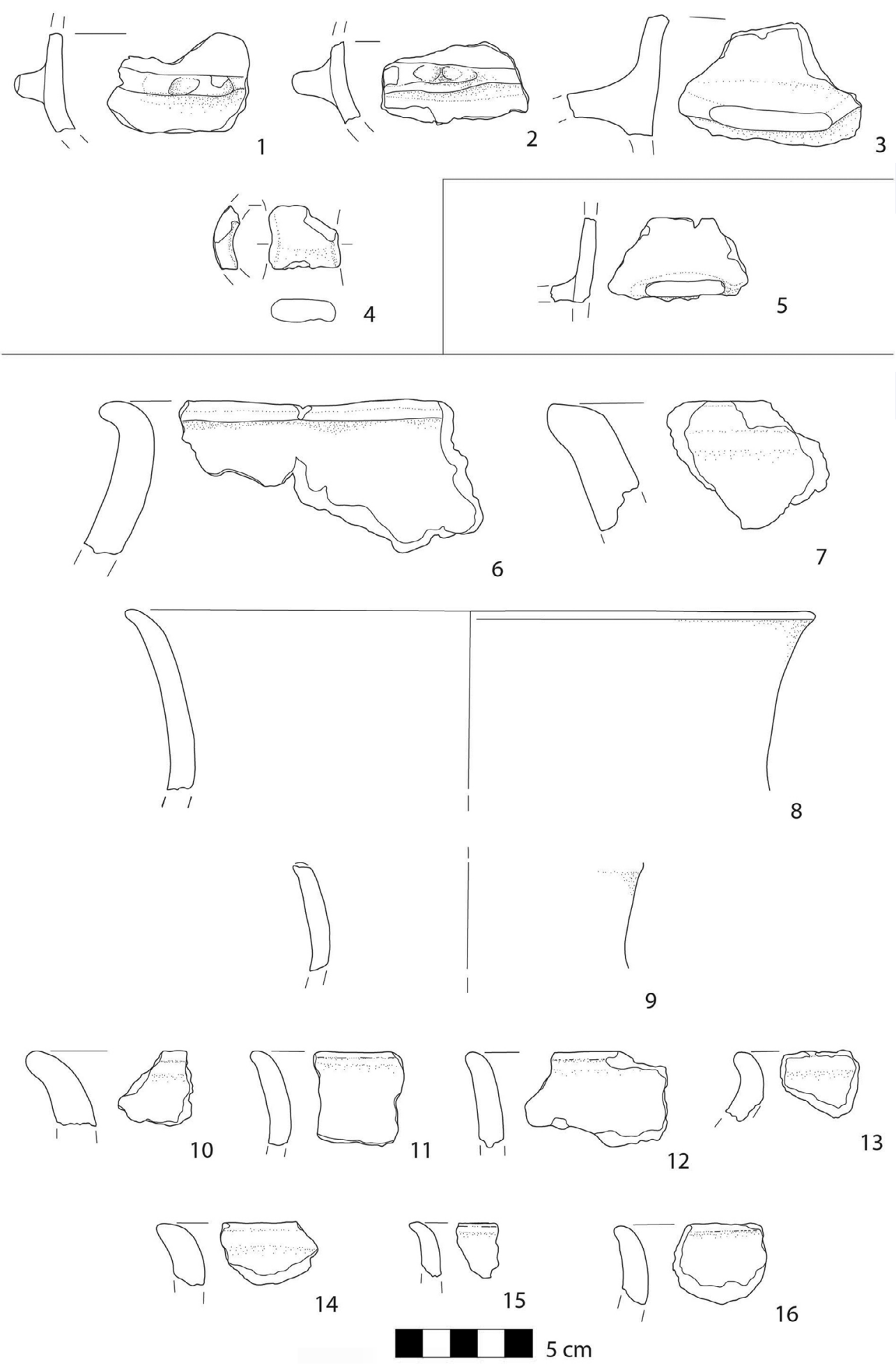

8

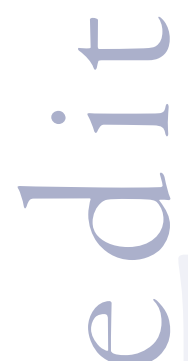

Tabla I. Hrastovlje. I-4 (sonda I), 5 (sonda 2), 6-16 (sonda 3). Vse keramika. M. = I : 2. 

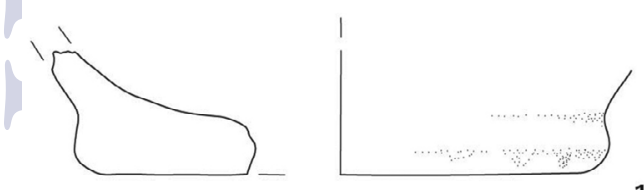

17
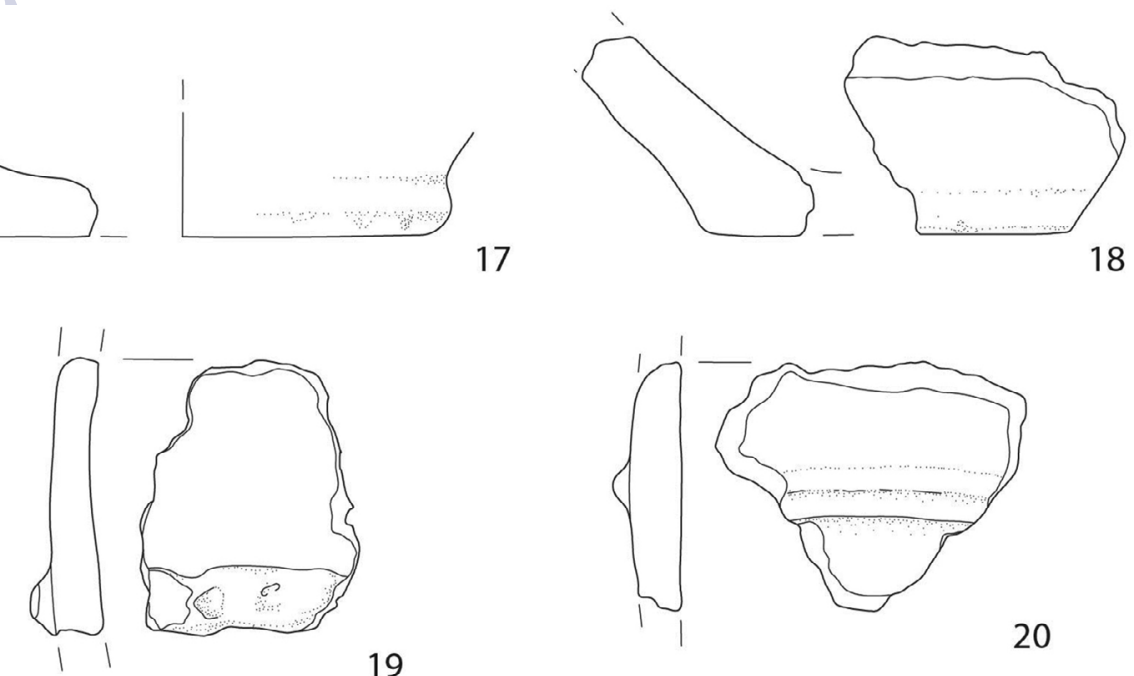

19
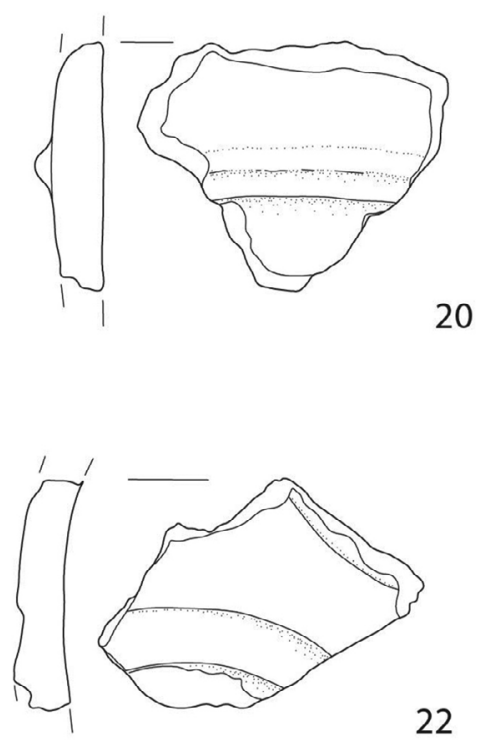

22
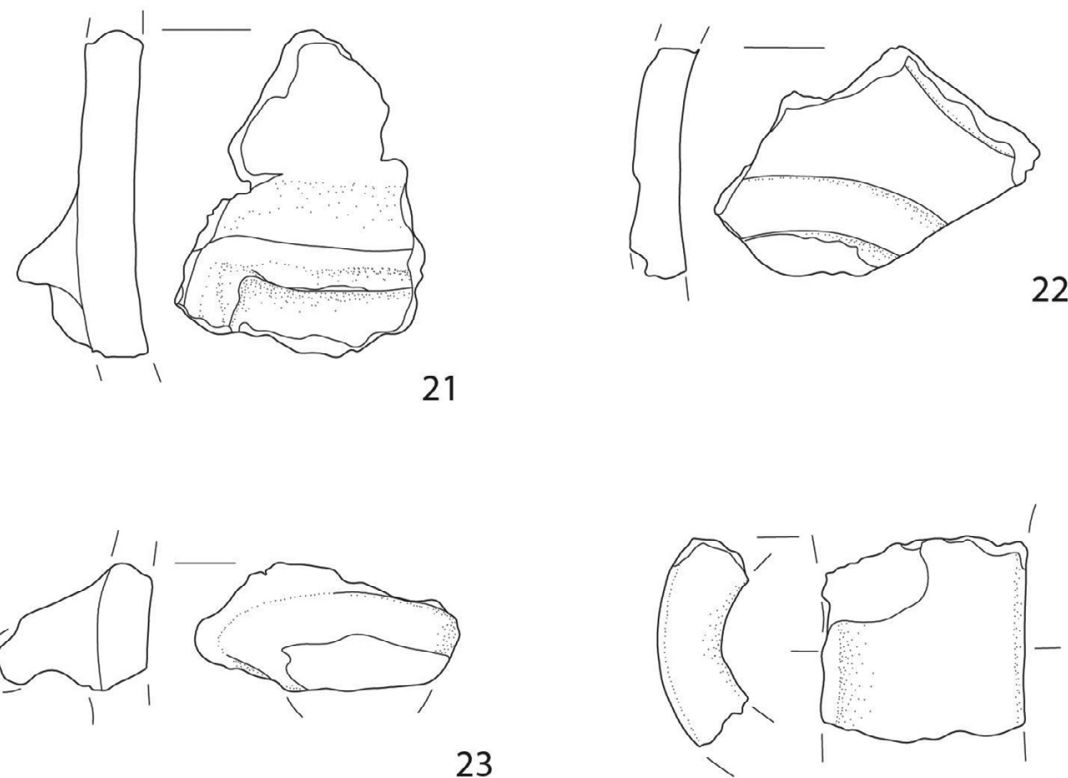

23

Tabla 2. Hrastovlje. 17-24 (sonda 3). Vse keramika. M. = I : 2. 


\section{Povzetek}

V prispevku predstavljamo arheološko najdišče Ključ v dolini Rižane. Nahaja se na nižji vzpetini, ki leži na stičišču treh pokrajin, Kraškega roba, Bržanije in doline Rižane. Kraški rob je imel skupaj z Bržanijo od nekdaj strateški pomen. Tu se ločuje Istra in Kras oz. Sredozemlje in celina. Na tem stiku so že v prazgodovini stala številna gradišča oz. kaštelirji (slika I).

Arheološko najdišče Ključ prvič omenja Alberto Puschi, prve arheološke raziskave, pod vodstvom Sama Hvalca in Mateja Drakslerja (Skupina STIK) pa so tu potekale leta 2014 , in sicer na parc. št. 42I/I, $42 \mathrm{I}$ in I407/I, vse k. o. Loka.

Najprej je bilo izkopanih Io testnih sond velikosti I $\times$ I m. Na podlagi arheoloških rezultatov je bilo izkopno polje na prostoru predvidene postavitve treh pomožnih gospodarskih stavb, kasneje razširjeno. Izkopane so bile tri sonde $(\mathrm{I}-3)$, velikosti $6,3 \times 6,3 \mathrm{~m}$, skupne površine ca. $\mathrm{I} 20 \mathrm{~m}^{2}$ (slika 2).

Izkazalo se je, da leži najdišče na močno prepereli in razpokani apnenčevi sklani osnovi (SE IO05, SE 2004, SE 3003; slika 4). Na razgibani podlagi je z naravnimi in antropogenimi procesi nastala različno debela plast temno rumenkasto rjavega glinenega melja (SE IO०2, SE 2002, SE 3002; slika 3). V tej plasti smo našli prazgodovinske najdbe, ki so bile najštevilnejše v razpokah in kotanjah apnenca. Pri izkopavanju sonde 3 je bila najdena večja koncentracija prazgodovinske lončenine, ožgane gline ter glinenega ometa, kar nas napeljuje k predpostavki, da lahko na tem delu najdišča domnevamo enega ali več prazgodovinskih objektov.

Od vseh prazgodovinskih najdb (743 kosov), smo podrobneje obravnavali 24 odlomkov. Lončenino smo obravnavali tehnološko in tipološko. Ugotovili smo, da je z vidika načina izdelave zelo enotna. Izdelana je prostoročno. Prevladujejo finozrnate mase (79\%), ostalo so zelo finozrnate (2I \%). Ugotovili smo 8 različnih lončarskih mas (LM), pri katerih gre z izjemo LM I, v kateri smo prepoznali kamnino (A), ki reagira z $10 \% \mathrm{HCl}$ raztopino, za kombinacije sljude (C), organskih materialov (D), železovih oksidov (E), groga $(\mathrm{G})$ in/ali glinenih jeder (F). Ugotavljamo odsotnost kalcijevega karbonata (B). Pri dodelavi površine je prevladovalo brisanje (96\% oz. 23 odlomkov). Določili smo tri načine žganja, in sicer redukcijsko (I7 odlomkov ali 7I \%), nepopolno oksidacijsko ( 5 odlomkov oz. 2I \%) in redukcijsko z oksidacijsko atmosfero v končni fazi (2 odlomka oz. $8 \%$ ). Keramika je zelo (II odlomkov oz. $46 \%$ ) in izredno trda (I2 odlomkov oz. 50 \%). Tipološko je gradivo zelo enotno, saj gre večinoma za lonce, ki so jim pripadali ročaji, držaji ter okrašena ostenja. Poleg teh loncev sta bila določena dva odlomka shrambenega lonca (slika 7).

Tako tehnološka kot tipološka analiza keramike kažeta na čas zgodnje in/ali srednje bronaste dobe. Primerjave za keramiko najdemo na najdiščih v Vipavski dolini, v Ljubljanski kotlini, na območju Tržaškega zaliva (jamska najdišča, gradišča) in v Istri.

Arheološke raziskave, izvedene na najdišču Ključ leta 20I4, so pokazale, da gre za tip poselitve, ki v dolini Rižane in pod Kraškim robom še ni bil znan. Ključ po našem mnenju predstavlja neutrjeno naselbino na neizpostavljeni lokaciji, torej gre za tip poselitve, kakršnega poznamo v Istri, Dalmaciji in Hercegovini pod izrazom zunajgradiščne naselbine. O sami funkciji tovrstnih naselbin lahko le domnevano, čeprav se nam zaenkrat zdi edina smiselna razlaga sezonska oblika poselitve. Trenutno gre za edino tovrstno najdišče iz zgodnje bronaste dobe na tem prostoru. V neposredni bližini Ključa in celotni dolini Rižane ter pod Kraškim robom beležimo le eno sočasno najdišče, to je jama pod Brežcem. Tako majhno število najdišč iz tega časa na tem prostoru pa je po našem mnenju le posledica stanja raziskav.

\section{Summary}

In this article, we present archaeological site Ključ in Rižana valley. It is situated on the lower rising ground, which lies at the junction of three landscapes, Karst Edge, Bržanija and Rižana valley. The Karst Edge together with Bržanija has always been of strategic importance. Here is Istria separated from the Karst or the Mediterranean from continent. We can find a lot of prehistoric hillforts (or kaštelirji) at this junction (Figure I). Alberto Puschi first mentioned archaeological site Ključ. The first archaeological research, under the leadership of Samo Hvalec and Matej Draksler (Skupina STIK), was conducted in 2014 at plot number $42 \mathrm{I} / \mathrm{I}, 42 \mathrm{I}$ and 1407 , all cadastral community Loka.

First we excavated Io testing trenches, size $\mathrm{I} \times \mathrm{I} \mathrm{m}$. Due to archaeological results we've enlarged excavation area at area of three farm buildings expected for building. We excavated 3 trenches $(\mathrm{I}-3), 6,3 \times 6,3 \mathrm{~m}$, total area of ca. I2O m2 (Figure 2). 
It turned out that site is lying on a strongly rotten and cracked limestone rock (US 1005, 2004, 3003; Figure 4). Due to natural and anthropogenic processes, different layers of dark yellow brown clayey-silty soils (US IOO2, 2002, 3002; Figure 3) were formed on this rock. In this layer we've found many prehistoric finds, most of them in limestone cracks and depressions. During the archaeological excavations of trench n. 3 , a greater concentration of prehistoric pottery, burnt clay or plaster was found, which leads us to the assumption that one or more prehistoric objects can be presumed in this part of the site.

Of all the prehistoric finds ( 743 pieces), we studied in more detail 24 of them. Pottery was studied from technological and typological point of view. We've found that pottery is made in uniform manner and hand made. Most of it is fine-grained (79\%), the rest are very fine-grained (2I \%). We've found out eight different clay admixtures (LM). They represent mixed combination of rock (A), that doesn't react with HCI solution, mica (C), organic material (D), iron oxides (E), grog $(G)$ and/ or clay pellets $(\mathrm{F})$. There is no calcium carbonate (B). Most of the surface treatment is burnishing ( $96 \%$ or 23 pieces). We've recognized three types of firing techniques, reduction ( 17 pieces or $71 \%$ ), incomplete oxidation ( 5 pieces or $21 \%$ ) and reduction with oxidation in final phase ( 2 pieces or $8 \%$ ). Pottery is very (II pieces or. $46 \%$ ) or extraordinarily hard ( 12 pieces or. $50 \%$ ). Types of vessels are very united. Most of the pieces belong to pots or parts of them, as handles, lugs and decorated vessel. Two pieces belong to bigger (storage) pot (Figure 7). Both technological and typological ceramic analysis indicates the time of the Early and/or Middle Bronze Age. We've found analogies in the Vipava valley, in the Ljubljana basin, in Gulf of Trieste (cave sites and hillforts) and in Istria.

Archaeological excavations conducted at the Ključ site in 2014 showed that this is the type of the settlement that wasn't yet known in the Rižana valley or under the Karst Edge. We believe that Ključ site represents unfortified settlement on unexposed location. It is a type of settlement, as we know in Istria, Dalmatia and Herzegovina under the term hillfort in the open area. The function of this kind of settlements we can only presume, although for the moment the only explanations seems to be seasonal settlement type. So far, this is the only known kind of settlement from Early Bronze Age in this area. In close vicinity of the Ključ and the entire Rižana valley and under the Karst Edge we know only one contemporaneous site, the cave site Jama nad Brežcem. In our opinion, such a small number of Early Bronze Age sites in this area is only a consequence of the state of research.

\section{Literatura}

Batović, Š. 1990. »Novija istraživanja prapovijesti u biogradskom kraju «. Biogradski zbornik I: 85-195.

Benussi, B. 1927-1928. »Dalle annotazioni di Alberto Puschi per la Carta archeologica dell'Istria.« Archaeolografo Triestino I4: 243-82.

Bratina, P. 2014a. »Zemono pri Vipavi.«V Absolutno datiranje bronaste in železne dobe na Slovenskem / Absolute dating of Bronze and Iron Ages in Slovenia. Katalogi in monografije 40, uredila B. Teržan in M. Črešnar, 563-69. Ljubljana: Znanstvena založba Filozofske fakultete, Narodni muzej.

Bratina, P. 2014b. »Log pri Vipavi.«V Absolutno datiranje bronaste in železne dobe na Slovenskem / Absolute dating of Bronze and Iron Ages in Slovenia. Katalogi in monografije 4O, uredila B. Teržan in M. Črešnar, 569-8I. Ljubljana: Znanstvena založba Filozofske fakultete, Narodni muzej.

Buršić Matijašić, K. 1998. Gradina Monkodonja. Tipološko-statistička obrada keramičkih nalaza srednjebrončanodobne istarske gradine Monkodonja kod Rovinja / The Monkodonja Hillfort. A Typological and Statistical Analysis of Pottery Finds from the Middle Bronze Age Hillfort of Monkodonja near Rovinj. Monografije i katalozi 9. Pula: Arheološki muzej Istre.

Buršić Matijašić, K. 20II. »Ne samo gradine.« Histria Antiqua 20: 63-76.

Čović, B. 1983. »Regionalne grupe ranog bronzanog doba.« V Praistorija jugoslavenskih zemalja IV - Bronzano doba, 
uredil A. Benac, II 4־90. Sarajevo: Svjetlost: Akademija nauka i umjetnosti Bosne i Hercegovine.

Čović, B. 1989. »Posuška kultura.« Glasnik Zemaljskog muzeja BiH, n. s. 44: 6I-I27.

Čuka, M. 2009. »Tipološka obrada ulomaka prapovijesne keramike iz Pećine kod sela Srđani.« Histria archaeologica 40: 13-44.

Draksler, M., in R. Klasinc. 2014. »Arheološke raziskave na najdišcu Hrastovlje - Park avtohtonih živali.« Končno strokovno poročilo o raziskavi. Neobjavljeno poročilo. Ljubljana: Skupina STIK.

Hänsel, B., K. Mihovilić, in B. Teržan. 2015. Monkodonja. Istraživanja protourbanog naselja brončanog doba Istre. Knjiga I. Iskopavanje i nalazi gradevina / Monkodonja. Forschungen zu einer protourbanen Siedlung der Bronzezeit Istriens. Teil I. Die Grabung und der Baubefund. Monografije i katalozi / Monographien und Kataloge 25. Pula: Arheološki muzej Istre.

Hellmuth Kramberger, A. 2017a. Monkodonja: istraživanje protourbanog naselja brončanog doba Istre. Brončanodobna keramika s gradine Monkodonja / Forschungen zu einer protourbanen Siedlung der Bronzezeit Istriens. Die Keramik aus der bronzezeitlichen Gradina Monkodonja. Monografije i katalozi / Monographien und Kataloge 28. Knjiga / Teil 2/r, Tekst. Pula: Arheološki muzej Pula.

Hellmuth Kramberger, A. 2017 b. Monkodonja: istraživanje protourbanog naselja brončanog doba Istre. Brončanodobna keramika s gradine Monkodonja / Forschungen zu einer protourbanen Siedlung der Bronzezeit Istriens. Die Keramik aus der bronzezeitlichen Gradina Monkodonja. Monografije i katalozi / Monographien und Kataloge 28. Knjiga / Teil 2/2, Katalog. Pula: Arheološki muzej Pula.

Horvat, M. 1999. Keramika: tehnologija keramike, tipologija lončenine, keramični arhiv. Razprave Filozofske fakultete.
Ljubljana: Znanstveni inštitut Filozofske fakultete.

Fabec, T., in M. Vinazza. 2018. »Tomaj: Gradišče in Tabor. Poskus prepoznavanja dinamik preoblikovanja tomajskega griča od prazgodovine do danes.« Goriški letnik 42: $13-49$.

Gaspari, A. 2008. »Bronastodobno kolišče Mati Otavnik na Ljubljanskem barju.« Arheološki vestnik 59: 57-89.

Gili, E. in E. Montagnari Kokelj. 1992 (1993). >La grotta dei Ciclami nel Carso Triestino (materiali degli scavi 1959-196I).«Atti della società per la preistoria e protostoria della regione Friuli-Venezia Giulia VII: 65-162.

Gorenc, N. 2006. Gradovi, utrdbe in mestna obzidja. Vodnik po spomenikih. Zbirka Dnevi evropske kulturne dediščine. Ljubljana: Zavod za varstvo kulturne dediščine Slovenije.

Josipovič, D., M. Stokin in J. Horvat. 1997. »Sonde.«V Sermin. Prazgodovinska in zgodnjerimska naselbina $v$ severozahodni Istri / A Prehistoric and Early Roman Settlement in Northwestern Istria. Opera Instituti archaeologici Sloveniae 3, uredila J. Horvat, 22-29. Ljubljana: ZRC SAZU. Mihovilić, K. 2007-2008. »Gropi-Stari Guran. Analiza prapovijesne keramike.« Histria archaeologica 38-39: 37-79.

Register kulturne dediščine RS:

http://giskd6s.situla.org/giskd/ (dostop: I. 7. 2018).

Lonza, B. 1981. La ceramica del castelliere degli Elleri. Società per la preistoria e protostoria della Regione Friuli-Venezia Giulia, Quaderno 4. Trieste: Italo Svevo.

Sakara Sučević, M. 2004. »Arheološko gradivo iz jame nad Brežcem št. 5415 pri Podgorju, občina Koper.«Annales 14-2: 229-42.

Svetličič, V. 1997. »Prazgodovina / Prehistory.《 V Sermin. Prazgodovinska in zgodnjerimska naselbina v severozahodni Istri I A Prehistoric and Early Roman Settlement 
in Northwestern Istria. Opera Instituti archaeologici Sloveniae 3, uredila J. Horvat, II3-16. Ljubljana: ZRC SAZU.

Svoljšak, D. 1988-1989. »Posočje v bronasti dobi.« Arheološki vestnik 39-40: 367-86.

Šinkovec, I. 1995. »Katalog posameznih kovinskih najdb bakrene in bronaste dobe / Catalogue of Individual Metal Finds from the Eneolithic and Bronze Age. V Depojske in posamezne kovinske najdbe bakrene in bronaste dobe na Slovenskem I 1 Hoards and Individual Metal Finds from the Eneolithic and Bronze Ages in Slovenia I, uredila B. Teržan, 29-I27. Katalogi in monografije 29. Ljubljana: Narodni muzej Slovenija.

Šiškovič, R. 1990. »Prirodno-geografski oris in rast prebivalstva.« V Kraški rob in Bržanija. Zbornik ob soo-letnicifresk v Hrastovljah, 9-19. Koper: Pokrajinski muzej Koper.

Zupančič, M. 1990. »Arheološka podoba Brega s Kraškim robom.« V Kraški rob in Bržanija. Zbornik ob soo-letnici fresk $v$ Hrastovljah, 19-27. Koper: Pokrajinski muzej Koper.

Truhlar, F. 1975. »Hrastovlje.« V Arheološka najdišča Slovenije, I29. Ljubljana: Ljudska pravica.

Zendron, F. 2017. »In cammino verso la storia. I manufatti dell'età del Bronzo e dell'età del Ferro.«V Monte Castellier. Le pietre di Elleri narrano la storia, uredili P. Maggi, F. Pieri in P. Ventura 209-51. Triste: EUT. 
-

r

$\downarrow$

G

1

-

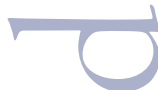

( )

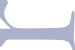

(U)

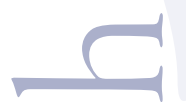




\title{
Are worksheets death? Words in museum education
}

\author{
Lenka Mrázová, Masaryk University, Brno
}

Delovni listi so obravnavani kot materiali, značilni za sodobne muzeje in njihovo odzivnost na izobraževalne potrebe obiskovalcev. To didaktično orodje, ki izhaja predvsem iz besedil, postopoma prehaja vširoko uporabo znotraj muzejskih služb, in kaže na njihovo odzivnost do obiskovalcev in na kompetence muzejskih delavcev, ki se ukvarjajo z njimi. Besedilo je zasnovano kot metodološki pregled osnovnih teoretičnih in predvsem praktičnih znanj s področja muzejske pedagogike, ki bi lahko pomagala pri procesu oblikovanja delovnih listov in njihovega optimalnega didaktičnega vpliva - oblike in predvsem vsebine.

Ključne besede: muzejska pedagogika, delovni listi, interpretacija dediščine muzejska publika, metodologija

Worksheets have been regarded as one of the materials which characterize modern museums and their responsiveness towards educational needs of visitors. This didactic and mainly on words based tool gradually becomes a widely used museum service, a material demonstrating both the responsiveness towards visitors, and the competence of museum workers who are engaged in working with audience. Text is intended as a methodology capturing basic theoretical and mainly practical knowledge in the field of museum education, which might help in the process of creation of worksheets and their optimal didactic impact - the form and mainly the content.

Keywords: museum education, worksheets, heritage interpretation, museum audience, methodology

W orksheets have been regarded as one of the materials which characterize modern museums and their responsiveness towards educational needs of visitors. This didactic tool gradually becomes a widely used museum service, a material demonstrating both the responsiveness towards visitors, and the competence of museum workers who are engaged in working with audience. It is not easy to elaborate educationally functional worksheets of relevant quality. Usually also another added values are expected, such as entertainment, representative character, low production and elab- oration costs for these worksheets which often must be made quickly and in provisional conditions. The material which you are holding in your hand $s^{\mathrm{T}}$ does not claim the right to represent the only possible set of approaches and topics for elaboration of worksheets. But it tries to capture basic theoretical and mainly practical knowledge in the field of museum education, which might help in the process of creation of worksheets and their optimal didactic impact - the form and mainly the content. Its aim is to give a

I This methodological material was published in Czech language (Mrázová 2012). 
helping hand to pedagogues ${ }^{2}$, lecturers and other workers in museum institutions who are engaged in the work with audience.

\section{Characteristics of museum worksheets}

It is not easy to characterise the content of the commonly used terms like worksheet, worksheets, workbook, etc. Under the term 'museum worksheets' we generally understand printed materials elaborated by museum workers, which are available to museum visitors. They are intended to complement and enliven the exhibitions and make them easier to understand.

The museum worksheets differ from the worksheets and workbooks used in schools mainly in their interconnection with a temporary or permanent exhibition, a close relationship to the exhibits and the focus laid primarily on boosting the perception and examination of these exhibits. Herewith it is a tool rather than the actual purpose of museum education.

The purpose and main function of the museum worksheets is to make the visitors observe the exhibits more thoroughly. The worksheets should show the visitors a possible way of how to regard these exhibits and offer them place for their own records, reflections and notes. To put it simply, the worksheets should help the visitors discover the collection items, so that the visitors rather keep an eye on the objects than on the worksheets. This is at the same time the most difficult aspect of the elaboration of museum worksheets. Some help can arise from appropriate impulses, instructions and tasks, which are targeted at drawing attention to the objects themselves, not only to easily available information in legends and complementary texts on the exhibition panels.

The ideal functional form of worksheets is always derived from particular permanent or temporary exhibition, pedagogical plans of individual museum pedagogues and their educational goals. Despite this, we can follow up sev-

2 For the sake of simplification, the term 'museum pedagogue' in the following text simply refers to all museum workers who are engaged in working with audience, creation of accompanying programmes and elaboration of worksheets. eral general rules which can simplify the creation process of worksheets and increase therewith the didactic effectiveness of this tool.

Worksheets can be elaborated for any types of visitors (the adults also like to test their intelligence and skills...), but the most frequent recipients of these materials remain children, mainly those in school groups. The second most appreciated category comprises the so-called family worksheets that is worksheets intended for parents with children, or grandparents with children, children accompanied by adults, etc.

\section{The role of museum worksheets}

The primary purpose of worksheets is to support the perception of exhibits by visitors. This purpose involves several functions, which the museums worksheets should fulfil to various extent. With the help of general didactics (Skalková 2007, 104-I05; similarly, e.g. Veverková 2002, I43; Průcha 1998, etc.) we can, for example, study the following functions:

- orientational and coordinative function the worksheets simplify the orientation in an exhibition and show herewith one of the possible ways of how to work with the exhibition; they should deliberately follow up the collection items exhibited and the original exhibition plan, and at the same time they should offer another new perspectives and interlinks between the information obtained;

- cognitive and systemising function - the worksheets usually contain basic knowledge, tasks and subjects linked with the topic of a temporary or permanent exhibition, their order also gives the visitors instructions, how to perceive and sort this new information;

- developmental, educational, fixative and controlling function - the worksheets with their appropriately chosen working methods in a temporary or permanent exhibition help the visitors develop their personal interest in the topic, support the education- 
al potential of museums, fixation of new knowledge, and validity check of the information acquired;

- motivational and self-educational function - the worksheets with their content and arrangement also should motivate the visitors to further interest in the topic.

In general, it can be said that worksheets give the visitors a hint how to work with an exhibition. They should contain a record and assortment of basic and most important pieces of knowledge, their fixation with the help of tasks and activities, or inspiration to individual research or working with attitudes and opinions of users.

\section{Worksheets - when yes and when no}

Museum worksheets gradually turn into a popular and widely used didactic tool, an almost common service to visitors. However, this tool and service is not always functional, beneficial to the educational process in museums. An inappropriately elaborated or used worksheet can even be counterproductive for the museum educational process. The museum pedagogy currently rather abandons the general and common use of worksheets in all temporary and permanent exhibitions and tends to their sparse but well-founded use.

Worksheets should never be purposeless, that is, they should not be elaborated only because it is expected. One of the main preconditions of well-functioning worksheets is their purposefulness with regard to the topic of a temporary or permanent exhibition, its design, character of collection items and the information communicated, as well as to the real need and space for using this material.

Worksheets in exhibitions which are, for example, rich in information are used as a logical instruction on how to understand the problem; exhibitions full of experiences and emotions, on the other hand, sometimes do not really require elaboration of accompanying didactic materials. It also depends on the conception of a museum pedagogue, how he/she intends to conceive the topic of a temporary or permanent exhibition and which method of working with these materials is supposed. The decision to create and use worksheets should always be completely within his/her authority.

The most frequent mistake is an erroneous perception of worksheets as the true essence of museum pedagogical work rather than a tool, a means of presentation of collection items and the exhibition topic to the audience.

\section{The form of worksheets}

Worksheets can be quite varied in their form, which is given by the way of their use, their extent, design and content.

In principle we can follow up two basicforms defined by the way of working with worksheets in museums (Šobáň 2007, 36-38):

- worksheets for working with a lecturer - they are used actively within accompanying museum programmes, serve as a foundation for own observations and notes, or as extension materials and a tool which, however, should not attract more attention than the programme itself and should not be dominant or disturbing with regard to the programme: "Since they take into account the commentary of a lecturer, they need not to contain formulated tasks. They are rather used for presentation of complementary photographic and information materials or offer space for written or visual artistic activities of the attendants..." (Šobáň 2007, 37);

- self-service worksheets - they place increased demands on the methodical aspect of this material, it is necessary that the tasks and activities are supplemented with instructions and additional comments, etc.: "Working with them does not require any additional explanation by the lecturer, because all the necessary information and instructions to the tasks are included in the text. This type of worksheets should of course be equipped with a key to solution of individual tasks..." (Šobáň 2007, 38). 
Another characteristic is evident from the way of use of museum worksheets (Jůva 2004, 137) - the talk is of worksheets used in following situations:

- before the museum visit - as a motivation;

- during museum activities - these worksheets are used directly in the course of a museum tour or within an activating programme which is part of a temporary or permanent exhibition;

- in work after the museum visit - as a source of information or a tool for development of further interest at home, or for subsequent work on the topic at school, or in the museum after the end of the tour or the activating programme.

The varied form of worksheets can also be defined by their extent (Jůva 2004, p. 138). You can use, for example:

- separate informative sheets - they only contain basic information on a temporary or permanent exhibition, are often designed as a typical brochure fold, which the museum visitors obtain for free when buying a ticket;

- separate worksheets - usually one page with tasks, activities and impulses to own records;

- informative booklets - text in the form of a slender brochure providing extended information on a temporary or permanent exhibition;

- workbooks - their content is similar to separate worksheets; they have the form of either a book or individual loose sheets placed in a folder;

- children catalogues;

- complete set of complementary materials.

Regarding the numerous variants of forms and the logical and thematic content of worksheets it is relatively difficult to classify these materials by their form and content. According to these criteria (Křístková, Křístek 2005, I-4) we can distinguish:

- informative worksheets - they are characterised by valuable and often very comprehensive information on the exhibition topic; their graphic design is often relatively expensive so that they have also been regarded as the representative material of educational museum activities; typologically seen, their format rather reminds of an exhibition catalogue; elaboration of this type of worksheets is connected with several risks, namely that their extent is too large and that the overall character of these materials reminds of schoolbooks;

- activating worksheets - their textual, informative and material aspects are less demanding than with the previous type of worksheets; they usually comprise simple instructions to various tasks and empty fields for own records; typologically seen, they rather remind of school workbooks; elaboration of this type of worksheets is connected with several risks, namely that they easily turn into too simple fill-in-theblanks, which mostly do not sufficiently motivate to work with the exhibition and rather lead to a fast filling in without any deeper considerations about the exhibition content;

combination of informative and activating worksheets - maybe the most widely used form in the museum practice; ideal form of these worksheets includes balanced informative and activating components, which contain both the most important professional information, and the visitors' own reflection on how they perceive the exhibition; elaboration of this type of worksheets is connected with risks of both the previous types of worksheets as well as with possible risk of shallow content but, when well-elaborated, they interconnect appropriately all the above-said advantages: they contain both the basic and most important infor- 
mation, and the impulses for an active fixation of new knowledge.

\section{Worksheets step by step}

It is not easy to create worksheets which are functional, which help the visitors to comprehend the exhibition topic and remember the most important information, which draw attention to objects and at the same time entertain the visitors. Their concrete and functional form always depends on the institution for which they are designed, on the temporary or permanent exhibition for which they are intended, on the purpose which they serve, and on the preferences and experiences of individual museum pedagogues. The elaboration of worksheets can thus only hardly be summarised in a simple general instruction, but we can generate some basic rules of creation of these materials. Respecting them will help to create worksheets which will meet the goals set out.

\section{Evaluate a temporary or permanent exhibition with regard to content and presentation.}

The first step should always be a detailed evaluation of a temporary or permanent exhibition with regard to content and presentation. Think about the topic of the temporary or permanent exbibition, about possibilities of developing this topic, about the most important exhibits, about possible points of view which are interesting or significant to visitors.

\section{Questions to contemplate}

What is the temporary/permanent exhibition about? What is the basic information on the topic? What is most important in the temporary/ permanent exhibition? What is most attractive? How does the exhibition present the topic? Which "story" it tells?

Also pay attention to space, in which the temporary or permanent exhibition is installed. The space influences both the choice of appropriate way of working with the worksheet and, to a certain extent, as well the choice of content and focus of the worksheet by the arrangement and way of installing the exhibition.

\section{Questions to contemplate}

In which space the temporary/permanent exhibition is situated? How is the temporary/permanent exhibition arranged in this space? How is the temporary/permanent exhibition installed? Which limitations or advantages for working with the worksheet result from this installation? Are there too many or rather fewer exhibits? Where are the most important exhibits? How does the ideal tour path look? Where are possible collision points for working with a group or with a large number of visitors (e.g. narrow or small spaces, poorly organised space, little space between showcases, etc.)? How to make the work here "exhibit-safe"? Where could the working with a worksheet be risky, e.g. if the visitors will want to rest or lay the worksheet somewhere? Where, on the other hand, are the conditions suitable for working with a worksheet - where the visitors can sit down, lay the sheet on a table, rest it on and fill it in comfortably?

Working with worksheets is also influenced by light conditions in a temporary or permanent exhibition. There is not always enough light for reading the information and writing it down, e.g. some installations are only illuminated by minimal light for the purpose of protection of exhibits or a dramatic accentuation of the topic or target of the exhibition; in some exhibitions the work with selected exhibits might be complicated by reflections from glass of the showcases, etc.

\section{Questions to contemplate}

How are the light conditions in a temporary or permanent exhibition? How the light changes depending on going through the exhibition? How are the light conditions in places of presumed working with a worksheet? Are the exhibits well visible (i.e. is it possible to study details, are the visitors perhaps not hindered by, for example, reflections on glass, shadow of some other exhibit, etc.)? 


\section{Think about your own pedagogical intents}

The next logical step is a consideration about own pedagogical intents concerning the given topic and space. Get clear about which part of the topic and exhibition you, as a museum pedagogue, consider important, from which perspective you want or need (e.g. due to compatibility with Framework Educational Programmes during elaboration of worksheets for schools) to present the exhibition? Temporary and permanent exhibitions usually are relatively extensive and rich in exhibits, which can be observed in various contexts and from many perspectives. Finding an optimal way of how to guide through an exhibition is crucial for creation of worksheets, otherwise it can happen that the resulting material is too extensive and exhausting. The course of your exhibition tour may or may not be compatible with the opinion of the curator who created and installed the exhibition. It is entirely legitimate to choose with the help of worksheets some other logical sequence of how to see an exhibition, another way of going it through, or, for example, only a single object to illustrate the topic, providing that the information transmitted remains professionally correct. However, you should always be well aware of the reasons for your choice, that is, why do you want and need the worksheets just in this way.

\section{Questions to contemplate}

How I intend to make the visitors familiar with the exhibition? What is to me, as a museum pedagogue, most crucial with regard to audience? What, in my opinion, should the visitors learn from the exhibition? How I want the visitors, who are working with a worksheet, go through the exhibition? Why?

\section{Choose the target group}

A very important criterion for creation of worksheets is of course represented by the exhibition visitors themselves. The choice of the target group of visitors, worksheet users, is a factor which directly determines the form of worksheets, their content, difficulty or language. To put it simply, the younger the target group for whom the worksheets are intended, the simpler the extent, graphics and content of the worksheets.

\section{Questions to contemplate}

For whom the topic of a temporary/permanent exhibition is suitable? Whom I want/need to make familiar with the exhibition topic with the help of worksheets? What are the characteristics of this visitor group? What are the risk factors, limitations, specifics of this group for the work with worksheets? How do these specifics influence the design of worksheets, their content, graphics, typology, structure of questions, tasks and information, language, etc.?

\section{Evaluate the progress of a planned educational programme}

Also important is the evaluation of the progress of a planned educational programme, which includes worksheets. It is important to realize, why do you want to include worksheets into the programme structure, where do you want include them within the programme structure, where the worksheets can help the content of the programme and how. Make sure that the worksheets and their tasks do not distract attention from the exhibition programme.

\section{Questions to contemplate}

How does the planned programme look? How is it structured? What are the main focal points? In which moments it can be supported by worksheets and in which, on the other hand, the worksheets could distract attention from the main focus of the programme? With which exhibits the programme is working? Do I want to draw attention to these main exhibits, or will I rather use worksheets to complement the information on other objects/exhibits? Is my intent to work continuously with worksheets, or will the visitors work with them only in some concrete moments of the programme?

Considerations about the previous procedural steps (evaluation of the exhibition, own 
pedagogical intents, target group of visitors, educational programme) will also verify the relevance of using worksheets to interpret the given exbibition, that is, whether or not the worksheets are suitable for this particular temporary or permanent exhibition.

\section{Choose the educational goals}

A step which is inevitable for creation of worksheets is the choice of goals of this didactic tool that is the very reason of its use. The goals form the content of worksheets and at the same time reflect their functionality. During elaboration of worksheets we are working with partial goals, that is certain knowledge and skills, to which the worksheets should lead the visitors. It is not necessary to set out too many of these goals two or three are fully sufficient, also legitimate is only a single goal. Think about what you want to teach the visitors, what you need the visitors to be aware, to know and to can. Get clear about these intended goals in the form of a binding statement, or a written statement, so that you can anytime return to their explicit formulation. For example, when you need to make sure that a question, activity, task or information in the content of worksheets is reasonable, or in retrospective evaluation of their functionality and effectiveness. Fulfilment and achievement of set out goals represent the most important evaluation factor. Formulate the worksheet goals in active declarative sentences of present tense, for example, the visitors can, know, distinguish, etc. Each of the selected activities, questions and pieces of information in worksheets should pursue and support these goals - if not, then it is unnecessary to the worksheets. The worksheet goals should always correspond to the goals and intents of both the exhibition and a possible programme, if the work with worksheets is included. The worksheets should in principle underline the exhibition topic, make it better understandable, more vivid and more profound, they should draw attention to unique details or interdisciplinary relations.

\section{Questions to contemplate}

What is the worksheet intended for? What should the worksheet support/show? What I want the visitors to learn, be aware, achieve with the help of the worksheet? Most important to me are the following pieces of knowledge, skills, feelings... Examples of formulated worksheet goals: the visitors are familiar with... can... know... will compare... will explain... will evaluate...

\section{Make a schedule}

If the worksheets are intended to be used with an exhibition, you usually have an idea of the time which you want the visitors spend filling in the worksheets. This estimated time to a certain extent influences the form, extent and contentual depth of a worksheet. In individual tasks consider the length of their solution and potential risks which might threaten or prolong their solution, and think about possible variants of how to eliminate these risks.

\section{Questions to contemplate}

How long lasts an ordinary exhibition tour? How long lasts the programme, which will include the worksheets? How much time I want the visitors spend filling in and working with the worksheets? How much time the visitors will spend reading the information or fulfilling particular tasks? Is there any risk connected with this particular task, which might prolong its fulfilment? What is it? Am I able to eliminate or minimize this risk somehow?

\section{Decide on the form of worksheets}

After having considered all the previous aspects and prior to working out the content of worksheets, it is inevitable to decide on the suitable form of worksheets. It should fully comply with conditions and responses, which you as a museum pedagogue have stipulated in considerations about the previous procedural steps. Choose the suitable form of worksheets according to particular temporary or permanent exhibition - its content and way of presentation, according to 
your own pedagogical intents, according to selected group of visitors for whom the worksheets are intended, according to the educational programme, which potentially should include the worksheets, according to particular goals which they should fulfil and time which should be spent by working with them.

\section{Questions to contemplate}

Will the worksheets be part of an accompanying programme or will they be self-service worksheets? Will I use the worksheets as a motivation for visitors before the exhibition visit, as a support during the visit, or as a review of knowledge after the end of the visit or at its end? Will the worksheets rather inform, or rather activate, or both? How will be the extent of worksheets?

\section{Choose the content and suitable exhibits}

The next step is the creation of content of the worksheets and selection of exhibits, on which the worksheets will be focused. The content will be given by pedagogical intents, with which you approach the creation of worksheets, and by the goals chosen. Afterwards it will be specified by exhibits which you will choose for the work with the worksheets. If you do not want the worksheets to be limited on only superficial information, they usually cannot work with all the objects exhibited. So, it is important to consider very thoroughly what to emphasize or, the other way round, what to omit, so that neither the worksheets nor the visitors are overloaded with information and tasks and so that it is not very time-consuming to fill the worksheets in. Selection of exhibits for the work with worksheets should be the higher, the lower the age of the target group, or the deeper you want the visitor to contemplate the exhibits or immerse emotionally in the topic. The selection should always be focused on what you intend, so that the visitors engrave on mind and put into context, which experiences they should "take home" and recall again with the filled-in worksheet, etc. It usually concerns important facts or contexts which are otherwise little known, or own experiences with the topic which represent a significant component of the educational aspect of these materials. Thorough selection of objects should thus focus on the most important, simply significant or most attractive exhibits and show their interconnection in a wider context, or, on the contrary, examine interesting details. You should always rather choose fewer exhibits and let the visitors work with them more thoroughly and more profoundly the worksheets thus can be based on only a single collection item and its more detailed presentation. Also important is to consider the distribution of selected exhibits in the exhibition premises, so that the working with worksheets is comfortable for the visitors - that is, so that the object chosen is well visible, easy to observe and examine, so that it is possible to fulfil the assigned task, or so that the working with worksheets does not interrupt the ordinary running of the exhibition and hinder the other visitors in their exhibition tour.

\section{Questions to contemplate}

Which pieces of knowledge should the visitors note down, remember, what should they become aware and explore? Which exhibits meet these criteria best? Where are these exhibits placed? Are they well visible? Can they possibly be observed by more visitors at once? Which other extending and deepening information on these exhibits I can use? Do the selected exhibits follow up each other in a logical way?

\section{Lay out the structure of worksheets}

The structure of a worksheet is one of important criteria which determine the success of a worksheet. Its logical arrangement, well-organised graphics and the choice of tasks, questions and information exert a direct influence on how the visitors will understand the topic. The structure of a worksheet can in principle follow the same methodical approach, which is usually applied during preparation and creation of the accompanying museum programmes; so it can be based on the same concepts and methods. For example, in terms of the RWCT method (Reading and 
Writing for Critical Thinking) ${ }^{3}$, the worksheets can follow up the three-stage learning cycle $\mathrm{E}$ $-\mathrm{R}-\mathrm{R}$ (evocation-realization of meaning-reflection), i.e. the initial task is making familiar with the topic, searches for previous knowledge of the topic. The following tasks and activities, just as the information recorded, already address the "core" of the problem and the last component should subsequently summarise and reflect on the problem. Following up the didactic procedures during creation of worksheets helps to keep them balanced and well-understandable. It helps to maintain the "storyline" of the worksheets in relation to selected goals and is herewith a certain guarantee of effectiveness of these materials.

\section{Questions to contemplate}

Do the tasks follow up each other in a logical way? Do they enhance the knowledge of the topic gradually? Are the worksheets well structured? Do they build on the previous knowledge of the visitors? Do the final activities reflect the most important pieces of knowledge and experiences?

\section{Change evenly and thoughtfully various types} of activities

When setting up the particular content of worksheets from various tasks, puzzles, research records, open questions etc., it is suitable to change evenly and thoughtfully various types of tasks and activities, so that the visitors employ cognitive (rational, intellectual), affective (emotional, attitudinal) as well as psychomotor (sensual, motional) skills. That is, so that the visitors explore and investigate with reason, are aware of their emotions, generate attitudes to the given topic and try out various practical skills and methods of work, production or creation, etc. Also important are research methods as the basic component of museum work. The procedures chosen

3 Reading and Writing for Critical Thinking (RWCT) is an educational method based on purposeful development of cognitive skills in learners. It proceeds from pedagogical constructivism and leads the learners to own perception of communicated information. You can see more on the website https://www.rwctic. org. should motivate the visitors to examine the objects and think about the contexts, not only to merely record the information, e.g. the requirement for a detailed description of an item will ensure its thorough examination, just as the requirement to make a drawing. Putting into context, following up the development and recording own ideas leads to a deeper consciousness of the importance of an object and to possible self-reflection or change of attitudes.

\section{Questions to contemplate}

Does each of the activities chosen support the worksheet goals? Which particular knowledge or skill will the visitors acquire? Are the tasks and activities targeted at substantial and most important knowledge and skills? Do the activities attract the attention of visitors to the exhibits and their examination? Do the activities employ various skills, are the tasks not monothematic, focused on only a single type of activity?

\section{Most frequent weaknesses}

- Textually too extensive worksheets, which remind of representative materials rather than of a functional didactic tool. Too extensive material discourages the visitors from working with worksheets.

- Overloading with script, text, pictures or information distracts attention from the temporary or permanent exhibition and the visitors lose their grip on the topic as well as on the worksheet itself. An overabundance of various markings and a too detailed division or a compact monotonous text are inappropriate in this regard.

- Distracting attention from the exhibition to worksheets and their texts. Instead of emphasizing the unique possibilities of acquiring knowledge in museums, the attention is often distracted by too many purposeless exercises.

- Useless information, incomprehensible, vaguely formulated or too extensive instructions to tasks - the worksheets often contain infor- 
mation, which from a didactic point of view is not inevitable and infests unnecessarily the space, e.g. a too long introductory narrative in worksheets intended for working with a lecturer, etc.

- Inappropriately chosen activities and tasks:

- too easy or too difficult;

- distracting too much attention from the exhibition and exhibits themselves to easily available information in accompanying materials, legends, texts etc., or the requirement for recording data which are neither relevant nor substantial (typical example is the search for date - you should always be sure that such an information is of value to the visitors, that the task is not there for itself, i.e. that it is, for example, a crucial date which the visitors should indeed know);

- distracting attention from the exhibition to worksheets, that is, tasks which do not stimulate the visitors to "raise their eyes" from the worksheets to the exhibition, e.g. crosswords, word searches, etc.; it is not necessary to give them completely up, only to place them more suitably in the structure of worksheets, e.g. to the revision and fixation part of the worksheet or among the tasks intended for individual work at home or at school; tasks without relation to objects instigate the effort to find the answers as quickly as possible, without any deeper contemplations of the content, so that a danger arises of something like a "high-speed" race among the visitors, that is filling in the worksheets and going through the exhibition as quickly as possible with lowest possible effort.

- Monothematic tasks: repeating similar questions and tasks focused always on the same type of information and knowledge, or employment of only a single skill, most frequently the verbal written language, and omitting the other skills.
- Insufficient space for the comments or observations by visitors, or a small space for the answers.

- Working with exhibits which are poorly accessible to visitors, e.g. they are placed high, are too small to be examined by more visitors at once, are situated in a narrow space where there is not enough place for everybody, etc.

- Inappropriately chosen technical parameters of worksheets can significantly reduce their functionality, whether it is a too large or too small format of the worksheets, an inappropriate choice of hardness and structure of the paper, small or poorly legible script, etc.

\section{What is important}

- Appropriate choice of objects for working with worksheets, which are significant with regard to the exhibition topic and at the same time well accessible for observation by even a large group of visitors, and their examination is not hindered by, for example, their being placed too high, or by reflections in the glass of showcases, etc.

- Worksheets should always attract attention to exhibits, support them and make them accessible.

- The amount and character of the text should correspond to primary goals and type of worksheets, the texts should be adequate to age and provide relevant information.

- Lucidity, simplicity or even austerity will surely pay off.

- Clear formulation of questions and tasks in worksheets, which should always be adequate to the target group, their age and level of knowledge.

- Questions and tasks focused on relevant and substantial information.

- Activities should rather be fewer in number, but open and motivating the visitors to reflect upon the issues, to search for relation- 
ships, to explore, and stimulating curiosity, interest and fantasy.

- It is appropriate to employ as many different skills as possible, that is not only verbal skills but, for example, drawing, mathematic or linguistic skills, and employ evenly the cognitive (rational, intellectual), affective (emotional, attitudinal) as well as psychomotor (sensual, motional) skills.

- Well-considered and balanced changing of various types of activities and skills.

- Thoroughly considered technical criteria of worksheets, that is a properly chosen format of the paper, its quality, suitable size and easily legible script, as well as well-understandable graphic design, can significantly increase the functionality and effectiveness of worksheets.

- Information on the temporary or permanent exhibition for which the worksheets are designed, and on the target group of visitors for whom they are intended. Worksheets, just as any other printed materials published by the museum, also are advertising materials, therefore they should contain the logo of the institution, name and contact, as well as the name of the author of worksheets.

- If the worksheets are intended for pupils to supplement the school teaching, they should observe the educational standards, that is currently the Framework Educational Programmes, and meet the needs of schools in relation to present-day curriculum.

\section{Evaluation of worksheets}

Worksheets should regularly be evaluated. Checking out their effectiveness is important for the museum visit itself, for a good response to the worksheets in museum visitors, and for those who create the worksheets (was I successful?, what does work?, what does not work and why?, what has to be changed? what, on the contrary, should be maintained?, what was difficult for the visitors?, what, on the contrary, was too easy?, etc.) and for the museum institution itself (what is the effect of worksheets?, does it pay off to invest time and manpower to create them?, etc.).

If you assess individual worksheets, it is necessary to focus on the pedagogical intent and goals which you wanted to achieve, and find out whether the visitors acquired the intended knowledge and information through the medium of the activities offered. Further, whether the tasks were appropriate for them and sufficiently interesting. It is also necessary to observe whether the worksheets do not attract too much attention or do not incite to fill them in without a thorough examination and working with the exhibition, or whether at all the visitors use the worksheets. Their disinterest can attest to insufficient motivation or inappropriate or incomprehensible instructions. Also to blame might be, for example, a chaotic or little attractive graphic design or an improperly chosen unsuitable format or material of the worksheets. The benchmark of success can also be the extent of filling in these materials by visitors or, for example, their verbal comments in a conversation with museum pedagogue.

A suitable tool for elimination of possible weaknesses is the pilot testing of the worksheets in practice, directly in the given temporary or permanent exhibition, on a group of visitors, for example an agreed school class, a hobby group or a group of companioned parents with children, etc. In ideal case, this pilot group is the same as the target group of visitors, both in age and assumed skills, and in number. This pilot testing provides a different view of the tasks and activities, helps to reveal weak points and make possible corrections. It also enables to verify the practical details, e.g. whether there is enough space for everybody to examine the selected objects, where are possible collision points and whether the supposed time necessary for filling in the worksheets at least roughly corresponds to real time - it usually turns out that working with worksheets goes faster in smaller groups. 


\section{Pay attention to following issues}

Did the visitors find the worksheets interesting? Do the visitors enjoy working with worksheets? Do the visitors understand the instructions to activities and tasks? Do they read the whole worksheets or do they skip some tasks/sections? Why? Where are possible problem points? Do the visitors manage to accomplish their working with worksheets in supposed time? Are there any spatial collisions during working with worksheets? Do the visitors have the skills and knowledge which should have been acquired with the help of the worksheets?

In relation to the worksheets you can, for example, consider following evaluation criteria:

Topic

Are the worksheets relevant to the exhibition? From which perspective they perceive the exhibition? If the worksheets are intended for school groups: to what extent this perspective is compatible with the Framework Educational Programmes?

\section{Space}

Are the worksheets relevant to the exhibition space? Do they follow the simple motion logic of the space (do they not lead confusedly through the exhibition space)? Is it possible to work with the exhibition worksheets comfortably (is there enough light, place to write, something to rest the worksheet against, place to make notes)? Are the worksheets safe for the collection items exhibited? Provided that a large group is working with a single type of worksheets, is there enough space for everybody to examine the exhibits?

\section{Target group of visitors}

Are the worksheets relevant to the target group? Are the tasks adequate to their age, abilities and skills? Are the instructions simple, well-understandable?

\section{Technical parameters}

Is the format of worksheets properly chosen? Is the size appropriate, are the worksheets not too large or too small? Is the type of paper suitable? Is the paper not too soft? Is it possible to write down on the paper without problems, e.g. does the script not blur? Is the font size appropriate? Are the tasks easy to read?

\section{Time}

How long does it take to tackle individual tasks? Is the supposed estimated time optimal?

\section{Structure}

○

Are the worksheets well structured? Are they not overloaded with text, information, pictures, tasks?

\section{Goals}

Has every information, instruction, task, activity its evident purpose? Do all the instructions meet and support the set out goals of worksheets?

\section{Content}

Do the tasks in worksheets work with collection items, do they draw attention to them and do they instigate more profound examination? Do the tasks stimulate thinking? Do they not require only shallow unimaginative activity? Is the information acquired important to the visitors? Do the activities change evenly? Do the worksheets not involve still the same repeating activity?

\section{The visitors' own records}

Do the worksheets offer enough space for the visitors' own activity? Is there enough space for filling in, drawing, notes?

\section{Masthead}

Do the worksheets contain the name and logo of the institution, exhibition, name of the author, validity date and the target group of visitors for which the worksheets are intended? 


\section{Conclusion}

Well-elaborated worksheets bring many advantages to the museum educational process because they facilitate the orientation of visitors in the exhibition, draw attention to significant objects and relationships, and with the help of properly chosen questions and activities they are able to captivate the visitors by the exhibition topic and events. They also offer place for taking notes of own observations and research results and generate space for expression of own attitudes and opinions on the given topic. And, last but not least, through the reflective processes they enable to fixate the acquired knowledge, experiences or skills. The worksheets, however, should always be strictly adequate to the target group of visitors, as regards the age, abilities, ways of perception and assumed previous knowledge.

Summary (methodical check list for making worksheets)

\section{What is a museum worksheet?}

- usually a printed material, which is available to visitors in order to elucidate, supplement or enliven a temporary or permanent exhibition;

- $\quad$ it is created by a museum pedagogue;

- it is intended for didactic support to the exhibition topic;

- the ideal form is always directly dependent on:

- particular temporary or permanent exhibition;

- intended way of working with this material;

- target group;

- abilities and didactic skills of a museum pedagogue.

\section{Which role the worksheets are playing in a}

\section{museum?}

- they give a hint how to work with an exhibition /orientational function/;
- they can record and sort the basic and most important knowledge/cognitive and systemizing function/;

- they fixate this knowledge with the help of tasks and activities /fixative, controlling, developmental and educational function/;

- they motivate to individual research or working with attitudes and opinions of the users /motivational, self-educational and coordinative function/.

\section{Which form the museum worksheets can have?}

With regard to the way of working with museum worksheets:

- worksheets for working with a lecturer;

- self-service worksheets (Šobáň 2007, 3638).

With regard to the way of use of worksheets we can speak of worksheets used:

- before the museum visit;

- during museum activities;

- $\quad$ in work after the museum visit (Jůva 2004, 137).

With regard to extent of worksheets we know, for example:

- separate informative sheets;

- separate worksheets;

- informative booklets;

- workbooks;

- children catalogues;

- complete set of complementary materials (Křístková, Křístek 2005, I-4).

\section{Before you begin, you should remember that:}

- worksheets are a tool, not the essence of pedagogical work in a museum;

- worksheets should never be purposeless, that is, elaborated only because it is expected, without any clear conceptual base, disregar- 
ding the focus of the exhibition or the real use of this material;

- an improperly elaborated or inappropriately used worksheet can even be counterproductive for the museum pedagogical process;

- if the worksheets are indeed supposed to be functional and purposeful, it is necessary to observe certain didactic rules and principles of the learning process, as well as further eligibility of these materials with regard to goals and topic of a temporary or permanent exhibition, or the intended way of working with the worksheets.

\section{How to proceed?}

- evaluate the temporary or permanent exhibition as regards the content and presentation /what the exhibition communicates, how, and in which space/;

- think about your own pedagogical intents concerning the given topic and space / what I want to teach, show, communicate/;

- choose the target group of visitors (worksheets should always be strictly adequate to the target group of visitors, as regards the age, abilities, ways of perception and assumed previous knowledge/;

- or, evaluate the course of the educational programme planned, if the worksheets are intended to be a part of.

! By considering these criteria you can also verify the effectiveness of using the worksheets for interpretation of the given temporary or permanent exhibition /does the worksheet to this exhibition, this topic and for this target group make sense?/.

- set out the educational goals of worksheets / particular knowledge or skill at the cognitive, affective and psychomotor level/;

- schedule the time, which the visitors should spend working with the worksheets;

- following up the educational goals, choose the suitable form/design of the worksheets; regarding the educational goals, choose the content - the worksheets should underline the topic of the exhibition, make it easier to understand, enliven and deepen, they should draw attention to unique details or interdisciplinary relations;

- an important criterion in fulfilling the content of worksheets is the selection of collection items for working with the worksheets / it is inevitable to consider thoroughly what to emphasize, what to omit, selection of objects should be distinctive and strict/;

- the structure of worksheets can in principle observe the same methodical procedure as in preparation and creation of accompanying museum programmes /e.g. in the concept of a syllabus to a lecture in the RWCT method (reading and Writing to Critical Thinking), the worksheets in a reduced form can thus follow up the three-stage learning cycle E $\mathrm{R}-\mathrm{R}$ (evocation-realization of meaningreflection), i.e. the initial task is making familiar with the topic, searches for previous knowledge of the topic; the following tasks and activities, just as the information recorded, already address the "core" of the problem and the last component should subsequently be summarising and reflective/;

- change evenly and thoughtfully various types of tasks and activities, so that the visitors employ as many different skills and working methods as possible.

The procedures chosen should motivate the visitors to examine the objects and think about the contexts, not only to merely record the information, e.g. the requirement for a detailed description of an item will ensure its thorough examination, just as the requirement to make a drawing; putting into context, following up the development and recording own ideas leads to a deeper consciousness of the importance of an object and to possible self-reflection or change of attitudes. 
Well-elaborated worksheets

- facilitate the orientation in an exhibition;

- draw attention to significant objects and relationships;

- are able to captivate the visitors by the exhibition topic and events with the help of properly chosen questions and activities;

- offer place for taking notes of own observations and research results;

- generate space for expression of own attitudes and opinions on the given topic;

- enable to fixate the acquired knowledge, experiences or skills.

\section{Povzetek}

Delovni listi so obravnavani kot materiali, ki so značilni za sodobne muzeje in njihovo odzivnost na izobraževalne potrebe obiskovalcev. To didaktično orodje postopoma prehaja vširoko uporabo znotraj muzejskih služb in je gradivo, ki kaže odzivnost do obiskovalcev in kompetence muzejskih delavcev. Ni lahko izdelati izobraževalno funkcionalnih delovnih listov ustrezne kakovosti. Običajno se pričakujejo tudi druge dodane vrednosti, kot so zabava, reprezentativni značaj, nizki stroški izdelave delovnih listov, ki jih je pogosto treba pripraviti hitro in v improviziranih pogojih. Njihov namen je pomagati pedagogom, predavateljem in drugim delavcem v muzejkkih ustanovah, ki se ukvarjajo z delom z obiskovalci.

Muzejski delovni listi se razlikujejo od šolskih delovnih listov in delovnih zvezkov, predvsem v povezavi z začasno ali stalno razstavo, tesnim odnosom do eksponatov in osredotočenostjo predvsem na spodbujanje dojemanja in pregleda teh eksponatov. Delovni listi so orodje ne pa cilj muzejskega izobraževanja. Namen in glavni namen muzejskih listov je, da obiskovalci temeljiteje opazujejo eksponate. Idealna funkcionalna oblika delovnih listov je vedno izpeljana iz posebnih stalnih ali začasnih razstav, pedagoških načrtov posameznih muzejkkih pedagogov in njihovih vzgojnih ciljev.

Dobro izdelani delovni listi prinašajo številne prednosti muzejskemu vzgojnemu procesu, saj olajšajo orientacijo obiskovalcev na razstavi, opozarjajo na pomembne predmete in odnose ter $s$ pomočjo pravilno izbranih vprašanj in aktivnosti pritegnejo obiskovalce. Ponujajo tudi prostor za zapisovanje lastnih opazovanj in rezultatov raziskav ter ustvarjajo prostor za izražanje lastnih stališč in mnenj o dani temi. In nenazadnje, s pomočjo refleksivnih procesov omogočajo fiksiranje pridobljenega znanja, izkušenj ali spretnosti. Delovni listi pa morajo biti vedno strogo prilagojeni ciljni skupini obiskovalcev, glede na starost, sposobnosti, načine zaznavanja in predznanje.

\section{Summary}

Worksheets have been regarded as one of the materials which characterize modern museums and their responsiveness towards educational needs of visitors. This didactic tool gradually becomes a widely used museum service, a material demonstrating both the responsiveness towards visitors, and the competence of museum workers who are engaged in working with audience. It is not easy to elaborate educationally functional worksheets of relevant quality. Usually also another added values are expected, such as entertainment, representative character, low production and elaboration costs for these worksheets which often must be made quickly and in provisional conditions. Its aim is to give a helping hand to pedagogues, lecturers and other workers in museum institutions who are engaged in the work with audience.

The museum worksheets differ from the worksheets and workbooks used in schools mainly in their interconnection with a temporary or permanent exhibition, a close relationship to the exhibits and the focus laid primarily on boosting the perception and examination of these exhibits. Herewith it is a tool rather than the actual purpose of museum education. The purpose and main function of the museum worksheets is to make the visitors observe the exhibits more thoroughly. The ideal functional form of worksheets is always derived from particular permanent or temporary exhibition, pedagogical plans of individual museum pedagogues and their educational goals.

Well-elaborated worksheets bring many advantages to the museum educational process because they facilitate the orientation of visitors in the exhibition, draw attention to significant objects and relationships, and with the help of properly chosen questions and activities they are able to captivate the visitors by the exhibition topic 
and events. They also offer place for taking notes of own observations and research results and generate space for expression of own attitudes and opinions on the given topic. And, last but not least, through the reflective processes they enable to fixate the acquired knowledge, experiences or skills. The worksheets, however, should always be strictly adequate to the target group of visitors, as regards the age, abilities, ways of perception and assumed previous knowledge.

\section{Sources}

Jůva, V. 2004. Détské muzeum: edukační fenomén pro 2I. století. Brno: Paido.

Křístková, M. and N. Kř́stek. 2006. "Pracovní listy." In Projekt Škola a muzeum pod jednou strechou: 2004-2006 [CD-ROM]. Praha: Národní galerie v Praze.

Mrázová, L. 2012. Tvorba pracovních listů. Metodický materiál. Brno: Metodické centrum muzejní pedagogiky, Moravské zemské muzeum.

"Reading and Writing for Critical Thinking." https://www.rwctic.org

Průcha, J. 1998. Učebnice: teorie a analýzy edukačního média Př́ručka pro studenty, učitele, autory a výzkumné pracovníky. Brno: Paido.

Skalková, J. 2007. Obecná didaktika. 2nd ed. Praha: Grada Publishing.

Šobáň, M. 2007. Škola muzejni pedagogiky 6: Stručná teorie a praxe muzejni pedagogiky. Olomouc: Univerzita Palackého v Olomouci.

Veverková, H. 2002. “Učivo.” In Zdeněk Kalhous and Otto Obst, Školni didaktika, I2I-I 48. Praha: Portál. 


\section{Pot tovarn kot pripoved o dediščini ribištva in predelovalne industrije s poudarkom na Izoli}

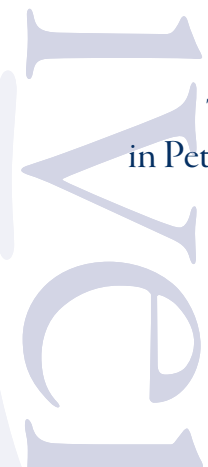

Tereza Prešeren (študentka), Alenka Janko Spreizer, Nataša Kolega

in Petra Kavrečič, Univerza na Primorskem, Fakulteta za humanistične študije

Srečko Gombač, Društvo Histrion

Pričujoči članek predstavi bralcu Pot tovarn oziroma pripoveduje bralcu/obiskovalcu zgodbo, ki jo je gospodarska dejavnost ribje predelovalne industrije pustila za seboj od zadnje četrtine 19. stoletja do današnjega časa. Pot pripoveduje zgodbo, ki se med Izolani še danes ohranja, živi naprej in predstavlja spomin na šest tovarniških obratov mesta Izole, postavljenih vse od zahodnega do vzhodnega zaliva mesta Izola. Skrajni dve točki poti sovpadata s primarno gospodarsko dejavnostjo mesta Izole, tj. predelavo male $\gg$ plave $\ll$ ribe.

Ključne besede: Pot tovarn, Študentski inovativni projekt za družbeno korist (ŠIPK), Riba na poti, kulturna dediščina, ribištvo in predelovalna industrija, Izola.

The present article presents the reader the Path of Factories or tells the reader/visitor the story left behind the former economic activity of the fish processing industry, operating from the last quarter of the Igth century to the present day. The path tells the story, which is still preserved today among Isolans, lives on and represents the memory about six factory plants in the city of Izola/Isola, which are placed all along the the way from the west to the eastern bay of the town. The two extremes of the route coincide with the primary economic activity of the city of Izola/Isola, processing small „blue “ fish.

Keywords: The track of factories, Students innnovative projects for social benefit (ŠIPK), fish on the way, cultural herritage, fisheries and fishing, food processing industries, Izola.

\section{Pot tovarn in projekt Riba na poti}

$\mathrm{V}$ okviru Študentskega inovativnega projekta za družbeno korist ŠIPK - »Riba na poti, riba napotí: dediščina ribištva in predelovalne industrije s poudarkom na Izoli $\ll$, ki je potekal od marca do junija 2018 , je nastalo več tematskih poti $\mathrm{z}$ interaktivnimi zemljevidi in opisom točk. Namen projekta je bil prispevati h kulturnemu turizmu in med drugim preko oblikovanja poti prispevati $\mathrm{k}$ oživljanju spomina na nekdanjo gonilno silo Izole, tj. na tovarne ribjih konzerv in predelovalno prehrambno industrijo. Oblikovali smo turistične itinerarije $\mathrm{v}$ Izoli in njeni okolici, ki so poveza- ni z vsakdanjim življenjem ribičev in delavk $\mathrm{v}$ tovarnah ribjih konzerv in predelave hrane. Preko Poti tovarn, Poti škverov, Poti fabrkink in Poti San Dona tako prispevamo k poznavanju zgodovine, geografije, kulture ter vsakdanjega načina življenja ribičev in delavk. Poleg tega želimo prispevati $\mathrm{k}$ valorizaciji in promociji ribištva in predelovalne industrije rib kot dela nacionalne ter predvsem regionalne dediščine, ki je vezana na obmorski prostor današnje Republike Slovenije in je umeščena $v$ čas političnih in družbenih transformacij nekdanjih držav »Avstrije «, Italije, Jugoslavije in Slovenije (19., 20. in 21. stoletje). Slovensko primorje z zaledjem se geografsko umešča v Istro in Sredozemlje in sodi med 
najzanimivejša multikulturna območja. To območje na stičišču romanskega, germanskega ter slovanskega sveta je bilo v preteklosti izpostavljeno pogostim spremembam političnih oblasti in konfliktom, kar je sprožilo številne migracije prebivalstva. Obmorski kraji imajo za različne prebivalce več pomenov, saj imajo bogato, a hkrati tudi sporno ali zamolčano zgodovino. Tak primer predstavljata ribištvo ter predelovalna industrija rib v Sloveniji, ki jima ni bilo posvečeno dovolj pozornosti, zlasti v primerjavi z raziskovanjem ribištva na Tržaškem. Oblikovane poti govorijo o značilnostih načina življenja in dela ljudi, ki (so) se ukvarjali z ribištvom in predelovalno industrijo rib.

Med drugim je nastala tudi Pot tovarn. Opis te poti je nastal kot skupno delo študentke zgodovine Tereze Prešeren, pedagoških mentoric izr. prof. dr. Alenke Janko Spreizer, doc. dr. Nataše Kolega, doc. dr. Petre Kavrečič in strokovnega sodelavca iz društva Histrion, Srečka Gombača.

Še danes živ spomin na obdobje delovanja tovarn ribjih konzerv lahko v Izoli spremljamo tudi v prostoru, ki ga mnogi obiskovalci dojamejo kot devastirane lokacije, saj v priobalnem pasu vidimo propadle tovarniške stavbe ali njihove ostanke (ruševine). Spomin se ohranja torej v obmorski krajini kot tudi v pripovedih Izolanov, ki pa jih mnogi obiskovalci ne morejo slišati. Pot tovarn torej predstavi zgodbo, ki jo je pretekla gospodarska dejavnost ribje predelovalne industrije pustila za seboj. Zgodbo, ki se med ljudmi starejše generacije še ohranja, se predaja in živi naprej ter predstavlja naracije o šestih tovarniških obratih mesta Izole, postavljenih vse od zahodnega do vzhodnega zaliva mesta.

\footnotetext{
$\mathrm{V}$ projektu so poleg navedene študentke, pedagoških mentoric in strokovnega sodelavca sodelovali tudi Ivana Riganova (marec), UP FHŠ, študentka kulturnih študijev in antropologije (2. stopnja); Katarina Barbara Reberc (april-junij) UL FKKT, študentka kemije, I. stopnja; Artur Steffe, UP FHŠ, študent dvopredmetnega študija antropologije in geografije, I. stopnja; Hana Hanžek-Turnšek, UP FAMNIT, študentka biodiverzitete, I, stopnja; Lan Rak in Katja Masten, oba UP FTŠ, študenta managementa turističnih podjetij, visokošolski program, I. stopnja, ter Andrej Sitar, UP FHŠ in FTŚ, študent dediščinskega turizma, 2. stopnja. Pri projektu je za administrativno plat izvedbe skrbela sodelavka Karin Bandelj.
}

Skrajni dve točki poti sovpadata s primarno gospodarsko dejavnostjo mesta Izole, tj. predelavo male »plave« ribe. Lokacija postavitve te ali one tovarne je bila tako del strateškega premisleka, kako v čim krajšem času pridobljen ulov tudi predelati, saj so nekoč uporabljali za transport predvsem ladje in poti po morju. $\mathrm{Z}$ arhitekturnega vidika so večje tovarne, Ampelea (Delamaris), Arrigoni (Argo oziroma Droga) ter Degrassi (ali pozneje podjetje Riba), ki so bile postavljene izven starega mestnega jedra, še danes opazne v zasnovi Izole, medtem ko se lokacij ostalih tovarn $\mathrm{v}$ prostoru ne da opaziti na prvi pogled.

\section{Tovarna Ampelea - Delamaris}

Zgodba tovarne Delamaris se je začela leta I879, ko je Émile Louis Roullet, uspešen francoski gospodarstvenik, postavil prvo tovarno za predelavo male plave ribe v mestu Izola (Volpi Lisjak 200I, 135). Že v začetku svojega delovanja je tovarna zaposlovala sto delavk (Tomšič 2002, 137).Tovarna je najverjetneje obstajala $v$ naslednjih štirih letih pod imenom Émile L. Roullet et CO., prodajala pa pod imenom De Saint Ange et CO (Volpi Lisjak 200I, 136).

$\mathrm{V}$ naslednjih nekaj letih je tovarna doživela velike tržne uspehe in Roullet je leta $1883 \mathrm{z}$ vzpostavitvijo delniške družbe Société Générale Française de Conserves Alimentairies C. A. razširil tovarniški kompleks (Tomšič 2002, I38).Tovarna je ob vzpostavitvi delniške družbe že obsegala 4,7 ha zemeljske površine ter 22,12 ha vodnih površin (morska laguna in močvirje). Delniška družba je prevzela vodenje tovarne 2I. januarja I883. Ustanovitelj delniške družbe, Émille Louis Roullet, pa je tako dobil v last 240 delnic po 500 frankov (Volpi Lisjak 2001, 136).

$$
\begin{aligned}
& \text { Tej tovarni so rekli fabrika, dei frančezi‘, rekli } \\
& \text { so ji tudi fabrika, aibani '. Namreč to je tovar- } \\
& \text { na, ki je stala v bližini izvira mineralne vode, } \\
& \text { termalne vode v predelu ob cerkvici svete- } \\
& \text { ga Petra, to je na vzhodnem delu izolske- } \\
& \text { ga, nekdanjega izolskega otoka. In tu so, tu } \\
& \text { je ta Francoz Roullet postavil prvo tovarno. } \\
& \text { (Intervju s Srečkom Gombačem, arhiv dru- } \\
& \text { štva Histrion) }
\end{aligned}
$$




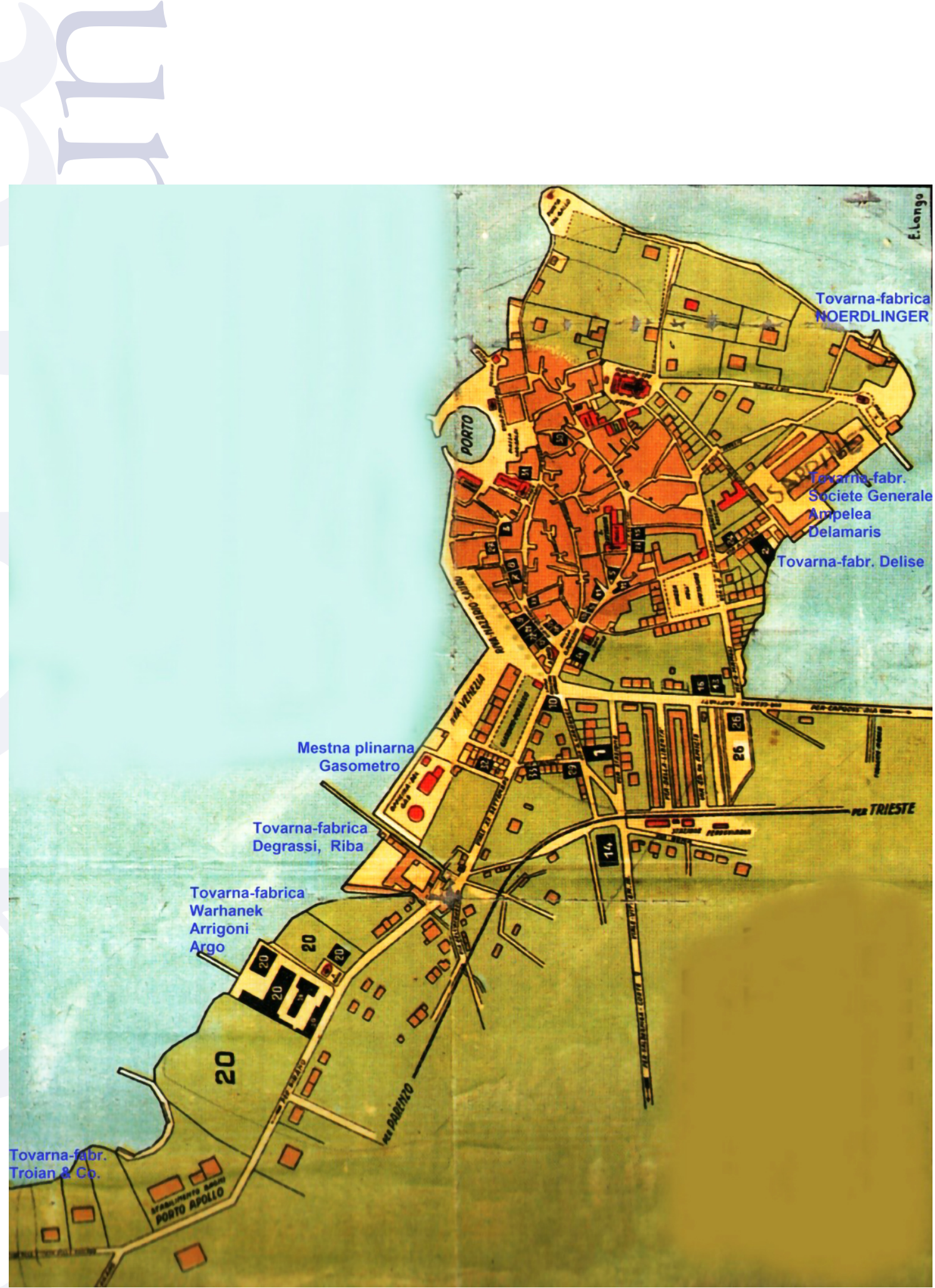

Slika I: Ilustrativni zemljevid tovarn v mestu Izola (Vir: Arhiv društva Histrion)

Leta I 888 je tovarna dobila dovoljenje za razširitev tovarniškega kompleksa. Ob morju so bili najprej postavljeni proizvodna hala, pristajal- ni pomol ter še nekaj manjših zgradb. Arhitekt Eugenio Marchetti je pozneje zasnoval osrednjo stavbo za proizvodnjo hrane in skladišče. Zraven 
pa je bilo postavljenih še nekaj drugih obratov za predelavo hrane, hala za izdelavo sodov in drugih mizarskih izdelkov, skladiščne hale ter hiša za osebje in hlev. Vse skupaj je tvorilo funkcionalno zasnovano celoto. Marchetti je racionalno zasnovo tovarniškega kompleksa omilil s tradicionalnimi elementi klasicizma, vidnimi na fasadi (pročelju) tovarne (poudarjenost polj, ritmičnost stavbnih odprtin). Bogat finančni status tovarne se je kazal tudi z opečnatimi dimniki (Tomšič 2002, 138). Konec 19. stoletja sta tovarni Ampelea in Arrigoni skupaj zaposlovali 760 delavk, malo več kot 200 ribičev in 26 pomorščakov, ki so se ukvarjali s prevozom izdelkov (Kramar 1987, 309).

Leta 1892 je tovarno prevzela anglo-avstrijska banka s sedežem v Trstu. Francoska delniška družba je tako dobila novega lastnika in tudi novo ime - Usines de l'Ancienne Société Générale Française de Conserves Alimentairies. Starega imena tovarne novi lastniki niso bistveno spreminjali, v strahu pred izgubo odjemalcev po celem svetu. Dodali so mu zgolj Usine de l'Ancienne, kar $\mathrm{v}$ prevodu pomeni stare tovarne (Volpi Lisjak 200I, 137). Tovarna je razširila svojo proizvodnjo konzerviranja hrane še na sadje (slive), zelenjavo (grah, fižol, paradižnik) in goveje meso (Kramar I987, 309). Za namene širitve proizvodnje so bili postavljeni še klavnica in hlevi, tovarna pa je dobila tudi svojo t.i. lokomobilo. Doživela je nov razcvet. Postala je glavni dobavitelj hrane za avstroogrsko vojsko, svoj izvozni trg pa je razširila tudi v Rusijo, v Ameriko ter na Bližnji Vzhod (Tomšič 2002, 138).

\footnotetext{
In leta 1915 so se vse te aktivnosti pravzaprav skoraj ugasnile, zaradi tega, ker je v teh krajih divjala prva svetovna vojna. Prva svetovna vojna je prinesla strahovite spremembe $v$ te kraje. Namreč, že to dejstvo, da je bila tu v bližini vojna, je pomenilo, da so ljudje pač trpeli lakoto in družba je postala neorganizirana ravno zaradi tega, ker se med vojno pač ne da normalno funkcionirat. In po prvi svetovni vojni je bil ta teritorij priključen kraljevini Italiji. /.../ je prišlo do zamenjave kapitala. Avstrijci so svoje premoženje prodali
}

\section{novim gospodarjem, ti novi gospodarji pa so postali ... v primeru/prej/francoske tovar- ne je to postala pač družba, ki se je imeno- vala Società Conservifici in ta družba je tovar- ni dala ime Ampelea. (Intervju s Srečkom Gombačem, arhiv društva Histrion)}

Med leti 1918 in 1920 je tovarna, zaradi posledic prve svetovne vojne, prekinila s svojim delovanjem (Volpi Lisjak 200I, 138). Leta I920 jo je, poleg še nekaj drugih izolskih tovarn, nato prevzelo tržaško podjetje Conservifici S.A. (Tomšič 2002, 139). Italijanski prevzem industrijskih obratov je bila posledica leta 1920 sklenjene Rapalske pogodbe med Kraljevino Italijo in Kraljevino Srbov, Hrvatov in Slovencev, po kateri je bila končno določena nova meja med državama. Slovensko Primorje, del Dolenjske in del Notranjske so po novem postali del italijanskega državnega ozemlja.

Konec dvajsetih let dvajsetega stoletja je arhitekt Romitta zasnoval nove vhodne stavbe, ki stoji še danes, ter poslovnih objektov za in ob njej. Stavba je bila zasnovana v klasicističnem stilu (dvoetažni vhodni atrij z dvignjenim fasadnim timpanonom in simetričnima stavbnima kriloma) z oblikovnimi elementi italijanskega modernističnega gibanja (širok polkrožni vhodni portal, zvišana polkrožna vhoda ob strani glavnega vhoda). Leta 1930 je tovarna ponovno dobila novo ime - tovarna Ampelea S. A. Conservifici. $\mathrm{V}$ naslednjih letih je prišlo do modernizacije in adaptacije starih objektov ter gradnje novih. Poseben tehniški dosežek predstavlja šestnajst metrsko strešno predalčje, ki zaključuje skladišče (Tomšič 2002, 139).

$\mathrm{V}$ medvojnem obdobju je začela Ampelea tudi s pridelavo ribje moke in ribjega olja, marmelade, paradižnikov mezge, ter konzerviranjem zelenjave, slanih filetov inčunov ter raznih paštet. Tik pred začetkom druge svetovne vojne je tovarna zaposlovala kar I200 delavcev, po večini žensk iz zaledja Izole, proizvedla pa je kar I 4 milijonov konzerv na leto (Volpi Lisjak 200I, 139):

Z jugoslovanskim prevzemom oblasti $\mathrm{v}$ Slovenskem primorju maja leta 1945 se je obra- 
Evakuacija je obsegala: a) $50 \%$ vseh strojev za izdelavo pločevinaste embalaže $\mathrm{z}$ vsem pripadajoči orodjem, transmisijami, električnimi motorji itd., b) $50 \%$ ali več surovin, c) celotno ribiško floto, č) celotne hladilnice, d) ostale stvari, ki bi lahko konkurirale jugoslovanski konzervni industriji (Kramar 1992, 176-178).

Zaradi odvzete flote je začela tovarna delovati v svoji okrnjeni obliki, svoje surovine pa pridobivati s strani zasebnih ribičev ali ribolovnih podjetij, izolskega podjetja Riba in piranskega Ribiča. Istega leta je bila tovarna tudi preimenovana v tovarno Ex-Ampelea. Devet let kasneje, leta 1956 , pa je tovarna ponovno dobila novo ime - Iris (Terčon 1989, I23-I25).

Tri leta kasneje, leta 1959 so ustanovili Kombinat konzervne industrije Delamaris (KKID), v katerem so se zaradi lažje organizacije proizvodnje in prodaje izdelkov združili Iris, Argo, Ikra in leta 1952 ustanovljeno podjetje Delamaris export-import. Proizvodnja tovarne Iris (Ampelea) se je takrat dokončno usmerila $\mathrm{v}$ predelavo in konzerviranje rib (Terčon 2013, 124).

Ime Delamaris je nastalo kot zloženka delov imen nekdanjih treh velikih tovarn na današnjem slovenskem obmorskem prostoru: DEL po tovarni De Langlade iz Kopra, AM po tovarni Ampelea, AR po tovarni Arrigoni in IS po mestu Izola (Isola), vedo povedati delavke, ki so v času združevanja delale $\mathrm{v}$ omenjenih tovarnah. Simbolizirale so ga poleg značilnega logotipa napisa še tri ribice. Danes novi logotip Delamarisa ponovno uporablja ribico, tokrat le eno samo.

Tovarna je konec osemdesetih let dvajsetega stoletja s procesom modernizacije in izgradnje novih objektov izgubila osrednjo stavbo in skladišče iz leta I888. Kljub predelavi pa je tovarniški kompleks ohranil svoje pomembnejše arhitekturne značilnosti (na primer vhodna stavba) (Tomšič 2002, I 40).

Leta 1992 se je (po številnih delitvah, združitvah in prestrukturiranjih, do katerih je prišlo zaradi reforme o samoupravljanju sredi sedemdesetih let) oblikoval Holding Delamaris, ki je združeval podjetja Delsar, Riba, Delmar, Lera in Frigomar. Tovarna in vsa podjetja, povezana $z$ njo, so dobila tudi svoje, še danes dobro poznano ime Delamaris (Volpi Lisjak 200I, I39).

\section{Tovarna Delise}

Zapisi iz leta 1925 že govorijo o vzpostavljeni tovarni Delise v Izoli, ki je delovala na območju vzhodnega zaliva mesta Izole. Točne letnice začetka delovanja ne poznamo (Kramar 1987, 423). Postavljena je bila malo pred tovarno Ampelea na današnji Zustovičevi ulici. Kot nam je znano iz zapisov, jo je vzpostavil Italijan Nicolo Delise (Terčon 1989, I25). Po obsegu je šlo za majhen tovarniški obrat, saj je $\mathrm{z}$ devetimi zaposlenimi delavci proizvedla zgolj $13.000 \mathrm{~kg}$ različnih konzerv na leto (Kramar, prav tam). Za primerjavo lahko vzamemo tovarno Ampelea, ki je v enem letu proizvajala ioos ton konzerv (Kramar 1987, 424).

\section{Tovarna Noerdlinger}

Tovarna Noerdlinger je bila postavljena leta I884, prav tako na območju vzhodnega zaliva mesta Izola, malo naprej od tovarne Ampelea, blizu križišča današnje Ulice Svetega Petra in Ulice ob pečini oziroma $v$ bližini porušene cerkvice Svetega Petra. Tovarno je ustanovila tržaška delniška družba Ditta $B$. Noerdlinger e fratello da Trisete, ki sta jo vodila brata Noerdlinger, njena dejavnost pa je bila usmerjena $\mathrm{v}$ konzerviranje sliv. Leta 1888 je tovarna povečala tovarniške prostore, vendar ni znano za koliko. Leta I9I2 je tovarna zaposlovala 86 delavcev (Kramar 1987 , 309-310).

Leta 1920 je bila med kraljevino Italijo in kraljevino Jugoslavijo podpisana Rapalska pogodba, po kateri je slovenski del Primorja pripadal Italiji. Največje industrijske obrate v Izoli prevzela italijanska družba S. A. Conservifici. Novi lastnik je poleg tovarne Noerdlinger prevzel še tovarni Degrassi in Torrigiani, ki jih je priključil ali tovarni Ampelea ali Arrigoni, odvisno kako blizu je bila manjša tovarna eni ali drugi lokaciji obeh večjih tovarn (Volpi Lisjak 2001, 138; Terčon 1989, 123-135). 


\section{Tovarna Degrassi - Torrigiani}

\section{- Podjetje Riba}

Tovarno Degrassi je leta I882 postavil Giovanni Degrassi na območju zahodnega zaliva mesta Izole, med tovarno Arrigoni in kasnejšim podjetjem Riba (Terčon 2013, I25). Danes nedaleč stran stoji Izolanom dobro poznani bar Moby Dick, ali nova hiša pic - Cassa della Pizza. Proizvodni proces tovarne Degrassi je bil manjšega obsega in je leta 1912 zaposloval le 68 delavcev, večinoma žensk. Usmerjena je bila v konzerviranje male » plave « ribe in graha (Kramar 1987, 309310). Do sredine dvajsetih letih prejšnjega stoletja je bila tovarna preimenovana $v$ tovarno Torrigiani in je bila tako kot še nekaj drugih priključena tovarniškemu obratu Arrigoni (Kramar 1987, 423; Volpi Lisjak 200I, I38).

Prostore tovarne Torrigiani je v času po drugi svetovni vojni prevzelo na novo vzpostavljeno podjetje Riba d.d., ki se je ukvarjalo z ribolovom. Novo podjetje je nastalo v kritičnem povojnem obdobju, ko sta tovarni Arrigoni in Ampelea izgubili svoji ribiški floti, posledično pa tudi dostop do vira surovin za svoje konzerve. Podjetje je večkrat spremenilo tudi svoje ime. Med leti 1948 in 1954 je delovalo pod imenom $\gg$ RIBA - Tržaška ribarska družba in trgovina z ribami d.d.《. Leta 1954 je bila preimenovana $\mathrm{v} \gg$ RIBA Izola $\ll$ in ohranila je svoje ime do leta 1962, ko je začela poslovati v sklopu KKID (Kombinat konzervne industrije Delamaris) in DO DROGA (Terčon 1989, 125).

\section{Tovarna Arrigoni}

Tovarna je nastala leta I88I v zahodnem delu zaliva, v predelu Sv. Lovrenca. Postavil jo je dunajski podjetnik Carel Warchanek (Tomšič 2002, I3I). Tekom osemdesetih letih I9. stoletja so začeli poleg male plave ribe predelovati gnoj iz ribjih odpadkov ter bosanske slive $\mathrm{v}$ marmelado (Terčon 2013, I2I).

Svojo osnovno prostorsko zasnovo je tovarna dobila leta $1888 \mathrm{z}$ oblikovno enotnimi načrti arhitekta in inženirja Eugenia Marchettija, ki je snoval tudi tovarniški kompleks Ampeleje (glejte zgoraj, poglavje 2). Zasnova je temeljila

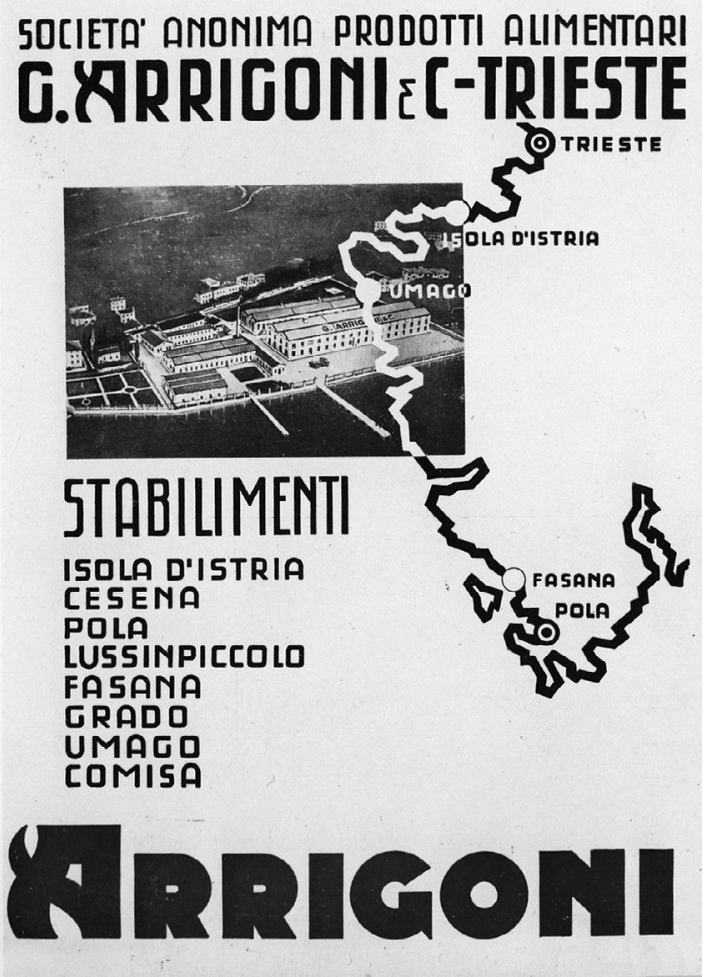

Slika 4: Tovarna Arrigoni v pred drugo svetovno vojno in njene široke gospodarske povezave od Trsta do Pule (Vir: Arhiv društva Histrion)

na treh podolgovatih halah, ki so bile namenjene osebju, proizvodnji, delavnicam in skladiščenju. Kompleks je predstavljal racionalno industrijsko arhitekturo z oblikovnimi prvinami klasicističnega stila. $\mathrm{Na}$ mestu stare tovarniške zgradbe iz leta I88I je bila postavljena nova osrednja podolgovata proizvodnja hala, krita s korci (Tomšič 2002, I3I-I32).

Leta 1912 je tovarna zaposlovala 200 delavcev (Kramar 1987, 310). Prva svetovna vojna je sicer močno prizadela delovanje tovarne, vsekakor pa so dvajseta leta dvajsetega stoletja zanjo pomenila popoln preobrat. Pod vodstvom tržaškega podjetja Società Anonima Prodotti Alimentari G. Arrigoni \& CO. in G. Sanguinettija je tovarna doživela pospešen razvoj in je postala največja tovarna v Istri. 
Leta 1925 je tovarna dobila svoje bolj poznano ime Arrigoni (Terčon 1989, I23-135). Svojo proizvodnjo so razširili na proizvajanje jušnih kock in antipaste (Kramar 1987, 423). V času dvajsetih let dvajsetega stoletja je tovarna dobila tudi svojo električno napeljavo, agregat in vodovodno napeljavo (Tomšič 2002, 132).

Novo vodstvo tovarne je prineslo snovanje nove proizvodna hale - osrednje arhitekture tovarniškega kompleksa. Tržaška projektanta B. Luignani in P. Bencian sta pri snovanju uporabljala takrat sodobne trende projektiranja, ki se kažejo skozi organizacijo prostorov in tehnologijo konstrukcije (dvoetažna železobetonska konstrukcija, stoječa na stebrih). Pri snovanju so prav tako opazni vplivi klasicistične tradicije (kompozicija in oblikovanje detajlov). Nova tovarna je bila odprta leta 1927 , na njeno otvoritev pa je prišel celo podpredsednik Italije (Tomšič 2002, I32):

$$
\begin{aligned}
& \text { Na drugi strani, tam kjer je bla pa tovarna, } \\
& \text { ki jo je postavu Warchanek, je pa nov last- } \\
& \text { nik biu italijanski državljan, ki mu je blo } \\
& \text { ime Sanguineti. Sanguineti je biu pa last- } \\
& \text { nik blagovne znamke Arrigoni. Arrigoni je } \\
& \text { stara blagovna znamka še iz sredine ig. sto- } \\
& \text { letja, ukvarjali pa so se predvsem z mesom. } \\
& \text { Oni so imel sedeže v Genovi in so uvažal } \\
& \text { meso iz Avstralije in ga potem distribuiral na } \\
& \text { italijanskem trgu. No in očitno je ta gospod } \\
& \text { Sanguineti videl nekako en razvojni poten- } \\
& \text { cial tudi v tem, da proizvaja ribje konzerve } \\
& \text { in je v ta namen potem pač v Izoli izjemno } \\
& \text { povečal tovarniške zmogljivosti. Tako da je } \\
& \text { ta tovarna konec } 20 \text {-ih let začela z novim el- } \\
& \text { anom in v bistveno večjem obsegu proiz- } \\
& \text { vajat kot je to pač počela prej.« (Intervju s } \\
& \text { Srečkom Gombačem, arhiv društva Histri- } \\
& \text { on) }
\end{aligned}
$$

Trideseta leta dvajsetega stoletja so prinesla reprezentančno urejanje kompleksa. Novozgrajeni tovarniški menzi ob cesti je sledila ureditev in gradnja reprezentančne ulične fasade $\mathrm{z}$ vhodnimi poslovnimi prostori, tj. gradnja dominantnega vhoda $\mathrm{z}$ upravnimi prostori, ki jo lahko opazujemo še danes. Leta 1936 je Luciano Marsico (Edilizia, Strade, Cementi) zasnoval levi trakt, temu pa je leta 1938 sledilo še snovanje desnega trakta pod vodstvom Dott. Ing. Rodolfa Coppe (Studio d'ingegneria civile, Impresa di construzione Trieste) (Tomšič 2002, 132). Enoten videz vhoda sestavljata dva polkrožno zaključena zrcalno postavljena traktata $\mathrm{z}$ ravno streho, ki se zaključi z dvignjeno odprto teraso in sklenjeno polkrožno betonsko konstrukcijo. Trakta spoštujeta ulično linijo, ob njima pa se prostor odpira v širok vhodni porton. Razgibana površina fasade dvoetažnih vhodnih objektov odseva notranjo funkcijo in ustroj prostorov. Višino stavbe še posebej poudarjajo visoki okenski in vratni segmenti. Okna etažnega dela so nižja kot okna zgornjih poslovnih prostorov. Zasnova predstavlja hkrati umirjeno in razgibano celoto, ki spaja funkcionalistično snovanje z umetniško rešitvijo. Vhodni arhitekturni objekt predstavlja prelom od tedaj aktualne režimske fašistične in italijanske nacionalistične arhitekture.

Štirideseta leta dvajsetega stoletja so prinesla izgradnjo polkrožne kurilnice $z$ optičnim videzom sakralnega objekta, šestdeset metrov visokega tovarniškega dimnika in pritlično skladišče za les z nazobčano strešno strukturo. Kurilnica optično spominja na sakralni objekt, v njej pa še leta 2002 stal originalni kurilni kotel iz konca tridesetih let. Dimnik je še danes jasen akcent izolske krajine, ki simbolizira gospodarski uspeh tovarne svoje dobe (Tomšič 2002, 133).

Konec druge svetovne vojne je prinesel menjavo oblasti in politično nestabilnost. Izola je kot del svobodnega tržaškega ozemlja spadala pod jugoslovansko cono B. Evakuacija strojev za izdelavo pločevinaste embalaže, orodja, večjega dela surovin, hladilnic, ribiške flote in ostalih premičnin leta 1947 so spremljale tudi kaotične razmere $\mathrm{v}$ delovanju tovarne. Ukinjen nadzor na vratih, konec zaklepanja skladišč in splošno pomanjkanje sta pomenila pogosto odnašanje kakšne konzerve ali nekaj rib s strani zaposlenih. Poleg tega je bil v veliki meri opuščen tudi računovodski nadzor, zaradi česar je tovarna poslova- 


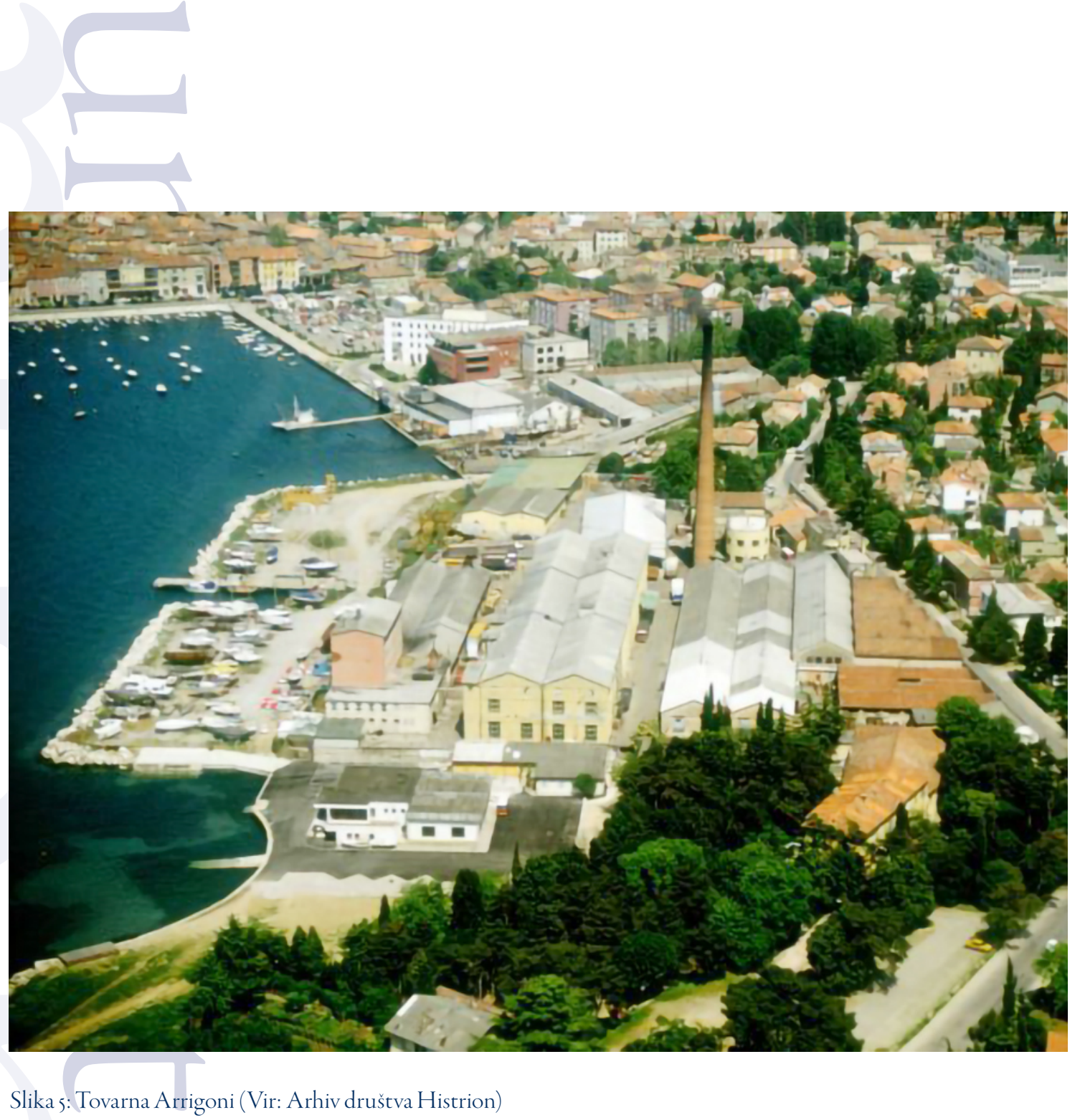

la neprofitabilno in $\mathrm{z}$ večletnim finančnim deficitom (Kramar 1992, 178).

Petdeseta leta so prinesla nove spremembe. Leta 1954 je bil z Italijo podpisan Londonski memorandum in cona B je dokončno pripadala socialistični Jugoslaviji. V istem letu je tovarna Arrigoni zaposlovala 547 delavcev (Terčon 2013, I25). Svoje, še danes v spominu zelo živo ime, je dobila leta 1958 , ko je bila preimenovana $v$ tovarno Argo. Proizvodnja je bila še vedno usmerjena $\mathrm{v}$ predelavo sveže in slane ribe, zelenjave ter izdelovanje paradižnikove mezge in jušnih kock (Terčon 1989, 130).

Proti koncu petdesetih let dvajsetega stoletja, leta 1959, je bil ustanovljen Kombinat konzervne industrije Delamaris (KKID), v ka-

terem so se zaradi lažje organizacije proizvodnje in prodaje izdelkov združila podjetje Iris (kasnejši Delamaris), Argo, Ikra in Delamaris export-import. Argo je v sedemdesetih letih opustil predelavo rib in se preusmeril $\mathrm{v}$ predelavo in izdelavo ostalih živil (Volpi Lisjak 200I, I24). Argo je sčasoma postala blagovna znamka tovarne Droga. Konec sedemdesetih let dvajsetega stoletja je namreč tovarna prešla pod Drogo Portorož. V procesu tranzicije pa so prav to blagovno znamko prodali.

Kombinat je zaposloval 1285 delavcev, od tega je bilo 848 žensk (Egić 2016). Osemdeseta leta dvajsetega stoletja je skladno s politično nestabilnostjo in tranzicijo Slovenije iz socialističnega $\mathrm{v}$ demokratično-kapitalističen sistem 

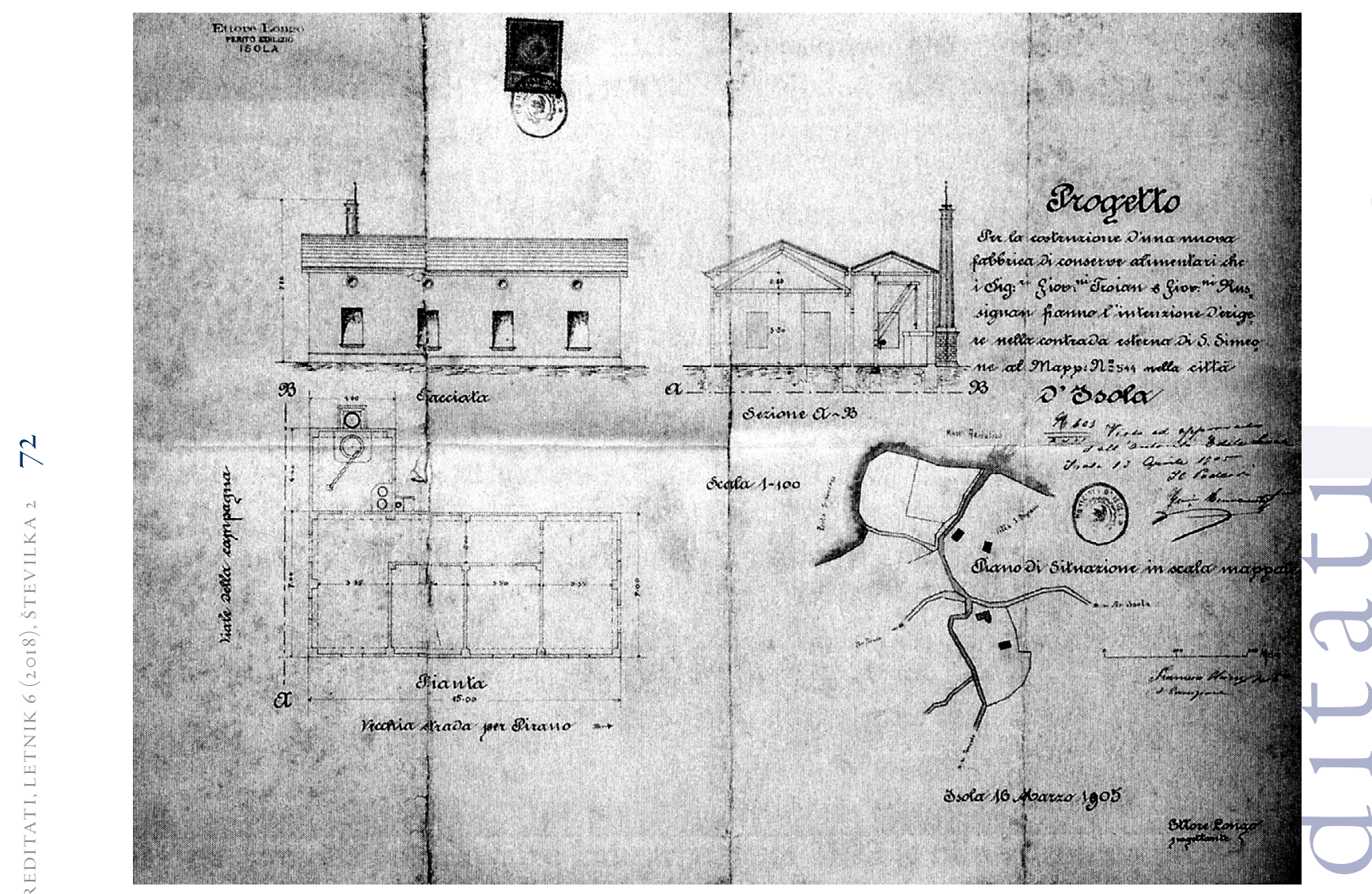

prišlo v Izoli do zatona ribje predelovalne industrije. Izguba skupnega jugoslovanskega trga, močna konkurenca trga zahodnih držav, zastarelost tehnologije, neučinkovito vodenje, večletni finančni deficit, ipd., so konec osemdesetih let dvajsetega stoletja pomenila konec obratovanja tovarne Arrigoni (Egić 2016). Danes nas na nekdanji prestiž tovarne opominjajo zgolj pripovedi iz spomina ter arhitekturni ostanki.

\section{Tovarna Troian}

Tovarna Troian je delovala med leti I88I in I9II pod imenom Giovanni Troian e Giovanni Russignani, skrajšano Troian \& CO (Terčon 1989 , I25; Terčon 2013, I2I). Leta 1920 je tovarno prevzela S. A. Conservifici in jo priključila $\mathrm{k}$ tovarni Arrigoni (Volpi Lisjak 200I, I38). Postavljena je bila v zahodnem zalivu mesta Izole pri San Simonu.

\section{Sklep}

Z oblikovanjem poti po lokacijah nekdanjih tovarn ribjih od vzhodnega do zahodnega dela Izole smo želeli prispevati $\mathrm{k}$ turistični ponudbi, ki ohranja kulturno dediščino, povezano $s$ prehrambno industrijo ribjih konzerv. Ribja predelovalna industrija je na severnem delu Jadranskega morja predstavljala velik delež $\mathrm{v}$ zaposlovanju ljudi, krojila je podobo kraja in $\mathrm{v}$ času Avstro-Ogrske je preskrbovala habsburški imperij $s$ »plavo « ribo, vse do Dunaja, Budimpešte, Prage in drugih velikih mest. Izolske tovarne so predstavljale del velikih proizvodnih verig in so skupaj še z nekaterimi drugimi tovar- 
nami v Istri predstavljale pomembne blagovne znamke. Prispevek opisuje zgodovino najpomembnejših tovarn ribjih konzerv, ki so še dokaj uspešno delovale tudi v času SFR Jugoslavije. Prikaže razvoj šestih tovarn, njihovo arhitekturno zasnovo, predstavi proizvodnje artikle in prikaže nekatere pomembne blagovne znamke. Tovarna Ampelea, pozneje Delamaris, je bilo eno najbolj uspešnih podjetij današnjega slovenskega Primorja, ki je od svojega začetka delovanja, postavljenega v leto 1879 in vse do selitve v Pivko, krojila življenjski ritem Izolanov in podobo vzhodnega dela mesta Izole. Danes na zlato obdobje te tovarne opozarja prazna propadajoča stavba $\mathrm{z}$ značilnim prenovljenim logotipom na tabli, ki stoji pri vhodu v dvorišče.

Tovarno Delise, ki se je nahajala v bližini Delamarisa, umeščamo med najkasneje postavljene obrate za predelavo hrane v Izoli, kot tudi med najmanjše. Postavljena je bila v dvajsetih letih prejšnjega stoletja in zaposlovala je zgolj devet delavcev. Delovala je krajši čas in je razmeroma slabo ohranjena v ustnem izročilu Izolanov, več pa o njej vedo lokalni ljubiteljski raziskovalci.

Tretjo največjo tovarno, tovarno Noerdlinger, ki je z malo manj kot devetdesetimi zaposlenimi predelovala bosanske slive $\mathrm{v}$ marmelado, sta postavila brata Noerdlinger na območju vzhodnega zaliva leta I884. Danes o njeni lokaciji pripovedujejo pretežno ljubitelji tehnične oziroma industrijske dediščine.

Tovarna Degrassi, kasneje Torrigiani, je predstavljala enega manjših obratov konzerviranja hrane v Izoli. Ustanovljena leta 1882 je tekom let zaposlovala manj kot sedemdeset oseb. Pozneje na tej lokaciji deluje podjetje Riba. Še danes se na tem mestu nahajajo stavbe in nekdanji škver, priročna ladjedelnica za vzdrževanje nekdaj številnega ribiškega ladjevja.

Prvi spomin na nekdanjo tovarno Arrigoni, poznejšo tovarno Droga, je zagotovo znana blagovna znamka »Argo juha«, poznejše generacije pa preverjeno poznajo paštete, ki so še danes spet $\mathrm{v}$ preoblikovani podobi znane kot paštete Argeta, na dobri strani kruha. Na nekdaj veličastno tovarno Arrigoni, spominjajo ruševine z dimnikom, ki po mnenju nekaterih kvarijo podobo marine, po mnenju drugih pa pričajo o velikem pomenu tega nekdanjega obrata.

O tovarni Troian ni veliko zapisanega. Postavljena je bila leta i88I nekje na območju San Simona - Simonovega zaliva, po prvi svetovni vojni pa je bila tudi ta proizvodnja priključena $\mathrm{k}$ tovarni Arrigoni. Lokacija tovarne ni natančno znana, ve pa se, da je stala $v$ omenjenem zalivu. Ker večina še obstoječih stavb nekdanjih industrijskih obratov neslavno propada in vzbuja pri obiskovalcih bodisi zgražanje bodisi radovednost, smo se odločili, da z oblikovano potjo tovarn poskušamo doseči, da se nekdanji družbeni spomin ohranja kot dediščina in da sloves nekdanjega ribiškega mesta iztrgamo pozabi.

\section{Summary}

The trail of factories is a short, almost three kilometres long tourist route which seeks to preserve the memory of fish canning factories and the food processing industry, the once leading industry in Izola, formerly known as a fishermen's and workers' town. A keen observer can discern the factory buildings set in the coastal landscape on the former outskirts of Izola, where the coastal strip is lined with now abandoned spacious halls, or more or less poorly preserved buildings or plain ruins. The memory of the factories in their operating days is kept in both the coastal landscape and Izolans' narratives. The purpose of this article is to present the reader with the Trail of Factories or the story written by the economic activity of the fish processing industry in the seaside town, which began in the last quarter of the nineteenth century and continues to the present day. The trail talks about the history that persists in the memory of the local inhabitants as well as lives on and represents the past operations of Izola's six factories lining the bay from the western to the eastern part of the town. The two extremes of the described route coincide with the processing of forage fish, which used to be Izola's primary economic activity. Strategically set on the shoreline, the factories' locations allowed for a speedy processing of the catch. For transport, fishing vessels and sea waterways were mainly used. From the architectural point of view, the 
three major factories, Ampelea (Delamaris), Arrigoni (Argo or Droga) and Degrassi (later Riba), are situated outside the old town and are still visible in Izolas zoning plan. Well located, the abandoned factory buildings are now interesting for capital investment and have been the object of successive resales due to a failed transition and misuse of former collective property. The article was written within the framework of the Student Innovation Project for Social Benefit (ŠIPK) - Fish on the Way, Fish Showing the Way: The Heritage of Fisheries and the Processing Industry with an Emphasis on Izola, which was carried out from March to June 2018. The aim of the project was to teach strollers enjoying Slovenian coastal landscapes about the cultural heritage associated with the fish processing industry and fisheries. By creating trails along the locations of the former fish canning factories from the eastern to the western part of Izola, actors wanted to contribute to the tourist offer, which preserves the cultural heritage associated with fisheries and the fish processing industry. In the northern part of the Adriatic Sea, the latter represented the main employer in the area; moreover, it shaped the image of the place and, during the Austro-Hungarian period, supplied the Habsburg Empire with forage fish all the way to Vienna, Budapest, Prague and other major cities. Izola's factories were part of large production chains and, together with some other factories in Istria, represented important brands. The article describes the history of the most important food processing industries and fish canning factories that, while still quite successful in the SFR Yugoslavia, were mostly blighted following Slovenia's independence and its transition to neoliberal capitalism. The article presents the development of six town factories, their architectural frame, production lines, and some important brands. One of the most successful companies of today's Slovenian Primorje, the Ampelea factory (later Delamaris) shaped the life of Izolans and formed the image of the eastern part of the town since 1879 , when the factory commenced its operations, and until it moved to Pivka. The golden period of the factory is evoked by abandoned and decomposing buildings with a distinctive renewed logo on the board standing at the entrance to the yard. The other factory, Delise, was opened in 1920, in the immediate vicinity of the first one. It is known as one of the smallest as it employed only nine workers and operat- ed for a short time. While the memory and oral history of the factory are not well kept among the local population, this gap is bridged by amateur researchers. The third largest factory, the Noerdlinger plant, where Bosnian plums were made into jam by less than ninety employees, was set up by the Noerdlinger brothers in the eastern section of the bay in 1884 . Today, this factory and its location are kept in oral histories of amateur researchers interested in technical or industrial heritage. Another in the series of minor food processing plants in Izola was the Degrassi (later Torrigiani) plant. Established in I882, it employed less than seventy persons over the years. Later on, the building complex housed the Riba company, known primarily for its fishing fleet. Even today, there are buildings and a former škver, a convenient shipyard, where the once-substantial fishing fleet was maintained. The first memory of the former Arrigoni (later Droga) factory is certainly the famous brand of "Argo soup", while the subsequent generations are more familiar with its pates, which are today revived as Argeta pate, with the slogan On the good side of bread.

What remains of the Arrigoni factory is its dilapidated buildings and a chimney, which, according to some, spoil the image of the marina and, according to others, testify to the great importance of this once magnificent plant. Little is written about the Troian factory as well. It was set up in 188I somewhere in the San Simon area and incorporated into the Arrigoni factory after World War I. Troian's location is not well known, but it is believed to have stood in the San Simon bay. Most of the existing buildings of former industrial plants are collapsing, triggering excitement of visitors, whether the ruins are seen as scandalous or feed the curiosity of walkers. Due to this fact, the authors of the project decided to transmit the former social memory as a legacy or cultural heritage, in the belief that the reputation of the former fishing town should not be consigned to oblivion.

\section{Viri in literatura}

Kramar, J. 1987. Izola: mesto ribičev in delavcev. Koper: Založba Lipa.

Kramar, J. 1992. »Ribja industrija v Izoli v letih od 1945-1954《. Annales no. 2: 175-182.

Egić, G. 2016. Ribja predelovalna industrija v Izoli. Diplomsko delo. Ljubljana: Univerza v Ljubljani - Filozofska fakulteta, Oddelek 
za zgodovino, http://zgodovina.si/ribjapredelovalna-industrija-v-izoli-4-delobdobje-po-drugi-svetovni-vojni/.

Terčon, N. 1989. »Razvoj industrijskega ribištva na slovenski obali v letih 1945-1959《, Kronika časopis za slovensko krajevno zgodovino 37 (I/2): I23-I35, https://www.dlib.si/details/ URN:NBN:SI:DOC-Q०OQIO॰G/?euapi $=\mathrm{I} \&$ quer $\mathrm{y}=27 \mathrm{keyword} \% 3 \mathrm{dnadja}+$ ter $\% \mathrm{C}_{4}$ $\% 8$ Don\%27\&pageSize $=25$.

Terčon, N. 2013. Vzpostavitev slovenskega pomorstva 1945-1958. Doktorska disertacija. Koper: Univerza na Primorskem, Fakulteta za humanistične študije.

Tomšič, D. 2002. »10235 Izola: Tovarna Droga«. V: Zgodnja industrijska arbitektura na Slovenskem : vodnik po arhitekturi, urednica Damjana Prešeren, I3I-I36. Ljubljana: Zavod za varstvo kulturne dediščine.

Volpi Lisjak, B. 200ı. »Ženska delovna sila v ribjih tovarnah v Izoli in Kopru. Konzerviranje in soljenje rib, $\ll$ Annales, Series Historia et Sociologia II (24): 135-I50, https://www.dlib.si/details/ URN:NBN:SI:DOC-MDBSIXVP/?euapi= $\mathrm{I} \&$ query=\%27keywords\%3dvolpi+lisjak\%2c +bruno\%27\&pageSize.

Intervju s Srečkom Gombačem ( $\mathrm{z}$ antropologinjo Alenko Janko Spreizer). Intervju. $\mathrm{MP}_{4}$ datoteka. Arhiv društva Histrion (25. 02. 2015). 
-

r

$\downarrow$

G

1

-

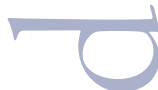

( )

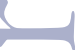

(U)

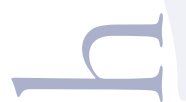




\title{
Why style matters? \\ Some noises and barriers for textual information processing
}

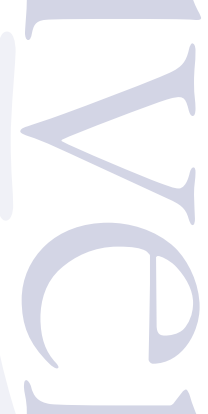

\author{
Helena Vičič, Red Tree Heritage
}

Veliko besed je bilo povedanih o uporabi besedil pri predstavitvah dediščine, zlasti za panoje in nalepke na muzejskih razstavah. Ugotovljeno je bilo, da akademski jezik ni primeren za posredovanje informacij obiskovalcem, zlasti kadar sta ciljni skupini otroci in družine. Poleg tega, ko gre za besedila na panelih in nalepkah, imajo vse ciljne skupine koristi od interpretativnega pristopa. Prispevek bo poskušal preučiti nekatere »šume (v vsakem smislu), ki lahko odvrnejo obiskovalca od branja in nekatere ovire, ki onemogočajo uspešno obdelavo informacij, in tako zmanjšujejo zanimanje za pisano besedo.

Ključne besede: interpretacija, interpretativna besedila, dediščinske lokacije, psihologija obiskovalcev, vedenje obiskovalcev.

Many words have been exchanged on behalf of the use of texts in heritage settings, especially for panels and labels in museum exhibitions. It has been acknowledged that academic language is not appropriate way to communicate information to the visitors, especially when children and families are targeted. Moreover, when it comes to the text on panels and labels, all target groups benefit from the interpretive approach. This paper will try to examine some 'noises' (in every kind of sense) that can distract a visitor from reading and some barriers that disable successful information processing and thus impairs an interest in a written word.

Keywords: interpretation, interpretive text, heritage sites, psychology of visitors, visitors' behaviour

W e often think that our visitors pay much more attention to the text itself, as they actually do. The comparison between the amount of work and money that is invested in the textual media and how little they are attended, is often disappointing.

Although the concept of accessibility understands barriers more in a physical sense, which is a very welcome and important step towards the inclusive society, we rarely think of our texts as inaccessible in intellectual sense. Leisure activities, that a visit to a heritage site often is, create different circumstances and are practiced by people with the aim to satisfy specific needs. It is our duty to understand our audiences and their processes while hosting them in our premises.

\section{To read or not to read?}

Many researches indicate, that the majority of people do not come to heritage sites primarily to learn. Socialising and group bonding usually appears on the top of the list of reasons, followed by relaxation, experiencing new things and only then gaining new information (Fáilte Ireland 2009, 16). The question is how this influences their mental abilities for reading and what text should interpretation provide in order for it to be attended. Many researchers encourage in- 
terpreters to devise means that contribute to the social exchange between visitors (Simon 20I0).

In average people spend less than Io seconds at one sign and read only about $10 \%$ of exhibits (Caputo, Brochu and Lewis 2008, 6). Whatever media visitors encounter, they subconsciously calculate whether is it worth attending or not. This cost-benefit calculation is called Fraction of selection. Namely, if the degree of effort that one invests into the reading, appears higher than the reward expected, they mainly choose not to attend (Zimmerman, Gross and Buchholz 2008, 24). This decision is taken very quickly, based on the Drawing power of a medium (Sandifer 2003). As a visitor first encounters a medium, creates an overall impression from the distance. If a medium possesses the so called Attraction power, a visitor approaches closer and quickly examines the medium in a couple of seconds. Usually such medium must be visually attractive. When a visitor starts reading, at first only scanning the text, but sometimes also reading in more detail, then such medium possesses a Holding power. When a visitor, instructed by the text, is looking around the place for original phenomena that were described or tasks to which the text invited, such medium has an Engagement power.

However, considering that people visiting heritage sites are interested in the heritage, why is the attendance to panels and labels so low? Why they so often conclude that the reward is not worth an effort? Moreover, the research also show that the majority of visitors to the heritage site is traditionally well educated and work in managerial and professional positions (Booth et al. 2017). Why then the reading presents such a challenge?

\section{Our brain is a busy place}

Every presentation intended to public shall be planned in respect to human cognition. Working memory capacities and limitations play an important part in individual's information processing, understanding and learning. Many theories argue about different bottlenecks in our brain, which permit through only certain senso- ry inputs (Baddeley 2007; Broadbent 1958; Paivio 1990). When processing two or more tasks of the same type, one or another will likely get attenuated or impaired. Text is verbal information, which is processed in the Phonological loop (Baddeley 2007), a brain centre in charge of reading, listening, talking or recalling stored verbal information from the memory. According to Dual-Coding Theory (Paivio 1990) dealing with two or more tasks of the same modality, in our case verbal information, cause a bottleneck effect. Knowing this, one can realise how difficult task is reading, while the Phonological loop is also dealing for example with listening to a distant audio track or to other people in the room or when our brain is dealing with many other thoughts.

In Cognitive Load Theory (Sweller 20II) three types of load are recognised: intrinsic cognitive load, which is intrinsic to the nature of the task (e.g. difficulty of concepts presented, vocabulary level, terminology, genre, etc.); extraneous cognitive load, which is posed by the manner of presentation (like amount and distribution of text, design, fonts, etc.) and germane cognitive load, which depends on the individual's cognitive processes, based on the pre-existing schemas and knowledge and working memory capacities.

While interpreters have no immediate influence on the last category of cognitive load, much can be done for the reduction of intrinsic cognitive load. Especially if we expect audiences, that possess little if any knowledge about the subject matter, a narrative text, which describes events and relations in a causal or thematic chain (Wolfe and Mienko 2007), would increase learning. For more knowledgeable individuals might be offered additional expository text (Wolfe and Mienko 2007), which describes structures and processes. Other general guidelines recommend using a simple, emotive and descriptive language, preferably on the level of IO-I2 years of age, with avoiding specific terminology, with presenting only the most important facts, etc.

In order to avoid unnecessary extraneous load, the design should allow to break out the 
text on layers and short paragraphs, make a use of subtitles, use an appropriate font size and spacing, corresponding colours and background. Since the article is not aiming to offer extensive guidelines, a reader is encouraged to peruse other sources for interpretive writing.

In decisions how many and which facts to include in the text, is particularly valuable the finding that people find hard to remember more than a certain number of ideas at the same time. The 'magical number' has decreased from five to nine ideas ( $7 \pm 2$ ), what Miller (Miller 1956 , 8I) discovered in 1965 onto three to seven ideas $(5 \pm 2)$ suggested by Ham for the people is $2 \mathrm{I}^{\mathrm{st}}$ century (Ham 2016, 28).

However, there are not cognitive capacities that divert us from reading. There are many theories that explain the physical, social and personal context, in which visitors try to pursue their various interests and needs.

\section{Visit is a social act}

During a visit, a great part of our attention goes to the surroundings and to other people. Full of impressions, especially if visiting for the first time, people examine the place and enjoy visual impressions. In the physical context (Falk and Dierking 2016) of the visit, visitors need to first find their way around, they try to select the parts of the content that are more interesting or relevant to them, on their way they are searching for facilities such as restrooms or refreshments, and nevertheless, they are concerned about the time. It has been proven for museum settings that no matter how large is the place or how many exhibitions a museum offers, in average people allocate one and a half hour to a single visit (Falk and Dierking 2016, 133), while a big museum contains as much text as one could read for days!

Most people come to heritage sites as part of a social group, with families or friends (Falk and Dierking 2016, I48). They would concern about their needs and behaviour, for instance, parents usually care for children's interests, learning opportunities and how can they provide also fun for them. During the visit, especially if the premises are crowded, their attention goes also to other people, sometimes due to the salient behaviour or due to the intrinsic human interest in other people.

Not all, that one experiences during the visit of heritage sites, has been described and yet it is obvious, what a variety and high number of elements occupies one's thoughts and how small are the chances for the attendance to the activity such as reading, which requires strong focus and vacant mental capacities. Naturally, humans are in power to consciously control and direct their actions to some extent, so one can choose to read or not to read at any time, but then again he or she would choose to read if a reward for the action is promising enough and the effort not too high.

\section{Does it have to do with $m e$ ?}

When the visitors are briefly scanning labels and panels, they are looking for words, that are familiar to them. In pursuing our interests and self-actualisation needs (Maslow 1943, 370), we are more attracted to the topics of which we already possess some knowledge or experiences. What proved especially effective with the readers are the three principles: Provoke - Relate - Reveal, by which a visitor is provoked to feel, think or do something, but prior to any such action, he or she must see the relevance with his or her own world: knowledge, experiences, beliefs, values or interests. When interpretation invokes curiosity or emotions or resonance, one's focal attention starts dealing with the subject matter in a short-term memory (Fennis and Stroebe 2010, 50), which is a pre-condition for any active consideration and also meaning-making.

\section{Conclusion}

Upper listed aspects are only the few from the vast field of psychological and sociological theories that are explaining the attitude towards labels and panels. Reading of online content, books and brochures is usually performed under different conditions and thus not a subject to this paper. 
Fortunately, much is written about the solutions for overcoming these barriers. Intellectual accessibility deserves much more serious consideration, especially if the heritage sites would like to increase visitation or attract more diverse audiences, also marginal groups, and especially if what they have got to share, conveys important messages for the whole society.

\section{Povzetek}

Članek polemizira odnos obiskovalcev do informativnih in interpretativnih besedil na tablah in panojih, ki so po večini manj obiskano sredstvo interpretacije. Raziskave kažejo, da obiskovalci v povprečju preberejo le okoli ro procentov besedil. Obiskovalci vsakokrat podzavestno tehtajo, kateri tekst se splača brati in ali obeta branje ustrezno nagrado. Razloge za takšen odnos gre iskati v psiholoških in socioloških teorijah. Po eno strani so zmožnosti obiskovalčeve kognicije na muzejskih razstavah ali v naravnem okolju drugačne kot v domačem ali delovnem okolju, saj možgani procesirajo veliko različnih dražljajev, ki se včasih izključujejo. Tako prihaja do kognitivne obremenitve, ki ne podpira koncentriranega branja besedil. Po drugi strani pa potrebe obiskovalcev na takšnih lokacijah pogosto izključujejo učenje kot primarno dejavnost. V ospredju so druženje, sprostitev in nova doživetja.

\section{Summary}

The article investigates the attitude that visitors to the heritage sites perform towards interpretive panels and labels, namely towards text. According to the research, in average only ro percent of text is actually read. According to Fraction of selection model, visitors attend to a panel, if the expected reward for reading is higher than the effort invested. The reasons for such behaviour have been found in psychological and sociological theories. The first suggest that visitor's cognitive capacities in leisure environment differ from the normal and that they are often overloaded. On the other hand, people often visit as a part of a group of other people, to which goes a great part of attention. Learning per se is namely not the main motivation for visiting heritage sites.

\section{References}

Baddeley, A. 2007. Working memory, thought, and action. Oxford psychology series Vol. 45 . Oxford: Oxford University Press.

Booth, K., J. O'Connor, A. Franklin and N. Papastergiadis. 2017. "It's a Museum, But Not as We Know It: Issues for Local Residents Accessing the Museum of Old and New Art". Visitor Studies 20 (I): 10-32.

Broadbent, D. 1958. "Effect of noise on an 'intellectual' task". The Journal of the Acoustical Society of America 30 (9): 824827.

Caputo, P., L. Brochu, and S. Lewis. 2008. Interpretation by design: graphic design basics for heritage interpreters. InterpPress,

Falk, J. H. and L. D. Dierking. 2016. The museum experience revisited. Lopndon and New York: Routledge.

Fennis, B. M. and W. Stroebe. 2010. The psychology of advertising. Hove, New York: Psychology Press.

-

Ham, S. H. 1992. Environmental interpretation: a practical guide for people with big ideas and small budgets. Golden, Colorado: North American Press.

Fáilte Ireland. 2009. Sharing our Stories: Using Interpretation to Improve the Visitors' Experience at Heritage Sites. Dublin: Fáilte Ireland.

Maslow, A. H. 1943. "A theory of human motivation". Psychological review 50 (4): $370-396$.

Miller, G. A. 1956. “The magical number seven, plus or minus two: Some limits on our capacity for processing information". Psychological review 63 (2): 81-97.

Paivio, A. 1990. Mental representations: $A$ dual coding approach. Oxford: Oxford University Press.

Sandifer, C. 2003. „Technological novelty and open-endedness: Two characteristics of interactive exhibits that contribute to the holding of visitor attention in a science museum. "Journal of research in science teaching 40 (2): I21-137. 
Simon, N. 2010. The participatory

museum. (Museum 2.0 blog). http://

museumtwo.blogspot.com/search/label/ participatory\%2omuseum

Sweller, J. 201r. "Cognitive load theory." In The psychology of learning and motivation: Vol.

55. The psychology of learning and motivation: Cognition in education, edited by Jose P.

Mestre and Brian H. Ross, 37-76. San Diego: Elsevier Academic Press.

Wolfe, M. B.W., and J. A. Mienko. 2007.

"Learning and memory of factual content from narrative and expository text." British Journal of Educational Psychology 77 (3): $54 \mathrm{I}-564$.

Zimmerman, R., M. Gross and J. Buchholz. 2008. Creating Exhibits that Expand the Imagination. Interpret Wales, workshop material. University of Wisconsin-Stevens Point. Better Visitor Center Workshop.

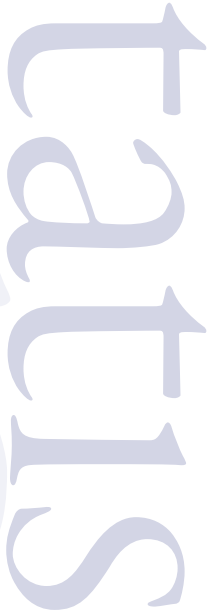




\section{NAVODILA ZA AVTORJE}

Revija objavlja primarno v slovenskem jeziku, toda tudi v večjih svetovnih jezikih (angleščina, nemščina, francoščina, italijanščina, ruščina). V primeru tujejezičnega članka morata biti izvleček in povzetek poleg angleščine obvezno v slovenskem jeziku. Izrazi v ne-latinični pisavi (npr.v cirilici) morajo biti prečrkovani po pravilih slovenskega pravopisa (http://bos.zrc-sazu.si/sp2oor.html; gl. pogl. $»$ Preglednice«, podpoglavje »Pisave za posamezne jezike «).Zavse poskrbi avtor.

Članek (dolžine ca. 7000, načeloma pa ne več kakor I0.000 besed) naj vsebuje:

I) avtorjev naziv, ime in priimek;

2) izvleček v slovenskem in angleškem jeziku do 250 besed;

3) ključne besede v slovenskem in angleškem jeziku (do 5);

4) naziv in naslovinstitucije

Članek naj vsebuje še:

I) povzetek v slovenskem ali angleškem jeziku in

2) seznam virov ter literature.

Prispevki naj bodo napisani v knjižni slovenščini (ali v knjižni različici katerega tujih jezikov) ob upoštevanju veljavnega pravopisa, v nasprotnem primeru si uredništvo pridržuje pravico, da članka ne recenzira oziroma ga zavrne.

Če je prispevek že bil objavljen v kaki drugi reviji ali če čaka na objavo, je treba to izrecno navesti.

Prispevek naj ima dvojni medvrstični razmik, tip črk naj bo Times New Roman, velikost 12 pik (v opombah Io). Besedilo naj bo levo poravnano, strani pa zaporedno oštevilčene. Odstavki naj bodo ločeni s prazno vrstico. Uporabiti je mogoče do tri hierarhične nivoje podnaslovov, ki naj bodo oštevilčeni (uporabljajte izključno navaden slog): I. - I.I -I.I.I

Za poudarke naj služi izključno ležeči tisk (v primeru jezikoslovnih besedil, kjer so primeri praviloma v ležečem tisku, lahko za poudarke izjemoma uporabite polkrepki tisk). Ležeče pišite tudi besede v tujih jezikih. Raba drugih tipografskih rezov (podčrtano, velike male črke, krepko kurzivno ...) ni dovoljena. $\mathrm{Ne}$ uporabljajte dvojnih presledkov, prav tako ne porabljajte preslednice za poravnavo besedila. Edina oblika odstavka, ki je dovoljena, je odstavek z levo poravnavo brez rabe tabulatorjev prve ali katerekoli druge vrstice v odstavku (ne uporabljajte sredinske, obojestranske ali desne poravnave odstavkov). Oglate oklepaje uporabljajte izključno za fonetične zapise oz. zapise izgovarjave. Tri pike so stične le, če označujejo prekinjeno besedilo, npr. bese... Pri nedokončani misli so tri pike nestične in nedeljive ... Prosimo, da izključite funkcijo deljenja besed.

Sprotne opombe naj bodo samo oštevilčene (številke so levostično za besedo ali ločilom - če besedi, na katero se opomba nanaša, sledi ločilo) in uvrščene na tekočo stran besedila.

Citati v besedilu naj bodo označeni z dvojnimi (» «), citati znotraj citatov pa z enojnimi (,') narekovaji. Izpuste iz citatov in prilagoditve označite s tropičjem znotraj poševnic /.../. Daljše citate (več kot 5 vrstic) izločite v samostojne odstavke, ki jih od ostale- ga besedila ločite z izpustom vrstice in umikom v desno. Vir citata označite v okroglem oklepaju na koncu citata.

$\mathrm{V}$ besedilu označite najprimernejša mesta za likovno opremo (tabele, slike, skice, grafikone itd.) po zgledu: [Tabela i približno tukaj]. Posamezne enote opreme priložite vsako v posebni datoteki (v .eps, .ai, .tif ali .jpg formatu, minimalna resolucija $300 \mathrm{dpi}$, tabele prilagajte v posebni datotetki v formatu .doc, grafe pa v formatu.xls, kjer naj ob grafu stoji tabela, ki je podlaga za graf). Naslov tabele je nad tabelo, naslov grafa/slike pa pod grafom/sliko.

Prostor, ki ga oprema v prispevku zasede, se šteje v obseg besedila, bodisi kot 250 besed (pol strani) ali 500 besed (cela stran).

V table z arheološkim gradivom vstavite merilo.

Ob oddaji preda avtor uredništvu članek $v$ formatu doc in hkrati tudi.pdf.

\section{Citiranje literature}

Za citiranje literature uporabljajte način Chicago Manual Style (University of Chicago Press 2010). Za reference med besedilom uporabljajte način citiranja avtor-datum s številom citirane (/-nih) strani, npr. Jackson (1979, I8I). Narekovaje uporabljajte v skladu s pravopisnimi pravili jezika v katerem je napisan članek. Seznam literature, urejen po abecedi, naj bo označen z naslovom $» V$ iri in literatura in naj sledi naslednjemu načinu (imena avtorjev naj bodo okrajšana z začetnicami):

- Beech, M.H. 1982. 'The Domestic Realm in the Lives of Hindu Women in Calcutta.' In Separate Worlds: Studies of Purdah in South Asia, edited by H. Papanek and G. Minault, IIo-38. Delhi: Chanakya.

- Jackson, R. 1979. 'Running Down the Up-Escalator: Regional Inequality in Papua New Guinea.' Australian Geographer I4 (5): $175-84$.

- $\quad$ Lynd, R., and H. Lynd. 1929. Middletown: A study in American Culture. New York: Harcourt, Brace and World.

- University of Chicago Press. 2010. The Chicago Manual of Style. 16th ed. Chicago: University of Chicago Press.

Priročnik citiranja Chicago-Style je na voljo na naslednji povezavi:

https://www.chicagomanualofstyle.org/tools_citationguide/citation-guide-r.html.

\section{Lektoriranje}

Prispevki morajo biti pred oddajo urejeni in lektorirani.

\section{Etika objavljanja in zlorabe}

S predložitvijo rokopisa avtorji potrjujejo, da so njihovi rokopisi njihovo izvirno delo, da rokopis trenutno ni v pripravi za objavo drugje in da so navedeni vsi viri, uporabljeni pri ustvarjanju rokopisa. Predloženi rokopisi so lahko predmet preverbe in odkrivanja primerov plagiatorstva.

Recenzenti opravljajo delo za revijo na prostovoljni osnovi; uredniku so dolžni razkriti vsa navzkrižja interesov, zaupnost informacij, ki se nanašajo na rokopis, in ocenjevati rokopise samo v njihovem intelektualnem smislu. Recenzenti morajo utemeljiti svoje izjave, osebna kritika ni dovoljena. 
Končna odločitev za objavo predloženega rokopisa je v pristojnosti urednikov. Rokopisi morajo biti obdelani v manj kot 6 mesecih od datuma predložitve.

\section{Recenziranje}

Vsi rokopisi so predmet dvojno slepega recenzentskega postopka in se oddajo na standardnem obrazcu.

\section{Postavljeni teksti}

Postavljeni teksti bodo v obliki PDF poslani po elektronski pošti ustreznemu avtorju; ta jih mora ustrezno dopolniti v petih dneh. Datoteke PDF naj bodo ustrezno dopolnjene v prostodostopnem Adobe Reader. V tej fazi je dovoljeno zgolj preverjanje postavitve, urejanje, popolnost in pravilnost formata. Bistvene spremembe članka niso več dovoljene.

\section{Avtorske pravice}

Avtorske pravice za članke, objavljene v Studia universitatis hereditati ostanejo avtorjem. Ti so sami odgovorni za pravice uporabljenih gradiv iz drugih virov.

Ćlanki so objavljeni v skladu z licenco Creative Commons CCBY-NC-ND 4.0 License.

\section{Plačila}

Za pošiljanje in obdelavo člankov ne bo zaračunan noben honorar. vom.

O morebitnih drugih posebnostih se posvetujte z uredništ-

\section{Naslov uredništva}

dr. Gregor Pobežin, Fakulteta za humanistične študije Univerze na Primorskem, Titov trg 5, SI-6000 Koper, gregor. pobezin@fhs.upr.si

\section{GUIDELINES FOR AUTHORS}

The journal publishes primarily in the Slovenian language, but also in other (major) world languages (Italian, English, German, French). An article published in a foreign language must also include a Slovenian abstract and summary in addition to the English text. Words originally written in non-Latin script (e.g. Cyrillic) will be transliterated according to the rules of Slovenian orthography (http://bos.zrc-sazu.si/sp2oor.html; see Ch. "Preglednice", SubCh. "Pisave za posamezne jezike"). This is author's responsibility.

An article (generally 7000 , but no more than 10.000 words) should begin with:

I) author's title, name and surname;

2) abstract in Slovene and English, up to 250 words;

3) keywords in Slovene and English (up to 5);

4) institution and address

An article should also include:

I) summary in Slovene or English and

2) sources consulted.

Articles should be written in regular Slovene (or regular foreign languages) with regard to current spelling, otherwise the editorial board reserves the right to refrain from reviewing the article or reject it. If the article has already been published in another journal or if it is in the process of being published, this should be stated explicitly.

Contribution to the double line spacing, font type should be Times New Roman, size r2pt (in footnote ropt). The text should be aligned left, the pages should be numbered consecutively. Paragraphs should be separated by a blank line. Up to three hierarchical levels of subtitling are allowed, which should be numbered (use only plain style): I - I.I -I.I.I

For highlights use only italics (in the case of linguistic texts, where examples are a general rule, bold print is acceptable). Words in foreign languages should be written in italics as well. The use of other typographical cuts (underlined, large lowercase letters, bold italics ...) is not allowed. Do not use double spaces; do not use the spacebar for text alignment. The only kind of paragraph permitted is left-aligned paragraph without the use of tabs (do not use the centre, two-sided or right paragraph alignment). Only use square brackets for phonetic or. recorded pronunciations. Three dots are contact only if they refer to broken text, e.g. con... In unfinished thoughts three dots are nonadjacent and indivisible ... Please turn off hyphenation,

Footnotes should be automatically numbered (numbers are immediately after a word or punctuation mark) and listed on the current page of text.

Quotes in the text should be marked with a double ("') and quotations within quotations with single (") quote marks. Omitted parts of quotations and adaptations should be clearly marked with slashes: /.../. Isolate longer quotations (more than 5 lines) in separate paragraphs,

separated from the rest of the text by omitting a row. Quote the source of the quotation mark in round brackets at the end of the quote.

Highlight the best places for graphics in the text (tables, figures, diagrams, charts, etc.), along the lines of: [Table I about here]. Attach individual units of equipment in a separate file (in .eps, .ai, .tif or.jpg format, minimum resolution of $300 \mathrm{dpi}$; enclose the tables in a special file in the doc format, graphs in the .xls format). Table title is above the table, graph title / picture is below the graph / image.

The space used for graphics counts as text, either as 250 words (half a page) or 500 words (entire page).

Include a scale on the tables with archaeological materials.

Upon submission, the author provides the article in the doc format as well as the .pdf format.

\section{References}

References should be formatted according to The Chicago Manual of Style (University of Chicago Press 2010). The author-date system of citation for references should be used in the text, followed by page number if a direct quotation is given, e.g., Jackson (1979, I8I). Quotation marks should be used in accordance with the spelling rules of the language in which the article is written. The alphabetized reference list should be titled 'References' with entries in the following format (please note that initials should be used for the authors'names): 
- Beech,M.H. 1982. 'The Domestic Realm in the Lives of Hindu Women in Calcutta.' In Separate Worlds: Studies of Purdah in South Asia, edited by H. Papanek and G. Minault, IIO-38. Delhi: Chanakya.

- Jackson, R. 1979. 'Running Down the Up-Escalator: Regional Inequality in Papua New Guinea.' Australian Geographer I4 (5): $175-84$.

- Lynd, R., and H. Lynd. 1929. Middletown: A study in American Culture. New York: Harcourt, Brace and World.

- University of Chicago Press. 2010. The Chicago Manual of Style. 16th ed. Chicago: University of Chicago Press.

https://www.chicagomanualofstyle.org/tools_citationguide/citation-guide-2.html

The Chicago-Style Citation Quick Guide is available at https://www.chicagomanualofstyle.org/tools_citationguide/citation-guide-r.html

The following examples illustrate the author-date system. Each example of a reference list entry is accompanied by an example of a corresponding in-text citation. For more details and many more examples, see chapter is of The Chicago Manual of Style.

\section{Copy Editing}

Papers should be copy-edited and spell-checked before submission.

\section{Publishing Ethics and Malpractice Statement}

By submitting a manuscript, authors certify that their manuscripts are their original work, that the manuscript is not currently being considered for publication elsewhere, and that they have identified all sources used in the creation of their manuscript. Submitted manuscripts may be subject to checks in order to detect instances of plagiarism.

Reviewers perform work for the journal on a volunteer basis; they are obligated to disclose to Editor any conflicts of interest, to keep information pertaining to the manuscript confidential and to evaluate manuscripts only for their intellectual content. Reviewers should argue their statements and personal criticism is not permitted.

The final decision for the publication of a submitted manuscript is the responsibility of the Editors. Manuscripts should be processed in less than 6 months from the date of submission.

\section{Peer Review}

All manuscripts are double-blind peer reviewed by at least two independent reviewers using a standard review form.

\section{Proofs}

Page proofs in PDF format will be sent by e-mail to the corresponding author; proofs should be corrected and returned within five days. PDF files can be annotated using freely available Adobe Reader. Proofs should be used only for checking the typesetting, editing, completeness and correctness of the paper. Significant changes to the article as accepted for publication are not permitted.

\section{Copyright}

Copyright for all articles published in Studia universitatis hereditati is held by individual authors. Authors are themselves responsi- ble for obtaining permission to reproduce copyright material from other sources.

Articles are published under the terms of Creative Commons CC BY-NC-ND 4 .o License.

\section{Author Fees}

No article submission or article processing fees are charged. For other issues, please consult the editorial board.

\section{Editor's address}

dr. Gregor Pobežin, Fakulteta za humanistične študije

Univerze na Primorskem, Titov trg 5, SI6000 Koper gregor.pobezin@fhs.upr.si
-

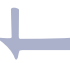

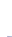

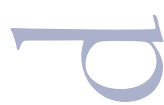

(

(

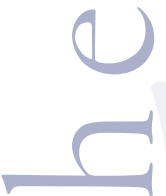




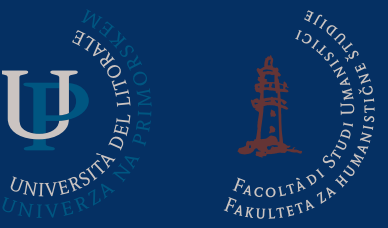

Založba Univerze na Primorskem www.hippocampus.si ISSN 2350-5443

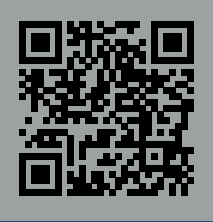

